\title{
Seltene Erkrankungen der Nase, der Nasennebenhöhlen und der vorderen Schädelbasis
}

\section{Rare Diseases of the Nose, the Paranasal Sinuses, and the Anterior Skull Base}

\section{(ㄷ) (i) (우) $\ominus$}

Autor

Fabian Sommer

Institut

Klinik für Hals-Nasen-Ohrenheilkunde, Kopf- und Hals-

Chirurgie, Universitätsklinik Ulm

\section{Schlüsselwörter}

Seltene Erkrankungen, Nase, Nasenennebenhöhlen, vordere Schädelbasis, Fehlbildungen

Key words

rare diseases, nose, paranasal sinuses, anterior skull base, malformation

\section{Bibliografie}

Laryngo-Rhino-Otol 2021; 100: S1-S44

DOI 10.1055/a-1331-2469

ISSN $0935-8943$

(C) 2021. The Author(s).

This is an open access article published by Thieme under the terms of the Creative Commons Attribution-NonDerivative-NonCommercial-License, permitting copying and reproduction so long as the original work is given appropriate credit. Contents may not be used for commecial purposes, or adapted, remixed, transformed or built upon. (https://creativecommons. org/licenses/by-nc-nd/4.0/)

Georg Thieme Verlag KG, Rüdigerstraße 14,

70469 Stuttgart, Germany

Korrespondenzadresse

Prof. Dr. med. Fabian Sommer

Univ. HNO-Klinik

Frauensteige 12

D-89075 Ulm

fabian.sommer@uniklinik-ulm.de

\section{ZUSAMMENFASSUNG}

Seltene Erkrankungen der Nase, der Nasennebenhöhlen und der vorderen Schädelbasis stellen aufgrund der niedrigen Inzidenz und den daraus resultierend eingeschränkten diagnostischen Kriterien sowie therapeutischen Optionen eine Herausforderung dar. Der Schwellenwert, ab dem eine Erkrankung als selten zu werten ist, liegt bei höchstens 5 Betroffenen pro 10000 Personen. Innerhalb dieser Erkrankungen gibt es allerdings extreme Schwankungen. So gehören einige seltene Erkrankungen, wie z.B. das invertierte Papillom, zu den regelmäßig diagnostizierten und therapierten Krankheitsbildern einer größeren Klinik für Hals-Nasen-Ohrenheilkunde. Andererseits liegen bei anderen seltenen Erkrankungen und Fehlbildungen weltweit deutlich unter 100 Fallberichte vor, was die Notwendigkeit einer Bündelung der verfügbaren Erfahrung zu Diagnostik und Therapie unterstreicht.

Die vorliegende Arbeit gibt eine Übersicht zu seltenen Erkrankungen der Nase, der Nasennebenhöhlen und der vorderen Schädelbasis aus den übergeordneten Bereichen Erkrankungen / Syndrome des olfaktorischen Systems, Fehlbildungen der Nase und Nasennebenhöhlen, Belüftungs- und Funktionsstörungen sowie benigne und maligne Tumore. Die Einordnung sowie Angaben zu Diagnostik und Therapiemöglichkeiten wurden unter Berücksichtigung der aktuellen Literatur erstellt.

\section{ABSTRACT}

Due to their low incidence and thus resulting limited diagnostic criteria as well as therapeutic options, rare diseases of the nose, the paranasal sinuses, and the anterior skull base are a significant challenge. The value as of which a disease has to be considered as rare amounts to a maximum of 5 patients per 10000 people. Within these diseases, however, there are extreme differences. Some rare or orphan diseases like for example the inverted papilloma belong to regularly diagnosed and treated diseases of larger departments of oto-rhino-laryngology whereas other rare diseases and malformations have only been described in less than 100 case reports worldwide. This fact emphasizes the necessity of bundling the available experience of diagnostics and therapy.

The present article gives an overview about rare diseases of the nose, the paranasal sinuses, and the anterior skull base from the field of diseases/syndromes of the olfactory system, malformations of the nose and paranasal sinuses, ventilation and functional disorders as well as benign and malignant tumors. The classification and data on diagnostic and therapeutic options were established based on the current literature. 


\section{Inhaltsverzeichnis}

Zusammenfassung

Abstract

1. Einleitung

1.1 Definition und epidemiologische Gesichtspunkte seltener Erkrankungen

1.2 Begriffsdefinition Inzidenz und Prävalenz

1.3 Nase, Nasennebenhöhlen und vordere Schädelbasis

2. Seltene Erkrankungen der Nase, der Nasennebenhöhlen und der vorderen Schädelbasis

2.

2.1.1

2.1 .2

2.1 .3

2.2

2.2.1

2.2 .2

2.2 .3

2.2 .4

2.2 .5

2.2 .6

2.2.7

2.3

2.3.1

2.3.2

2.3.3

2.3 .4

2.3 .5

2.3.6

2.3.7

2.4

2.4.1

2.4.1.1

2.4 .1 .1

2.4.1.1.2

2.4.1.1.3

2.4.1.1.4

2.4.1.1.5

2.4.1.1.6

2.4.1.2

2.4.1.2.1

2.4.1.2.2

2.4.1.2.3

2.4.1.3

2.4.1.3.1 Hamartom (REAH)

2.4.1.3.2 Sinunasales Ameloblastom

2.4.1.3.3 Chondromesenchymales Hamartom

2.4.1.3.4 Nasales Gliom

2.4.1.3.5 Cholesteatom

Kraniofaziale Gesichtsspalten und paramediane Nasenspalte

Belüftungs- und Funktionsstörungen

Silent Sinus Syndrom

Hypersinus

Pneumosinus dilatans

Pneumozele

Organisiertes Hämatom

Young-Syndrom

Primäre ziliäre Dyskinesie

Tumore

Benigne Tumore

Weichteil-, Nerven- und Gefäßtumore

Schleimhautpapillome

Schwannome

Neurofibrome

Meningeome

Osteome und Gardner Syndrom

Fibröse Dysplasie

McCune-Albright-Syndrom

Andere Weichteiltumore
2.4 .2

Maligne Tumore

17

2.4.2.1 Maligne epitheliale Tumore

2.4.2.1.1 Plattenepithelkarzinom

2.4.2.1.1.1 Verhornendes Plattenepithelkarzinom

2.4.2.1.1.2 Nichtverhornendes Plattenepithelkarzinom

2.4.2.1.1.3 Spindelzell-/Sarkomatoides Plattenepithelkarzinom

2.1.2.1.2 Lymphoepitheliales Karzinom

4.2.1.3 Sinunasales undifferenziertes Karzinom (SNUC)

2.4.2.1.4 Adenokarzinom

Adenokarzinom vom intestinalen Typ

Adenokarzinom vom nicht intestinalen Typ

Speicheldrüsenartige Karzinome

Adenoidzystisches Karzinom (ACC)

Azinuszellkarzinom

Mucoepidermoidkarzinom

Epithelial-myoepitheliales Karzinom

Neuroendokrine Neoplasien

Maligne Weichteiltumore (Sarkome)

Fibrosarkom 


\section{Einleitung}

\subsection{Definition und epidemiologische Gesichtspunkte seltener Erkrankungen}

In der Europäischen Union wird eine Erkrankung als selten angesehen, wenn maximal 5 von 10000 Personen von ihr betroffen sind [1]. In vielen Fällen stellen seltene Erkrankungen hinsichtlich der Stellung der richtigen Diagnose eine große interdisziplinäre Herausforderung dar. Innerhalb der EU sind ca. 6000 Erkrankungen als „selten“ gelistet. In Deutschland leiden ca. 4 Mio. Patienten an einer seltenen Erkrankung, europaweit wird die Zahl auf etwa 30 Mio. geschätzt. Aufgrund der Diversität der Erkrankungen und der jeweils nur geringen Anzahl betroffener Patienten ist die Forschung an Diagnostik und Therapie aus sozioökonomischen Gründen erschwert.

Anzahl und Definition der seltenen Erkrankungen sind aufgrund epidemiologischer Faktoren regional unterschiedlich. So können infektiöse Erkrankungen in Entwicklungsländern häufig auftreten, innerhalb Europas allerdings eine sehr geringe Inzidenz aufweisen.

\subsection{Begriffsdefinition Inzidenz und Prävalenz}

Inzidenz kennzeichnet die Anzahl neu auftretender Fälle einer Erkrankung in einer Population innerhalb eines definierten Zeitraums (meist 1 Jahr).

Prävalenz bezeichnet die gesamte Anzahl von Erkrankungen in einer Population zu einem bestimmten Zeitpunkt oder innerhalb eines definierten Zeitraums

Inzidenz $=\frac{\text { Neue Fälle }}{\text { Gesamtbevölkerung }} \quad$ Prävalenz $=\frac{\text { Anzahl der Fälle }}{\text { Gesamtbevölkerung }} \times 100$

Bei einigen Erkrankungen, die in der vorliegenden Arbeit beschrieben werden, existieren keine genauen Daten zur Inzidenz, da in der aktuellen Literatur nur sehr wenige Fallberichte beschrieben sind. Die Website http://www.orpha.net wurde 1997 in Frankreich ins Leben gerufen. Seit 2000 wird sie von der Europäischen Kommission gefördert und bietet Informationen zu vielen seltenen Erkrankungen. Die dort publizierten Informationen hinsichtlich Inzidenz und Prävalenz basieren auf gesammelten Originaldaten auf weltweiter oder europäischer Ebene oder extrapolierten Originaldaten, solange ein Founder-Effekt (Abweichung einer isolierten Population von einer Stammpopulation) für die Krankheit ausgeschlossen werden kann [2].

\subsection{Nase, Nasennebenhöhlen und vordere Schädel- basis}

Die menschliche Nase ist als Teil der oberen Atemwege u. a. für die Klimatisierung der eingeatmeten Luft verantwortlich. Die intakte Funktion der Mukosa beinhaltet einen Schleimfilm, der sich mithilfe der Zilien in konstanter Bewegung befindet. Diese Schicht stellt zum einen die Befeuchtung der eingeatmeten Luft sicher und stellt andererseits, gemeinsam mit dem Niesreflex, eine Barriere gegenüber eingeatmeten Fremdkörpern oder Erregern dar [3, 4]. Die gleichmäßige Verteilung der eingeatmeten Luft über eine möglichst große Fläche nasaler Schleimhaut ist für die intakte Funktion der Nase essenziell [4-7]. Eine Vielzahl von Erkrankungen kann zu einer Beeinträchtigung oder dem Verlust der Klimatisierungs- und Schutzfunktion, aber auch des Riechvermögens führen [6, 8].
Neben typischen Erkrankungen wie der chronischen Rhinosinusitis mit Polyposis nasi (CRSwNP) oder den viralen Rhinitiden existieren auch einige seltene Erkrankungen, die zu Einschränkungen oder vollständigem Verlust dieser Funktionen führen und aufgrund der Ähnlichkeit der Symptome häufig spät diagnostiziert werden.

Nase, Nasennebenhöhlen und vordere Schädelbasis stellen aufgrund ihrer unmittelbaren Nachbarschaft eine anatomische Einheit dar, die hinsichtlich Erkrankungen in diesem Bereich nicht voneinander getrennt werden kann. So existieren nur wenige Erkrankungen, die dezidiert einen der genannten Bereiche betreffen. Insofern ist eine strikte Trennung der entzündlichen und tumorösen Erkrankungen sowie Fehlbildungen auf die Bereiche der Nasenhaupthöhle, der Nasennebenhöhlen oder der vorderen Schädelbasis nicht immer möglich, da viele Pathologien die Grenzen zwischen den einzelnen Unterbezirken überschreiten.

Sinunasale Tumore erfüllen mit einer Inzidenz von ca. 1-1,5:100 000 grundsätzlich die Voraussetzung einer seltenen $\mathrm{Er}$ krankung $[9,10]$. Diese malignen Neoplasien repräsentieren nur $3 \%$ aller Kopf-Hals-Karzinome und weniger als $1 \%$ aller malignen Erkrankungen des gesamten menschlichen Körpers [11-14]. Insofern handelt es sich bei allen malignen Entitäten der Nase und Nasennebenhöhlen sowie der vorderen Schädelbasis per definitionem um seltene Erkrankungen.

Tumore der Nase, der Nasennebenhöhlen und der vorderen Schädelbasis können nicht in jedem Fall nach anatomischer Region differenziert werden, da aufgrund der engen räumlichen Lagebeziehungen häufig bereits in niedrigen Stadien mehrere Regionen betroffen sind. Die TNM-Klassifikation der Karzinome der Nasenhaupthöhle und Nasennebenhöhlen ist in > Tab. 1 dargestellt.

\section{Seltene Erkrankungen der Nase, der Nasen- nebenhöhlen und der vorderen Schädelbasis}

Seltene Erkrankungen der Nase, Nasennebenhöhlen und Schädelbasis können in folgende Kategorien eingeteilt werden:

- Erkrankungen/Syndrome des olfaktorischen Systems

- Fehlbildungen

- Belüftungs- und Funktionsstörungen

- Benigne und maligne Tumore

- Entzündliche/granulomatöse Erkrankungen

In einem Referat aus dem Jahr 2015 wurden bereits seltene rhinologische Erkrankungen mit Fokus auf eine granulomatöse Genese durch Martin Laudien dargelegt [15], weshalb die vorliegende Arbeit auf die ersten vier der genannten Aspekte fokussiert. Hierbei werden die wichtigsten seltenen Erkrankungen des olfaktorischen Systems, Fehlbildungen, Tumorerkrankungen und Funktionsstörungen der Nase, der Nasennebenhöhlen und der vorderen Schädelbasis unter Berücksichtigung der aktuellen Literatur dargestellt.

\subsection{Erkrankungen/Syndrome des olfaktorischen Systems}

Die Genese von Störungen des olfaktorischen Systems ist sehr variabel. Mögliche Ursachen liegen in rhinologischen Erkrankungen, Traumata, Neoplasien und kongenitalen Störungen oder sie werden als idiopathisch bezeichnet $[16,17]$. Zudem existieren viele vi- 
- Tab. 1 TNM-Klassifikation von Karzinomen der Nasenhaupthöhle und der Siebbeinzellen (in Anlehnung an das TNM-System des AJCC (Springer, 8. Auflage, 2017).

\section{T-Kategorien Nasenhaupthöhle und Siebbeinzellen \\ T1 Tumor auf einen Unterbezirk der Nasenhöhle oder der Siebbeinzellen beschränkt, mit oder ohne Arrosion des Knochens \\ T2 Tumor in zwei Unterbezirken eines Bezirks oder Ausbreitung auf einen Nachbarbezirk innerhalb des Nasen-Siebbeinzel- len-Komplexes, mit oder ohne Arrosion des Knochens \\ T3 Tumor breitet sich in die mediale Orbita oder den Orbitaboden aus oder in die Kieferhöhle, den Gaumen oder die Lamina cribrosa \\ T4 Tumor infiltriert eine oder mehrere der folgenden Strukturen: \\ T4a Inhalt der vorderen Orbita und/oder Haut von Nase oder Wange, minimale Ausbreitung in die vordere Schädelgrube, Processus pterygoidei, Keilbeinhöhle oder Stirnhöhle \\ $\mathrm{T} 4 \mathrm{~b}$ Orbitaspitze und/oder Dura, Gehirn, mittlere Schädelgrube, Hirnnerven (ausgenommen den maxillären Ast des $\mathrm{N}$. trigeminus [V2]), Nasopharynx, Clivus)}

rale Erkrankungen, die mit einer temporären und permanenten Hyp- bzw. Anosmie einhergehen können. Aufgrund der Themenstellung fokussiert die vorliegende Arbeit nicht auf alle seltenen Erkrankungen, die auch das olfaktorische System beeinträchtigen können, sondern auf jene, die primär das Riechen betreffen. Hierbei handelt es sich um folgende Syndrome bzw. Fehlbildungen:

- Isolierte kongenitale Anosmie

- Kallmann-Syndrom

- Neuroektodermales Syndrom Typ Johnson

\subsubsection{Isolierte kongenitale Anosmie}

Die isolierte kongenitale Anosmie ist extrem selten. Weltweit wurden bislang 15 Fälle einer isolierten kongenitalen Anosmie beschrieben [18]. Bei der isolierten kongenitalen Anosmie liegt eine seit Geburt bestehende Anosmie vor. Die Ursache ist eine Entwicklungsstörung des Bulbus olfactorius, die uni- oder bilateral vorliegen kann [19]. Eine weitere Genese scheint in dem Ersatz des olfaktorischen Epithels durch respiratorisches Epithel, welches die Nasenhaupthöhle auskleidet, zu liegen. Ursächlich ist eine autosomal dominante Störung mit unvollständiger Penetranz. Es existiert keine kausale Therapie der Fehlbildung.

\subsubsection{Kallmann-Syndrom}

Das Kallmann-Syndrom beschreibt eine erbliche Entwicklungsstörung, in deren Rahmen es zu einem kongenitalen hypogonadotropen Hypogonadismus aufgrund einer Gonadotropin-Releasing Hormon (GnRH)-Mangels kommt. Zusätzlich ist bei betroffenen Patienten eine Hyposmie oder Anosmie (bei Hypoplasie oder Aplasie des Bulbus olfactorius) zu beobachten, die auf eine unterbrochene embryonale Migration der GnRH-synthetisierenden Neuronen vom Riechepithel in die Hypothalamusregion basiert. Die Vererbung erfolgt X-chromosomal rezessiv [20]. Die Prävalenz des Kallmann-
Syndroms wird auf 3,75:100 000 geschätzt [2]. Therapien zielen auf die Induktion der Pubertät und später der Fertilität ab. Während in diesem Bereich gute Therapieerfolge erzielt werden können, ist eine Behandlung der Hyposmie oder Anosmie nicht möglich.

\subsubsection{Neuroektodermales Syndrom Typ Johnson}

Das Neuroektodermale Syndrom Typ Johnson beinhaltet die Symptome Alopezie, Anosmie oder Hyposmie, Schallleitungs-Schwerhörigkeit, malformierte Ohren, Mikrotie und/oder Atresie des äußeren Gehörganges und hypogonadotropen Hypogonadismus. Es wird nach den Erstbeschreibern auch Johnson-McMillin Syndrom bezeichnet [21,22]. Die Vererbung erfolgt autosomal dominant, allerdings ist die genaue Ätiologie nicht bekannt. Vermutet wird ein embryologischer Defekt bei der Ausdifferenzierung der Neuralleiste der Kopfregion.

Die Prävalenz des Syndroms wird auf deutlich unter 1:1.000 000 geschätzt. Eine Therapie der mit dem Syndrom assoziierten Hyposmie bzw. Anosmie ist nicht existent.

\subsection{Fehlbildungen der Nase und Nasennebenhöhlen}

In der aktuellen Literatur existieren mehr als 300 Syndrome mit Beteiligung der Nase. Bei vielen dieser Syndrome kann auch die Entwicklung der Nase beeinträchtigt sein, allerdings ist diese Pathologie im Gesamtaspekt der vielen, im Rahmen des Syndroms vorkommenden Pathologien als untergeordnet zu beurteilen. Der Übersichtlichkeit halber werden im folgenden Teil Pathologien dargestellt, die primär die Nase und je nach Ausprägung auch die Nasennebenhöhlen und vordere Schädelbasis betreffen. Hierbei handelt es sich um folgende Fehlbildungen:

- Arrhinie/Hemirhinie

- Bifide Nase

- Kraniorhinie

- Kraniofaziale Gesichtsspalten und paramediane Nasenspalten

- Duplikationsanomalien der Nase

- Proboscis lateralis

- Nasenrückenfistel

\subsubsection{Arrhinie/Hemirhinie}

Die kongenitale Arrhinie stellt eine extrem seltene Fehlbildung dar, bei der die äußere Nase nicht oder nur sehr rudimentär angelegt ist ( $\bullet$ Abb. 1) und deren Pathogenese noch nicht vollständig analysiert werden konnte. Es wird vermutet, dass eine Entwicklungsstörung der paarigen Nasenplakoden zwischen der 3. und 10. Gestationswoche eine Rolle in der Genese spielt. Die vorzeitige Fusion der medianen Nasenfortsätze, eine fehlende Resorption der nasalen Epithelpfropfen sowie eine abnorme Wanderung von Zellen der Neuralleiste werden als weitere Entstehungsmechanismen diskutiert. Eine Arrhinie kann als eigenständige Fehlbildung oder im Rahmen von Syndromen wie dem Treacher-Collins Syndrom, das eine oto-mandibuläre Dysplasie mit verschiedenen Defekten an Kopf und Hals beinhaltet und dem „Arhinie-Mikrophthalmie-Syndrom Bosma“ bzw. „Bosma-Henkin-Christiansen-Syndrom“, einer Kombination aus Arrhinie, Choanalatresie und Mikrophthalmie, auftreten.

Weltweit wurden ca. 20 Fälle beschrieben [2]. Noch seltener sind Fälle von kongenitaler einseitiger Arrhinie (Hemirhinie, fehlende 
Nasenhälfte (• Abb. 2)). In einigen Fällen wird das vollständige Fehlen einer Nasenanlage mit palpatorisch festem Untergrund beschrieben ( $\mathbf{A} \mathbf{b} b . \mathbf{1}$ ), andere Fälle zeigen eine rudimentäre Nasenanlage als blind endender Buckel oder Grübchen [23].

Die meisten berichteten Fälle einer Arrhinie sind sporadisch aufgetreten und zeigen einen unauffälligen Karyotyp [24, 25]. Die Überlebensrate von Patienten mit dieser Fehlbildung ist niedrig, da es in ihrem Rahmen zu schweren oberen Atemwegsobstruktionen, Atemnot und Infektionen der Atemwege sowie Mangelernährung kommen kann [26]. Die chirurgische Therapie ist Mittel der Wahl,

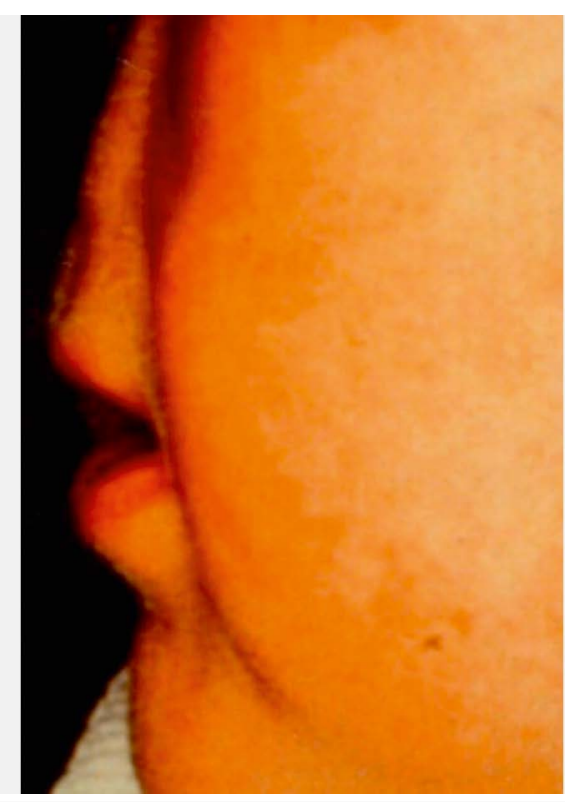

Abb. 1 Klinisches Bild eines 5 Monate alten Patienten mit einer Arrhinie ohne Rudimente.

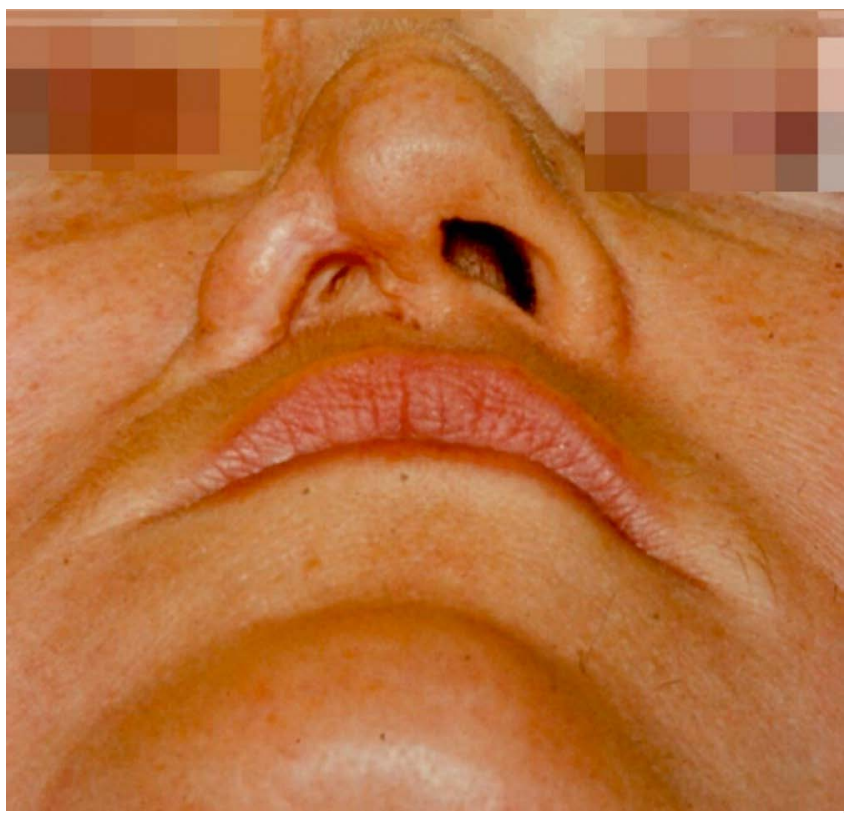

Abb. 2 Patientin mit Z.n. Rekonstruktion der rechten Nasenhälfte bei Hemirhinie. allerdings existieren nur wenig Daten hinsichtlich der Technik und des besten Zeitpunktes für eine Operation. Eine Tracheostomie sollte initial erfolgen, um die Atmung sicherzustellen. Allgemein wird empfohlen, die rekonstruktive Operation spätestens bis zum Vorschulalter zu planen.

\subsubsection{Bifide Nase}

Bei der bifiden Nase handelt es sich um eine seltene angeborene Missbildung mit vermutlich autosomal-dominantem oder rezessivem Erbgang. Kennzeichen ist eine Nasenspalte, deren Ausprägung sehr variabel ist. Diese reicht von einer wenig auffälligen Furche am Nasensteg oder der Nasenspitze ( $>$ Abb. $\mathbf{3}$ ) bis zur vollständigen Spaltung der darunter liegenden Knochen und Knorpel, was zur Ausbildung zweier Halbnasen führen kann. Der Atemweg ist im Rahmen dieser Fehlbildung meist adäquat ausgebildet. Eine bifide Nase kann als milde Form einer frontonasalen Dysplasie gesehen werden [27], aber auch andere Fehlbildungen wie Hypertelorismus und Mittellinienspalten der Lippe treten in Zusammenhang mit der Nasenfehlbildung auf [28].

Die Ursache der frontonasalen Dysplasie ist unbekannt. Die vermutete Ätiologie ist ein Fehler bei der Entwicklung der Nasenkapsel, in dessen Verlauf zwischen der 4. und 6. Woche der Embryoge-

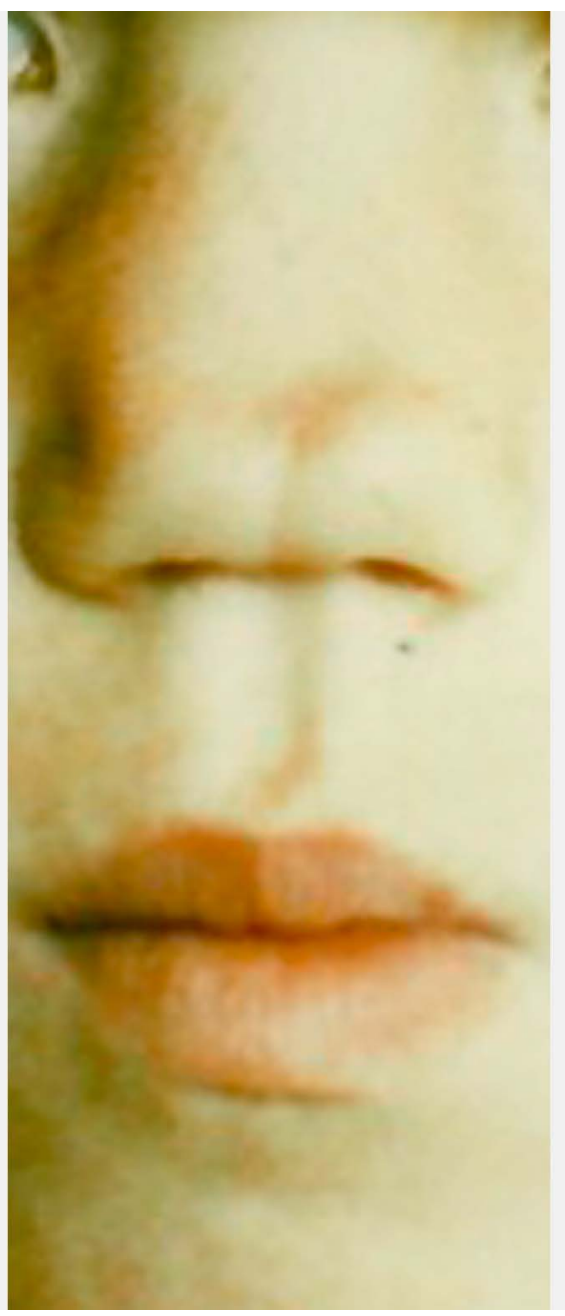

Abb. 3 Milde Form einer bifiden Nase. 


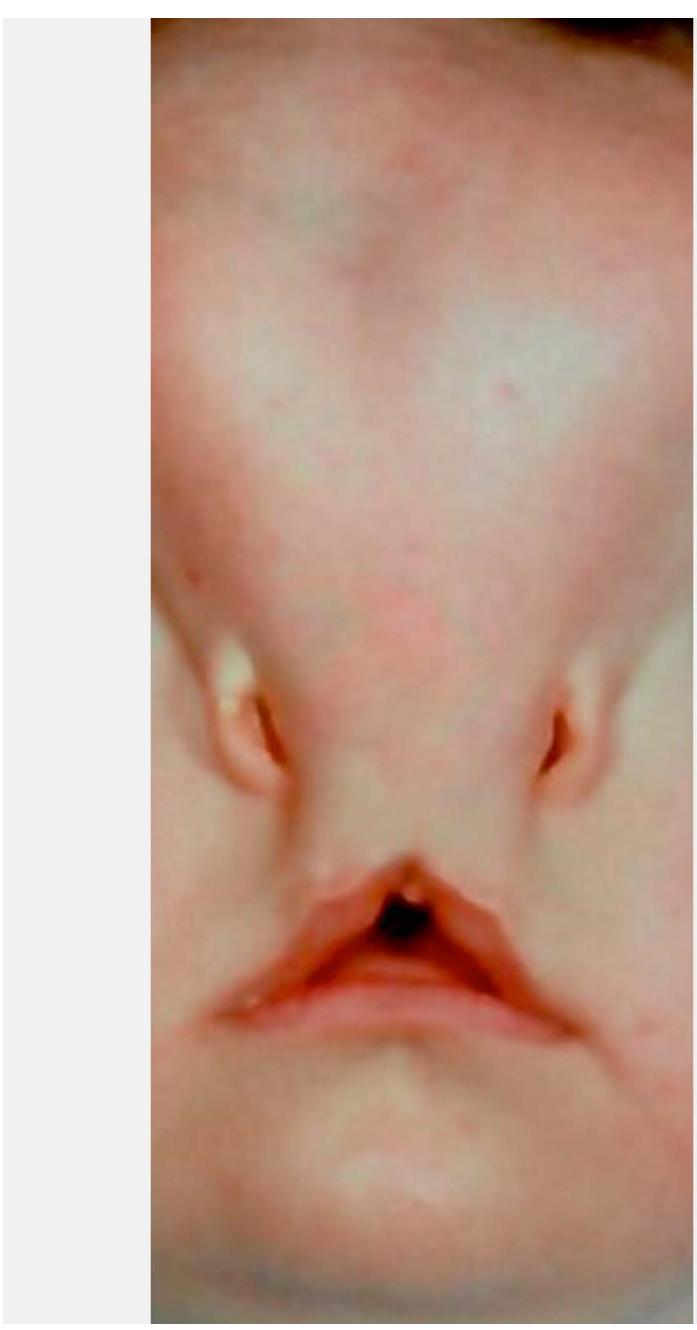

Abb. 4 Mediane Gesichtsspalte, frontonasale Dysplasie.

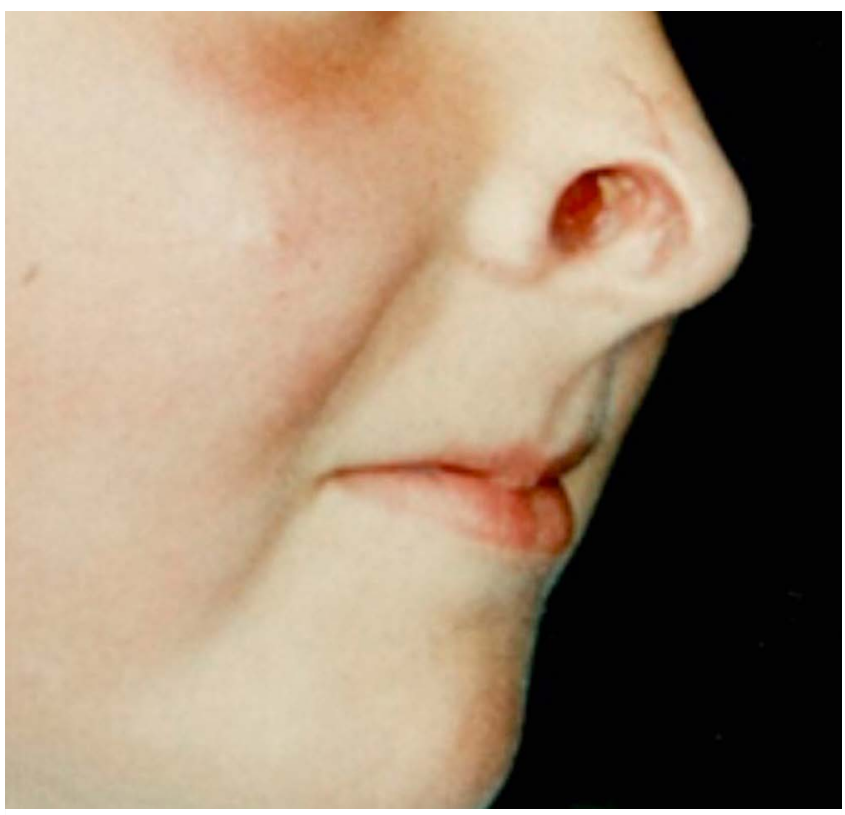

Abb. 5 Paramediane Nasenspalte. nese die Migration des olfaktorischen Epithels in die Nasenkapsel aufgehalten wird. Diese bildet sich nicht vollständig aus und das primitive Hirngewebe füllt den Raum zwischen dem dehiszenten Nasenrücken aus [29].

Eine CT oder MRT Bildgebung ist vor einer operativen Therapie dringend erforderlich, da auch milde Formen der frontonasalen Dysplasie mit intrakraniellen Anomalien einhergehen können.

Operativ wird bei der milden Verlaufsform einer bifiden Nase i.d.R. eine offene Rhinoplastik durchgeführt [27], was ein übersichtlicheres Operationsfeld ermöglicht und die Gefäßversorgung der Haut und des Weichteilmantels der Nase erhält. Es wird angenommen, dass die Columellainzision sowie die Anhebung der Nasenhaut, die bei der offenen Technik angewandt werden, das Wachstum der kindlichen Nase nicht beeinflusst [30].

\subsubsection{Kraniorhinie}

Merkmale einer Kraniorhinie sind Brachyzephalie, fliehende Stirn, eine sklerotische Schädelbasis, allerdings ohne Kraniosynostosen. Der Ductus nasolacrimalis ist nicht ausgebildet. Die Nase ist breit konfiguriert, die Alae nasi wirken aufgebläht und antevertiert. Es zeigt sich ein nasaler Hirsutismus und bilateral symmetrische, kugelförmige, zystenartige Strukturen mit kleinen Fisteln direkt unterhalb der Nase. Ein Hypertelorismus kann zusätzlich vorhanden sein. Die Vererbung ist wahrscheinlich autosomal dominant, allerdings legen Fälle mit konsanguinen Eltern nahe, dass eine pseudodominante autosomal rezessive Übertragung nicht völlig ausgeschlossen werden kann [31, 32]. Weltweit wurden vier betroffene Familien beschrieben [2].

\subsubsection{Kraniofaziale Gesichtsspalten und paramediane Nasenspalte}

Kraniofaziale Gesichtsspalten sind äußerst seltene Fehlbildungen der Embryogenese. Primäre oder echte Spaltbildungen treten zwischen der 4. und 8. Gestationswoche auf, weil die Fusion zwischen den verschiedenen Gesichtsprozessen nicht vollständig abgeschlossen wurde. Sekundäre oder Pseudospalten treten später auf. Sie betreffen die mesenchymale Differenzierung und können als Dysplasie bezeichnet werden. In beiden Situationen ist das zukünftige Wachstumspotenzial im Vergleich zum übrigen Gesicht vermindert. Die Inzidenz kraniofazialer Gesichtsspalten wird mit 1,44,9:100 000 angegeben [33].

Von der Spaltbildung kann Hirngewebe, Weichgewebe und Knochen betroffen sein. Knöcherne Fehlbildungen treten an der Stirn, Orbita, Sinus ethmoidalis, Maxilla und Gaumen auf. Meningozelen und Meningoenzephalozelen können bei intrakranieller Beteiligung vorkommen.

Mediane und paramediane Gesichtsspalten sind häufig mit Hypertelorismus, anteriorer oder basaler Enzephalozele, Lageanomalien des Oberkiefers und Nasendeformitäten assoziiert ( $>$ Abb. 4). Es können auch Weichteilmissbildungen wie Lippen- und Gaumenspalten und Lidkolobome auftreten [33].

Die paramediane Nasenspalte stellt einen seltenen Entwicklungsdefekt während der Embryogenese dar, der durch ein einseitiges oder beidseitiges Kolobom der Nase gekennzeichnet ist ( $>$ Abb. 5). Sie ist eine milde Form einer kraniofazialen Gesichtsspalte. Die Fehlbildung kann in Form einer kleinen Kerbe, die zu einer geringfügigen Abweichung der Nasenscheidewand führt, bis 
hin zu Nasenspalten unterschiedlicher Größe, die mit kleinen Zysten der Nasennebenhöhlen in der Nasenmittellinie assoziiert sein können, auftreten. Paramediane Nasenspalten treten isoliert oder in Verbindung mit Lippenspalten und/oder anderen kraniofazialen Anomalien (z. B. Hypertelorismus, Verbreiterung der Nasenwurzel, Mittellinienspalte) auf. Nasenrücken und Nasenspitze sind in der Regel gut erhalten [34].

\subsubsection{Duplikationsanomalien der Nase: Polyrhinie und akzessorisches Nasenloch}

Duplikationsanomalien der Nase beinhalten die Polyrhinie („doppelte Nase“) und das akzessorische Nasenloch. Beide Nasendeformitäten treten extrem selten auf (entsprechend Orphanet wird die Inzidenz auf unter 1:1.000 000 geschätzt). In der Literatur sind insgesamt 8 Fälle beschrieben, von denen 4 eine Polyrhinie und 3 ein isoliertes akzessorisches Nasenloch sowie ein Patient ein akzessorisches Nasenloch in Verbindung mit einer Lippenspalte aufwiesen [35].

Die Polyrhinie ist eine angeborene Fehlbildung, bei der es zu einer vollständigen Duplikation der Nase kommt. Alle publizierten Fälle waren sporadisch. Es wird vermutet, dass der Fehlbildung ein embryonaler Entwicklungsdefekt mit Duplikation des medialen Nasenfortsatzes zugrunde liegt [36].

Das akzessorische Nasenloch ist eine ebenfalls äußerst seltene angeborene Fehlbildung, die durch das Vorhandensein eines oder mehrerer akzessorischer Nasenlöcher mit oder ohne akzessorischen Knorpel gekennzeichnet ist. Die akzessorischen Löcher sind medial, oberhalb, unterhalb oder lateral der anderen Nasenlöcher lokalisiert. Im Gegensatz zur Polyrhinie besteht keine Duplikation des Nasenseptums. Das akzessorische Nasenloch ist häufig mit anderen Fehlbildungen der Kopf-/Halsregion assoziiert [37, 38].

\subsubsection{Proboscis lateralis}

Der Proboscis lateralis ist eine äußerst seltene Fehlbildung, die 1861 zum ersten Mal beschrieben wurde. Die fehlgebildete Seite der Nase zeigt eine schlauchartige, rudimentäre Nasenanlage, die an jedem beliebigen Punkt entlang der embryologischen Fusionslinie zwischen der anterioren Maxilla und dem Processus frontonasalis ansetzen kann. In den meisten Fällen ist der Ansatz dieses Rudiments am medialen Anteil des Orbitadaches lokalisiert [39].

Der genaue embryologische Mechanismus, der für die Entwicklung des Proboscis lateralis verantwortlich ist, konnte bislang nicht analysiert werden. Zu den populären Theorien gehören die unvollkommene Verschmelzung der lateralen Nasen- und Kieferfortsätze und die irreguläre Verschmelzung des Kieferfortsatzes der betroffenen Seite mit dem medialen Nasenfortsatz [40-42].

Entsprechend den existierenden Daten wird empfohlen, die chirurgische Therapie in der frühen Kindheit zu beginnen, um mögliche psychosoziale Konsequenzen zu vermeiden. Die abschließende ästhetische Rekonstruktion der Nase sollte allerdings erst in der späteren Jugend erfolgen, wenn das Wachstum des Nasengerüsts abgeschlossen ist.

Es existieren verschiedene chirurgische Techniken zur initialen Korrektur des Proboscis lateralis. Eine häufig angeführte Technik beschreibt die Desepithelisierung des mittleren bis distalen Anteils des rudimentären Schlauches, der dann in die eröffnete und fehlgebildete ipsilaterale Nasenwand eingearbeitet wird [39].

\subsubsection{Nasenrückenfistel}

Die Nasenrückenfistel ist eine seltene Fehlbildung, die sich durch das Vorhandensein einer Dermoidzyste auf dem Nasenrücken definiert. Die Inzidenz liegt bei 1:20 000-1:40 000 [43]. Klinisch präsentiert sich eine fest palpable, langsam wachsende Raumforderung, die Haut und dermale Elemente, wie Haarfollikel und Talgdrüsen enthält. Es kann zu intermittierender oder chronischer Sekretion von Talg und seröser Flüssigkeit sowie zu lokalen Infektionen kommen. In einzelnen Fällen besteht eine Verbindung nach intrakraniell, weshalb anamnestisch auf meningitische Beschwerden und Krampfanfälle fokussiert werden sollte. In sehr seltenen Fällen kann es zu intrakraniellen Abszessformationen kommen. Therapie der Wahl ist die vollständige Exzision des Befundes, je nach Ausdehnung in Kooperation mit der Neurochirurgie. Bei vollständiger Resektion sind Rezidive selten [44].

\subsection{Belüftungs- und Funktionsstörungen}

\subsection{Silent Sinus Syndrom}

Das Silent Sinus Syndrom bezeichnet eine i.d.R. einseitige Erkrankung des Sinus maxillaris, die mit einem verringerten Volumen, einer Absenkung des Orbitabodens und einem damit assoziierten Bulbustiefstand (Hypoglobus) assoziiert ist [45]. Bereits 1964 wurden von Montgomery 2 Fälle eines Enophthalmus bei maxillären Mukozelen beschrieben [46], der Begriff Silent Sinus Syndrom entstand im Rahmen der Beschreibung einer Fallserie von 19 Patienten mit Enophthalmus und einem einseitigen „Kollaps“ des Sinus maxillaris [47]. In extrem seltenen Fällen ist das Siebbein oder die Stirnhöhle von der Erkrankung betroffen $[48,49]$. Weltweit wurden bisher 98 Fälle beschrieben [2].

Betroffene Patienten sind weitestgehend frei von sinunasalen Beschwerden, können aber über gelegentliches Druckgefühl der betroffenen Seite des Oberkiefers berichten [50,51]. Trotz der durch den Enophthalmus und Hypoglobus veränderten Sehachse kommt es wegen der nur langsam fortschreitenden Symptomatik nur selten zu Visusstörungen.

Als wahrscheinlichste Ursache für die Entstehung eines Silent Sinus Syndroms wird eine Obstruktion am Ostium der betroffenen Nebenhöhle vermutet. Es kommt zu einer konsekutiven Unterdruckbildung, eingezogenen knöchernen Wänden und nachfolgenden Sekretretention [52-56]. Die ursprüngliche These, es handele sich um eine Kieferhöhlen-Hypoplasie, konnte durch Studien widerlegt werden, bei denen Computertomografien aus der Zeit vor der Erkrankung analysiert wurden, auf denen ein normal konfigurierter Sinus maxillaris ersichtlich war $[54,57,58]$. Auch eine chronische Rhinosinusitis wird als Ursache diskutiert [56].

Bei der Endoskopie zeigt sich ein stark retrahierter, ggf. atelektatischer Processus uncinatus. Computertomografisch lässt sich ein hypoplastisch anmutender Sinus maxillaris mit gleichmäßiger Einziehung aller Wände darstellen. Das Lumen des Sinus kann frei oder Sekret-verlegt sein [59]. In koronarer Schichtung lässt sich in der Computertomografie der nach kaudal eingezogene Orbitaboden darstellen, der zu einer konsekutiven Verlagerung des Orbitainhalts führt ( $\mathbf{A}$ Abb. 6). Magnetresonanztomografisch lässt sich ein hyperintenses Signal in der T2-Wichtung bei homogener Abbildung des Lumens darstellen [51, 59-61].

Bei entsprechenden Beschwerden ist eine Kieferhöhlen-Fensterung Typ 2-3 [56, 62-64] zur Wiederherstellung der Belüftung 
möglich. Nach Eröffnung des Lumens zeigt sich normale bis leicht hypertrophe Schleimhaut und je nach Befund mukozelenartig konfiguriertes Sekret, welches abgesaugt werden kann.

Im Falle von Visusstörungen ist die Korrektur des Orbitabodens Gegenstand zahlreicher Diskussionen. Zur Rekonstruktion bzw. Anhebung des Orbitabodens können alloplastische oder autologe Materialen verwendet werden $[55,65]$. Mehrere Fallberichte zeigten allerdings eine Rückbildung des Enophthalmus und Hypoglobus $[52,57,65,66]$, weshalb eine operative Therapie frühestens ein Jahr nach Wiederherstellung der Kieferhöhlen-Belüftung erfolgen sollte, um spontane Remissionen abzuwarten [62, 65, 67].

\subsubsection{Hypersinus}

Der Terminus Hypersinus bezeichnet eine Nasennebenhöhle, deren Ausdehnung die normalen Begrenzungen deutlich überschreitet

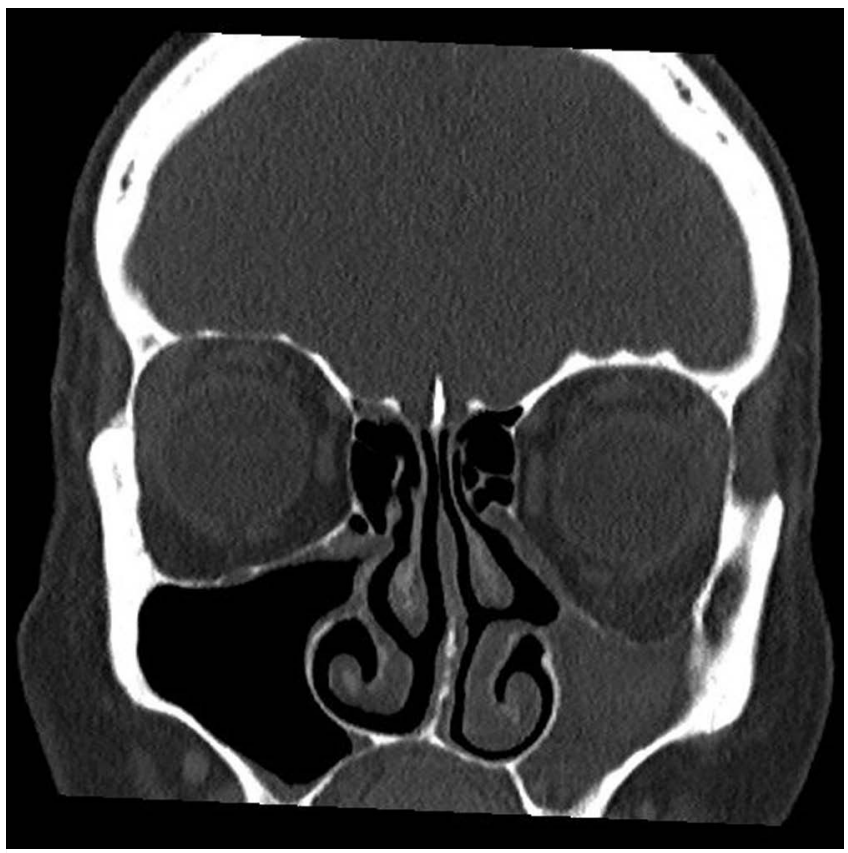

-Abb. 6 Koronare CT-Rekonstruktion eines Patienten mit Silent Sinus Syndrom linksseitig. Die Kieferhöhle ist verlegt, der Orbitaboden nach unten gezogen. und deren knöcherne Begrenzungen und Belüftungssituation normal konfiguriert sind [68]. Die Ausdehnung der betroffenen Nebenhöhle erstreckt sich innerhalb der Schädelknochen-Begrenzungen, ohne diese - wie im Falle des Pneumosinus dilatans oder der Pneumozele - zu verdrängen bzw. zu verlagern. Insofern existieren bei betroffenen Patienten keine kosmetischen oder funktionellen Probleme. In $>$ Abb. 7 ist die starke Pneumatisation des Sinus frontalis beidseits gut zu erkennen. In sagittaler Rekonstruktion zeigt sich der weit nach kranial reichende Sinus frontalis ebenfalls, allerdings ohne die Kontur der Stirn stark zu beeinträchtigen.

Der Hypersinus verursacht keine Beschwerden, weshalb diese anatomische Variante nicht als Pathologie gezählt wird. Trotz einer bereits 1987 festgelegten Nomenklatur [69] werden die Begriffe Hypersinus, Pneumosinus dilatans und Pneumozele bisweilen unscharf oder sogar synonym verwendet, weshalb die Abgrenzung des Hypersinus in diesem Zusammenhang aufgeführt wird.

\subsubsection{Pneumosinus dilatans}

Der Pneumosinus dilatans stellt eine massive Ausweitung meist einer Nasennebenhöhle dar und manifestiert sich in den meisten Fällen an der Stirnhöhle. Auch die Siebbeinzellen und die Keilbeinsowie Kieferhöhlen können von der außergewöhnlich starken Pneumatisation betroffen sein [56]. Vorwölbungen des Stirnbeins oder intrakranielle, ethmoidale und orbitale Ausdehnung können auftreten [69]. Die Erkrankung ist nicht zwingend mit Beschwerden verknüpft, kann aber in einigen Fällen lokales Druckgefühl und Cephalgien verursachen. Während der Befall der Stirnhöhle zu kosmetischen Beeinträchtigungen für den Patienten führen kann, existieren Fallberichte mit ophthalmologischen Komplikationen bei Lokalisation im Siebbein oder der Keilbeinhöhle [70-72] durch eine Kompression des Nervus opticus.

Die weltweit berichtete Fallzahl wird mit 134 angegeben $[73,74]$. Die Ätiologie der Erkrankung ist unbekannt. Als mögliche Ursachen werden spontan drainierte Mukozelen, eine Infektion mit gasbildenden Mikroorganismen, eine genetische Prädisposition oder fibro-ossäre Dysregulation sowie hormonelle Dysregulationen diskutiert [74]. Die derzeit wahrscheinlichste Theorie ist ein Ventilmechanismus der Abflusswege der Nebenhöhlen, der aufgrund des gesteigerten Drucks zu einer langsamen, gleichmäßigen Ausdehnung des Sinus führt und spontan drainierte Mukozelen dis-

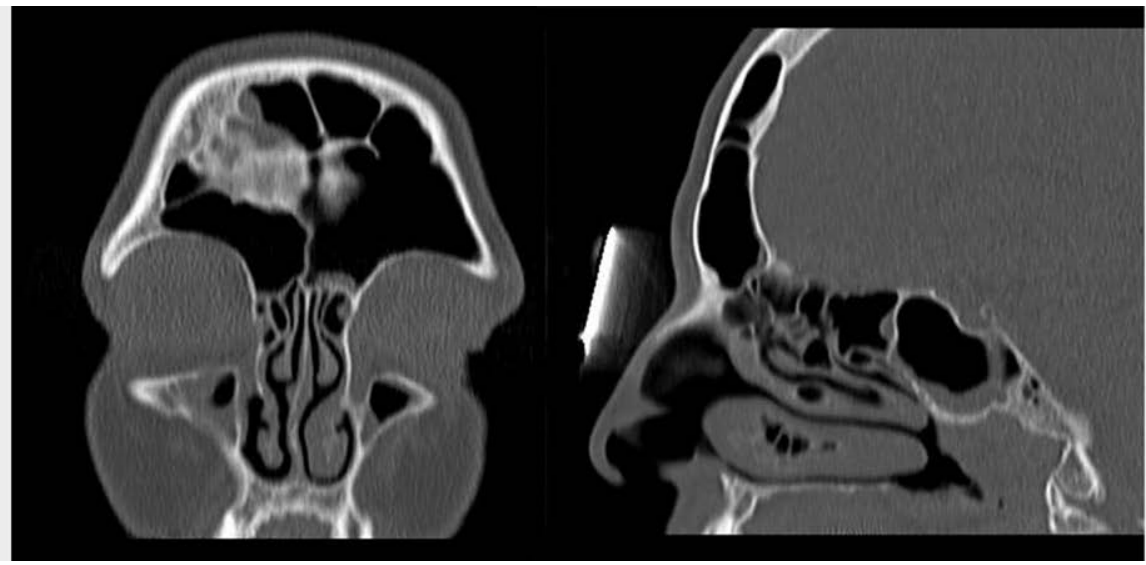

Abb. 7 Koronare und sagittale CT-Rekonstruktion eines Patienten mit Hypersinus frontalis bds. 
kutiert. Publikationen der letzten 20 Jahre geben zudem Hinweise auf eine Assoziation mit Meningeomen und Arachnoidalzysten [73, 75-77].

Bei der Nasenendoskopie zeigt sich ein meist unauffälliger Befund des mittleren Nasengangs und der betroffenen Ostien, sofern diese einsehbar sind. Computertomografisch ist die betroffene $\mathrm{Na}$ sennebenhöhle (meist) gleichmäßig vorgewölbt und i.d.R. ohne Ausdünnung des begrenzenden Knochens darstellbar. > Abb. 8 zeigt eine koronare Computertomografie eines Patienten mit Pneumosinus dilatans. In sagittaler Rekonstruktion ist die Vorwölbung der Stirnhöhlenvorderwand sowie der hierdurch veränderte nasofrontale Winkel zu erkennen.

Es existiert keine kurative Therapie. Unter der Annahme eines Ventilmechanismus kann eine funktionelle NasennebenhöhlenOperation mit Erweiterung des Ostiums und damit Beseitigung der Stenose in Betracht gezogen werden. Bei Patienten mit kosmetischer Beeinträchtigung im Rahmen eines Pneumosinus dilatans frontalis wurden Techniken zur operativen Modellierung der Stirnhöhlenvorderwand von Draf et al. beschrieben [78]. Bei Visusstörungen kann in Abhängigkeit der Beschwerden und der Lokalisation der Pathologie die Dekompression des Nervus opticus in $\mathrm{Er}$ wägung gezogen werden. Auch ein Pneumosinus dilatans der Kieferhöhle kann sich entwickeln und zeigt sich primär in einer äuBeren Deformierung [56].

\subsubsection{Pneumozele}

Pneumozelen sind Ausdehnungen einer Nasennebenhöhle über die normalen Grenzen hinaus. Im Gegensatz zum Pneumosinus dilatans finden sich Irregularitäten der knöchernen Begrenzung der betroffenen Nebenhöhle mit Ausdünnungen und teilweisem Integritätsverlust [69, 79]. Die Symptome sind ähnlich wie bei einem Pneumosinus dilatans. Bei Lokalisation im Sinus maxillaris, frontalis und ethmoidalis kann es zu Verlagerung des Orbitainhalts mit konsekutiver Protrusio bulbi kommen [80-82]. Ein Fallbericht schildert einen temporären Visusverlust im Rahmen einer Pneumocele des Sinus sphenoidalis [83, 84].

Als Ursache für die Entwicklung einer Pneumozele wird ein Ventilmechanismus im Bereich des Ostiums angenommen, der eine rasche Angleichung von Druckdifferenzen zwischen der Nasenhaupthöhle und der betroffenen Nebenhöhle verhindert.
Im Falle einer Protrusio bulbi kann die Entlastung der Orbita mit Resektion der Lamina papyracea erfolgen. Bei einer Kompression des Nervus opticus im Bereich des Sinus sphenoidalis aufgrund von nicht ausgeglichenen Druckdifferenzen der Nasenhaupthöhle und des Sinus sphenoidalis ist die operative Wiederherstellung der Belüftung des Sinus sphenoidalis Therapie der Wahl. In o.g. Fallbericht wurde eine Resektion eines Polypen durchgeführt, der das Ostium verlegte.

\subsubsection{Organisiertes Hämatom}

Das sinunasale organisierte Hämatom ist eine seltene, gutartige Erkrankung. Es kommt zu wiederholten Einblutungen, die möglicherweise durch ein sehr kleines Ostium und/oder eine nicht ausreichende mukoziliäre Clearance des betroffenen Sinus raumfordernden Charakter entwickeln. Im weiteren Verlauf kommt es zu Fibrosierungen und Neovaskularisation. Aufgrund des expansiven Wachstums kann es zu Destruktionen umgebender Strukturen kommen, weshalb bildmorphologische Aspekte malignen Wachstums oder einer Pathologie mit lokal aggressiver Expansion ähnlich einem invertierten Papillom oder einer Pilzsinusitis entstehen können $[85,86]$. Diverse Studien haben die Charakteristika der Erkrankung analysiert, allerdings ohne genauere Daten hinsichtlich der Inzidenz zu liefern [85-87].

Primäre Beschwerden sind häufig rezidivierende Epistaxis, Schmerzen, Druckgefühl im Gesichtsbereich und gelegentlich Hypästhesien im Versorgungsgebiet des N. infraorbitalis [85-88].

CT- und MRT-grafisch zeigen sich mit expansiven Gewebsmassen angefüllte Sinus, häufig mit Ausdehnung in die ipsilaterale Nasenhaupthöhle [87]. Lokal aggressives Wachstum kann zu Expansion in den Sinus ethmoidalis, die Orbita, die Fossa pterygopalatina und die Fossa infratemporalis, die Wange und sogar den Hartgaumen führen. In der Computertomografie stellen sich die Areale heterogen und mit unregelmäßig fleckiger Kontrastmittelaufnahme dar. Auch Kalzifikationen können auftreten. Magnetresonanztomografisch zeigen sich vergleichbare Kontrastmittelanreicherungen in der T1 Wichtung mit eher hypointensem Randsaum.

Histopathologisch zeigen sich Einblutungen mit frischeren und älteren Arealen, extensiv dilatierte Gefäße, amyloides Material mit irregulär konfigurierten Gefäßen, Zonen mit deutlicher Neovaskularisation sowie Hämosiderinablagerungen und Fibrosen [87].

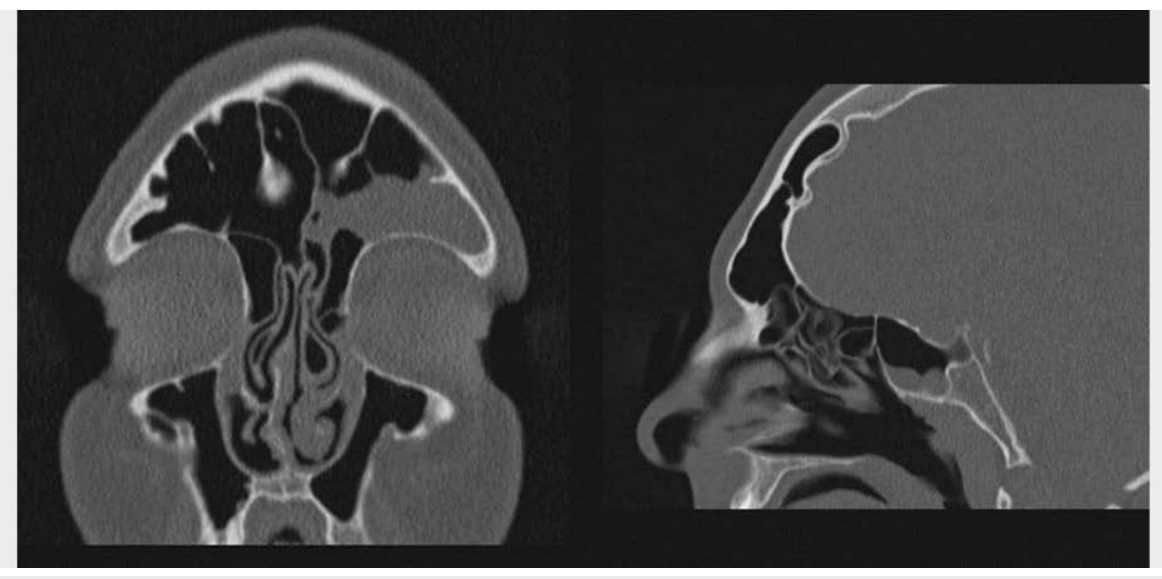

- Abb. 8 Koronare und sagittale CT-Rekonstruktion eines Patienten mit Pneumosinus dilatans mit Vorwölbung des Os frontale. 
- Tab. 2 Zu erwartende endoskopische und radiologische Befunde bei Silent-Sinus-Syndrom, Organisiertem Hämatom und Pneumosinus dilatans, entnommen aus [56].

\begin{tabular}{|c|c|c|}
\hline Erkrankung & Endoskopischer Befund & Radiologischer Befund \\
\hline Silent-Sinus-Syndrom & $\begin{array}{l}\text { Erweiterung des mittleren Nasengangs mit } \\
\text { Lateralisation des Proc. uncinatus }\end{array}$ & $\begin{array}{l}\text { CT: } \\
\text { " Verkleinerung des Kieferhöhlen-Volumens } \\
\text { " Retraktion aller Kieferhöhlen-Wände } \\
\text { " Kaudalverlagerung Orbitaboden } \\
\text { " Volumenvergrößerung Orbita } \\
\text { " homogene Verschattung der Kieferhöhle } \\
\text { " Proc. uncinatus liegt der Orbita an }\end{array}$ \\
\hline Organisiertes Hämatom & $\begin{array}{l}\text { Gewebsvermehrung im mittleren Nasengang } \\
\text { und in der Nasenhaupthöhle, Fibrin, } \\
\text { Granulationen. Z. T. polypöse Schleimhaut- } \\
\text { schwellung und Vorwölbung der lateralen } \\
\text { Nasenwand }\end{array}$ & $\begin{array}{l}\text { CT: } \\
\text { " unscharfe Begrenzung } \\
\text { " inhomogene KM-Aufnahme } \\
\text { " Ausdünnung KH-Wände } \\
\text { " glatt begrenzte Knochendestruktion } \\
\text { MRT: } \\
\text { " T1: homogen isointens mit Muskulatur, heterogene } \\
\text { KM-Anreicherung } \\
\text { - T2: inhomogen mit hypointensem Randsaum }\end{array}$ \\
\hline Pneumosinus dilatans & Unauffälliger Befund & $\begin{array}{l}\text { CT: Erweiterung des Sinus maxillaris über die natürlichen Grenzen } \\
\text { hinaus ohne Ausdünnung der knöchernenWände }\end{array}$ \\
\hline
\end{tabular}

Die explorative Endoskopie in Narkose wird zur Diagnosesicherung und Therapie empfohlen. Über einen endonasalen Zugang sollte das Hämatom vollständig entfernt werden. Im Rahmen der Ausräumung kommt es häufig zu stärkeren diffusen Blutungen. Um einer weiteren Abkapselung des Befundes vorzubeugen wird empfohlen, ausreichend weite Zugänge zu dem betroffenen Sinus anzulegen. Rezidive sind in der derzeit bekannten Literatur äußerst selten beschrieben [85-88].

Die zu erwartenden endoskopischen und radiologischen Befunde bei Silent-Sinus-Syndrom, Organisiertem Hämatom und Pneumosinus dilatans sind in > Tab. 2 aufgelistet.

\subsubsection{Young-Syndrom}

Erstmals beschrieben wurde das Young-Syndrom von dem Urologen David Young, dem aufgefallen war, dass 54\% der Patienten mit obstruktiver Azoospermie Lungendefekte aufwiesen [89]. Im Jahr 1978 wurden sinunasale Beschwerden in die Symptomatik aufgenommen. Seither ist das Krankheitsbild als Trias aus obstruktiver Azoospermie, chronischer Rhinosinusitis und Bronchiektasien oder chronischen Bronchitiden definiert [90, 91].

Hinsichtlich der Inzidenz des Young-Syndroms existieren keine verlässlichen Daten. Eine Quecksilber-Exposition scheint mit dem Auftreten der Erkrankung assoziiert zu sein. Untermauert wird dies durch die nach der Erstbeschreibung beschriebene hohe Inzidenz von bis zu 1 von 500 Männern auf heute nur noch wenige Fallberichte, was dem generellen Verschwinden von Quecksilber aus Industrie und Medizin geschuldet sein dürfte [92]. Eine positive Familienanamnese ist laut aktuellem Stand keine Prädisposition für das Auftreten der Erkrankung.

Das Young-Syndrom betrifft junge Männer. Primärer Grund für das Aufsuchen ärztlicher Hilfe ist in den meisten Fällen die Infertilität, nur selten chronisch sinunasale oder pulmonale Beschwerden. Die chronisch sinunasalen Beschwerden verschwinden mit dem
Abschluss der Adoleszenz wohingegen die pulmonalen Beschwerden persistieren [93-95].

Die mukoziliäre Clearance ist bei betroffenen Patienten deutlich verlängert, was allerdings kein spezifisches diagnostisches Kriterium darstellt [96]. Initial vermutete Strukturdefizite der Dynein-Arme innerhalb der Zilien konnten nicht als Ursache bestimmt werden. Stattdessen geht man heute von einer veränderten Konsistenz des nasalen Schleimfilms aus, die für die Beschwerden der Patienten verantwortlich ist [91].

Differenzialdiagnostisch muss an eine Mukoviszidose, eine primär ziliäre Dyskinesie und das Kartagener Syndrom gedacht werden.

Wang et al. untersuchten ein Kollektiv von 33 Patienten mit obstruktiver Azoospermie und beschrieben 4 Patienten mit einer dokumentierten Anamnese einer chronischen Rhinosinusitis, einer auffälligen Bildgebung der Nasennebenhöhlen, einer positiven Familienanamnese sowie einer Medikation, die die mukoziliäre Clearance beeinträchtigen kann. Da die Anzahl der in der Literatur dargelegten Fälle seit der Erstbeschreibung massiv gesunken ist und aufgrund der lange inkonsistent verwendeten Definition einer chronischen Rhinosinusitis wurde die Existenz des Young-Syndroms 2009 von Arya et al. sogar angezweifelt [91].

\subsubsection{Primäre ziliäre Dyskinesie}

Die primäre ziliäre Dyskinesie ist eine Störung der Struktur und Funktion der beweglichen Zilien der Schleimhaut der Nasenhaupthöhle und der Nasennebenhöhlen, die zu chronischen sinunasalen und pulmonalen Beschwerden führt. Die primäre ziliäre Dyskinesie äußert sich typischerweise in Atembeschwerden bei Säuglingen, frühem ganzjährigem Husten und einer Nasenatmungsbehinderung. Aufgrund der fehlenden Zilienfunktion kommt es zu einer Stase des Schleimhautfilms in der Nase und den Nasennebenhöhlen, die bei betroffenen Patienten zu einer purulenten Sekretion 
führt. Die korrekte Diagnosestellung ist eine Herausforderung, da eine Vielzahl von Erkrankungen existiert, die zu ähnlichen Symptomen führen. Das Kartagener-Syndrom ist eine Trias aus chronischer Rhinosinusitis, Bronchiektasien und dem Vorliegen eines Situs inversus als Folge einer ziliären Dyskinesie [97].

Ursächlich ist eine genetische Störung, die zu einer gestörten Ultrastruktur der Zilien der Nasenschleimhaut und damit deren Funktionslosigkeit führt. Derzeit sind 33 Gene bekannt, die mit der Ausbildung einer primären ziliären Dyskinesie assoziiert sind und deren Mehrheit einem autosomal rezessivem Erbgang folgt [97]. Die Prävalenz liegt bei 1:15000 Lebendgeburten

Bei der primären ziliären Dyskinesie führen Mutationen in Genen, die für axonemale Strukturen kodieren, zu funktionsgestörten Zilien. Defekte bei der primären ziliären Dyskinesie können äußere Dyneinarmdefekte, innere Dyneinarmdefekte, zentrale mikrotubuläre Anomalien, radiale Speichendefekte und äußere ultrastrukturelle Anomalien beinhalten. Auch der Spermienschwanz und die Fimbrien der Eileiter besitzen bewegliche Zilien, weshalb Infertilität bei betroffenen Männern und Frauen auftreten kann. Anomalien der Anatomie sind möglich, da der Defekt der beweglichen Flimmerhärchen während der Embryogenese zu einer abnormalen thorakoabdominalen Ausrichtung führt. Ein Situs inversus tritt bei 50 \% der Fälle von primärer ziliärer Dyskinesie auf, da die normale Bewegung der Zilien gestört ist und die viszerale Rotation hierdurch ein Zufallsereignis wird [97-99].

Die Diagnose wird durch eine Kombination aus Symptomen und den Ergebnissen einer Nasen- oder Bronchialbürstenbiopsie zum Nachweis einer gestörten ziliären Ultrastruktur und Ziliarbeweglichkeit gestellt. Die Analyse der Nasenschleimhaut mit Hochgeschwindigkeits-Videomikroskopie zur Beurteilung der Ziliarmotilität ist sehr sensitiv und spezifisch.

Bei Patienten über 5 Jahren sind nasale Stickstoffmonoxidmessungen sensitiv und können die Diagnosestellung erleichtern. Der Gehalt des durch die Mukosa produzierten Stickstoffmonoxids ist bei Patienten mit primärer ziliärer Dyskinesie im Vergleich zu gesunden Patienten deutlich erniedrigt. Aufgrund der teilweise ähnlichen Symptome sind ein Schweiß-Chlorid-Test und ggf. genetische Tests sinnvoll, um eine Mukoviszidose ausschließen zu können [97, 100-102].

Es existieren keine großen, langfristig angelegten randomisierten Studien zur Therapie der primären ziliären Dyskinesie, weshalb viele Aspekte der Versorgung auf empirischen Empfehlungen anderer Lungenerkrankungen mit ähnlichen Pathologien basieren. Trotz des Versuches, einen europäischen Konsensus aus den Erfahrungen großer spezialisierter Zentren zu erzielen, existieren große Unterschiede in den Ansätzen, die Erkrankung zu therapieren [103, 104].

Eine engmaschige Betreuung durch Pulmologen ist erforderlich. Regelmäßige Spirometrien, Sputum-Kulturen und RöntgenThorax Kontrollen werden empfohlen. Vor allem bei Kindern ist die regelmäßige Hals-Nasen-Ohrenärztliche Kontrolle aufgrund der rezidivierenden Otitiden und daraus resultierenden Schallleitungsstörungen erforderlich.

Nasale Symptome manifestieren sich in der Regel als Rhinorrhoe und Nasenatmungsbehinderung. Eine Polypenbildung bei betroffenen Kindern ist selten. Prophylaktische Antibiotika helfen, die infektiöse Komponente der Rhinosinusitis zu reduzieren. Die Indika- tion zur Nasennebenhöhlenoperation sollte zurückhaltend gestellt werden, da deren Wirksamkeit umstritten ist. Es gibt keine Evidenz für den Nutzen intranasaler Steroide, allerdings können sie bei der Behandlung einer zusätzlichen allergischen Rhinosinusitis hilfreich sein. Verbesserte genetische Diagnosestellungen sind der erste Schritt hin zu einer zukünftigen, genbasierten Therapiestrategie wie z. B. Genersatztherapie, Aminoglykosid-induziertes „translationales Überlesen“ (read-through) und pharmakogenetischen Ansätzen [105].

\subsection{Tumore}

Tumore des Sinunasaltrakts und der vorderen Schädelbasis können primär in dieser Region entstehen oder ihren Ursprung an einer entfernteren Stelle der Kopf-Hals-Region, allerdings eine Manifestation innerhalb des Sinunasaltrakts oder an der Schädelbasis aufweisen. In der Einteilung der World Health Organization von 2017 wird auf eine weitere Gruppe von Neoplasien verwiesen, deren Auftreten innerhalb des Sinunasaltrakts und der vorderen Schädelbasis aus differenzialdiagnostischen Gründen von Bedeutung ist. Die folgende Einteilung benigner und maligner Entitäten des Sinunasaltrakts und der vorderen Schädelbasis entstand in Anlehnung an diese Klassifikation der WHO [106].

\subsubsection{Benigne Tumore}

Benigne Tumore des Sinunasaltrakts werden in drei Hauptkategorien eingeteilt, die im folgenden Teil dargestellt werden:

- Weichteil-, Nerven- und Gefäßtumore

- Ossäre Tumore

- Andere Weichteiltumore

\subsubsection{Weichteil-, Nerven- und Gefäßtumore 2.4.1.1.1 Schleimhautpapillome}

Drei unterschiedliche Varianten von Schleimhautpapillomen werden unterschieden. Allen gemeinsam ist die Entstehung aus der sogenannten Schneider-Membran, die Nasenhaupt- und Nasennebenhöhlen auskleidet [107-110]. Diese ektodermal entstandene, mit Zilien besetzte Mukosa entwickelt sich als eine Invagination von olfaktorischem Ektoderm in der vierten Woche der embryonalen Entwicklung [111]. Aus pathologischer Sicht werden 3 Schneider-Papillome unterschieden:

- Invertiertes Papillom

- Exophytisches Papillom

- Onkozytäres Papillom

\section{Exophytisches Papillom:}

Diese Entität ist auch als fungiformes oder septales Papillom bekannt und stellt 6-50\% aller Schneider-Papillome. Im Gegensatz zum invertierten Papillom treten sie vorwiegend bei Männern im Alter zwischen 20 und 50 Jahren auf. Manifestationsort ist in den meisten Fällen das anteriore Nasenseptum, gelegentlich auch die laterale Nasenwand. Multifokales Auftreten ist möglich, bilaterale Manifestationen wurden sehr selten beschrieben [112]. Eine Manifestation in den Nasennebenhöhlen ist äußerst selten. Makroskopisch imponiert das exophytische Papillom als rosig bis graue Raumforderung mit gefältelter Oberfläche. Die Therapie der Wahl ist die Exzision. Eine maligne Entartung wurde nicht beschrieben. 


\section{Onkozytäres Papillom:}

Diese Entität ist mit 2-26\% die seltenste Ausprägung der Schneider-Papillome. Die Geschlechterverteilung ist annähernd gleich, eine Manifestation ist meist nach der fünften Dekade feststellbar. Die onkozytären Papillome entstehen ausschließlich an der lateralen Nasenwand, dem Sinus ethmoidalis oder maxillaris $[113,114]$. Sie sind dem invertierten Papillom in vielen Punkten sehr ähnlich, sodass einige Autoren die onkozytären Papillome als mikroskopische Variante des invertierten Papilloms bezeichnen $[111,115,116]$. Eine maligne Entartung ist - analog zum invertierten Papillom - möglich (siehe folgendes Kapitel).

\section{Invertiertes Papillom:}

Invertierte Papillome repräsentieren mit 47-78\% die häufigste Entität der Schneider-Papillome. Sie zeigen ein polypöses, meist gelapptes Wachstum, mikroskopisch in das Stroma der Mukosa eingestülpte Epithelzapfen. Entstehungsort ist in $48 \%$ der Sinus ethmoidalis, in $28 \%$ der Sinus maxillaris, in 7,5\% der Sinus sphenoidalis und in 2,5\% der Sinus frontalis. Auch Manifestationen an der Schleimhaut des Nasenseptums sind möglich. Typischerweise ist eine unilaterale Manifestation festzustellen. Eine bilaterale Manifestation ist äußerst selten beschrieben $[117,118]$. Eine sekundäre metachrone Malignisierung ist in bis zu $4 \%$ der invertierten Papillome dargestellt mit dem Plattenepithelkarzinom als häufigste Entität, die bei Rezidiven eines invertierten Papilloms auf bis zu $11 \%$ ansteigt [119-121].

Die Inzidenz des invertierten Papilloms liegt zwischen 0,5 und 1,5:100 000 Einwohnern pro Jahr mit einem Altersgipfel zwischen der 5. Und 6. Dekade. Männer sind häufiger betroffen (M:W 2-5:1) $[108,118,122]$.

Patienten mit invertiertem Papillom berichten von Nasenatmungsbehinderung, Epistaxis und Epiphora, sofern eine Affektion der ableitenden Tränenwege oder des unteren Nasengangs vorliegt. Je nach Lokalisation und invasivem Wachstumsverhalten kann es zu der Ausbildung einer Mukozele oder einer Protrusio bulbi kommen.

Klinisch präsentiert sich meist eine ödematöse, eher durchsichtig wirkende Polypenformation. Allerdings unterliegt das Erscheinungsbild starken Variationen, da die polypöse Raumforderung auch entzündlich und fleischig imponieren kann [123].

Die Computertomografie ist die bildgebende Modalität der Wahl, da knöcherne Erosionen, die auf eine Maligne Transformation hinweisen, dargestellt werden. Häufig ist am Entstehungsort des invertierten Papilloms eine Hyperostose oder Sklerose der knöchernen Grenzen zu erkennen. Auch kann eine Kalzifikation innerhalb der Raumforderung vorkommen [124].

Die Exzision mit der unmittelbar umgebenden Schleimhaut ist Therapie der Wahl. Ein Sicherheitsabstand von 1-1,5 cm sollte berücksichtigt werden $[62,125,126]$. Zudem ist die Abtragung bzw. Ausdünnung des Knochens im Bereich der Ansatzstelle erforderlich. Rezidive treten bei unzureichender Resektion deutlich häufiger auf [127]. Bei defensiver Polypektomie oder lokaler Exzision wurden in bis zu 78\% der Fälle Rezidive beschrieben [128]. Innerhalb der letzten Jahre haben sich durch die mediale Maxillektomie und ihre Variationen effizientere Zugangswege zu allen Bereichen der Kieferhöhle etabliert [64]. Diese Technik hat den ursprünglichen Caldwell-Luc Zugang in den meisten Fällen ersetzt [129, 130]. Eine Übersichtsarbeit mit Positionspapier zeigte gleichwertige, wenn nicht sogar bessere Ergebnisse für die endoskopische Resektion von invertierten Papillomen. Bei der Lokalisation in der Kieferhöhle ist der endonasale Zugang dem offenen Vorgehen hinsichtlich Rezidiv-Häufigkeit überlegen [121, 131]. Bei Verwendung eines prälacrimalen Zugangs ist die Rezidivrate noch geringer [125]. Grundsätzlich sind die langfristigen Ergebnisse umso besser, je gründlicher die erkrankte Schleimhaut reseziert wird [118].

\subsection{Leiomyome}

Leiomyome sind gutartige Tumore mit muskulärer Differenzierung. Bei Angioleiomyomen besteht zudem eine vaskuläre Differenzierung.

In der Kopf-Hals-Region sind sie extrem selten und repräsentieren insgesamt nicht einmal $1 \%$ aller insgesamt vorkommenden Leiomyome [132]. In den meisten Fällen sind die Patienten Erwachsene ohne Bevorzugung eines Geschlechts. Die meisten sinunasal vorkommenden Leiomyome weisen eine vaskuläre Differenzierung auf $[106,132,133]$.

Das Tumorwachstum ist lange unbemerkt und sorgt zumeist für unspezifische Symptome wie Druckgefühl und langsam progredienter Nasenatmungsbehinderung. Epistaxis und Schmerzen können hinzukommen.

Makroskopisch präsentieren sich nasale Leiomyome polypoid bis nodulär und gut abgrenzbar mit einer weißlich/bräunlichen Schnittfläche. Die Raumforderung liegt meist unter intakter Schleimhaut. Ulcerationen treten selten auf. Spindelförmige Tumorzellen sind in sich überlappenden Faszikeln angeordnet mit ovalen, länglichen, zigarrenförmig anmutenden Zellkernen ohne Atypien. Eosinophiles, fibrilläres Zytoplasma ist vorhanden. Im Gegensatz zum Leiomyosarkom existieren keine mitotischen Veränderungen. Das Angioleiomyom besitzt zusätzlich prominente Gefäße, die von Muskelzellen umgeben und eng mit ihnen verbunden sind [106].

Trotz des seltenen Vorkommens existiert die Möglichkeit einer malignen Transformation hin zu einem Leiomyosarkom. Insofern sollte eine Verzögerung der Therapie vermieden werden. Therapie der Wahl ist die Tumorresektion. Die Prognose ist bei vollständiger Exzision äußerst gut. Rezidive sind in diesem Fall extrem selten [134-136].

\subsection{Hämangiome}

Das lobuläre kapilläre Hämangiom wurde durch die Franzosen Poncet und Dor 1897 erstmals beschrieben und als Botryomycosis hominis bezeichnet [137]. Ursprünglich wurde vermutet, die Erkrankung sei von Pferden auf Menschen übertragen, was allerdings durch Hartzell einige Jahre später widerlegt wurde [138]. Heutige Synonyme sind Granuloma pyogenicum, kapilläres Hämangiom und Epulis gravidarum.

Mukosale Hämangiome repräsentieren ca. $10 \%$ aller Kopf-/HalsHämangiome und ca. 25\% aller nichtepithelialen Neoplasien des Sinunasaltrakts $[106,139,140]$.

Ihren Ursprung nehmen die Hämangiome in Kapillaren, wenn deren Dichte zu groß wird und diese trotzdem ihre ursprüngliche Architektur mit Stamm und Verästelungen sowie umgebenden Perizyten behalten. Aufgrund der Assoziation mit Traumata bzw. Manipulationen und hormonellen Umstellungen im Rahmen von Schwangerschaften wird eine reaktive Entstehung der lobulären 

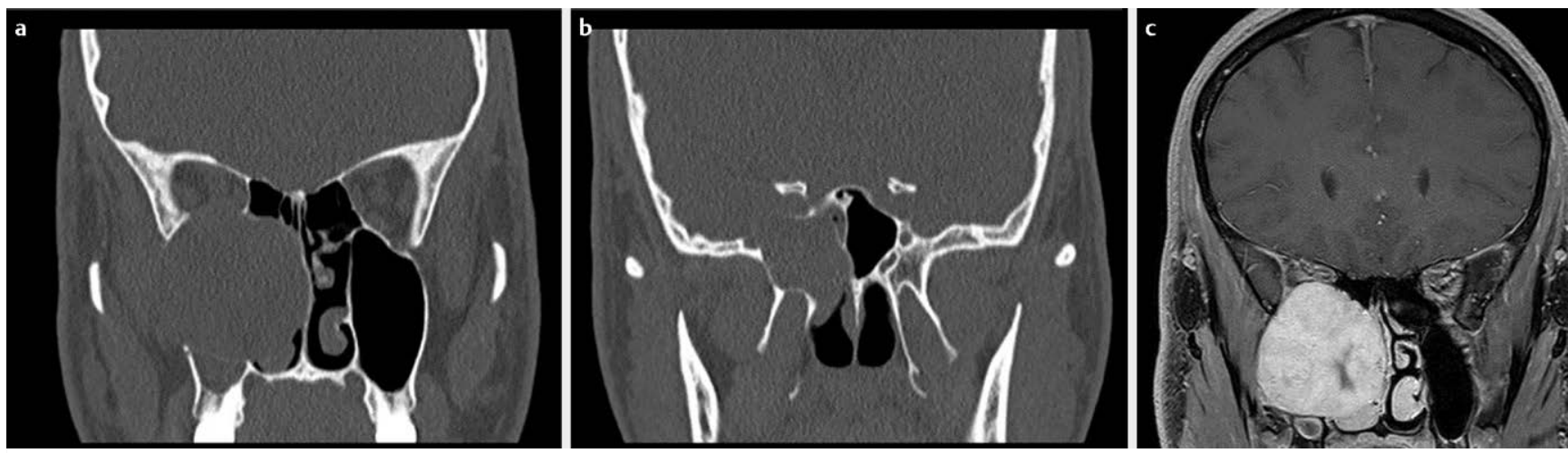

Abb. 9 a \& b Koronare und sagittale CT-Rekonstruktionen eines Patienten mit Schwannom des Nervus maxillaris. In Bild b ist der Ursprung am Foramen rotundum rechts zu erkennen. Bild c T1-gewichtete koronare MRT des Schwannoms rechts.

kapillären Hämangiome diskutiert [141]. Ein gehäuftes Auftreten wird zudem bei Anwendung des Proteinkinase-Inhibitors Vemurafenib berichtet [142].

Das lobuläre kapilläre Hämangiom (Granuloma pyogenicum) tritt in allen Altersstufen auf, zeigt allerdings eine Häufung bei Kindern und adoleszenten Männern sowie Frauen im gebärfähigen Alter. Jenseits der 4. Dekade ist die Geschlechterverteilung gleich.

Die Läsionen können eine Größe von bis zu $5 \mathrm{~cm}$ erreichen. Die Oberfläche ist rotbläulich unter intakter Mukosa gelegen. Der Tumor tastet sich weich, ist kompressibel und mutet gelegentlich polypös an.

Histologisch zeigen lobuläre kapilläre Hämangiome ein stammund astartig verzweigtes Muster aus kapillärer Proliferation, das von Perizyten umgeben ist. Die einzelnen Lobuli sind durch ein fibromyxoides Stroma voneinander getrennt. Inflammatorische Infiltrate treten vor allem bei ulzerierten Oberflächen auf [141].

Primäres klinisches Symptom ist die unilaterale Epistaxis gefolgt von einer schmerzlosen, obstruktiven Raumforderung. Häufigste Manifestationsorte sind vorderes Nasenseptum und der Kopf der unteren Nasenmuschel. Ein Auftreten in den Nasennebenhöhlen ist ebenfalls möglich ebenso wie der Befall der äußeren Nase.

Therapie der Wahl ist die Tumorexzision. Ausgedehntere Befunde können einer präoperativen Embolisation zugeführt werden, um das Blutungsrisiko zu verringern. Bei schwangeren Patientinnen ist eine Regression nach Geburt zu erwarten. Multiple Rezidive sind bei unvollständiger Resektion vor allem bei Kindern zu erwarten [143].

\subsection{Schwannome}

Schwannome sind gutartige Tumore, die von Schwann-Zellen ausgehen. Synonym werden die Begriffe Neurilemmom und benigner peripherer Nervenscheidentumor verwendet.

25-45\% aller Schwannome entstehen in der Kopf-Hals-Region. Am häufigsten in genanntem Bereich finden sich Manifestationen entlang des $N$. vestibulocochlearis. Nur etwa $4 \%$ aller Schwannome manifestieren sich im Sinunasaltrakt. Laut Orpha.net liegt die Inzidenz von benignen Schwannomen bei 6:100 000, die sinunasale Ausprägung ist damit als noch wesentlich geringer anzunehmen. Die Altersspanne der sinunasalen Manifestationen ist mit 17-81
Jahren weit gefasst und zeigt einen Altersgipfel bei 50 Jahren auf ohne Bevorzugung eines Geschlechts [106, 144].

Ursprünge sind entlang der Äste der Hirnnerven V und IX sowie des autonomen Nervensystems zu finden. Die entstehenden Tumore können die Nasenhaupthöhle und alle Nasennebenhöhlen betreffen [144, 145].

Primäre Symptome sind Nasenatmungsbehinderung, Epistaxis, Hyposmie und gelegentlich Schmerzempfindungen sowie die Ausprägung eines Horner Syndroms. Bildgebende Verfahren zeigen eine inhomogene Tumormasse niedriger Dichte mit gelegentlicher Knochenarrosion. Differentialdiagnostische Überlegungen schließen daher Ästhesioneuroblastome, adenoidzystische Karzinome und Plattenepithel-Karzinome mit ein. ( $\mathbf{A b b}$. 9) zeigt eine computertomografische Darstellung eines großen Schwannoms des Nervus maxillaris, welches den Ursprung im Foramen rotundum hat. Magnetresonanztomografisch zeigt sich ein in der T1-Wichtung hyperintenses, inhomogenes Binnensignal der Raumforderung.

Schwannome haben eine kugelförmige, gut abgrenzbare Konfiguration. Der Tumor tastet sich fest und zeigt eine gelblich-bräunliche, teils zystischen Oberfläche [106]. Histologisch sind Schwannome unbekapselte Tumore, die sich aus zellreichen, sogenannten Antoni A Arealen mit nukleären Palisaden sowie zellarmen, myxoiden Antoni B Arealen zusammensetzen. Die Tumorzellen zeigen ein fusiformes Bild mit zystoplasmatischen Ausziehungen, das einen wellige bis spindelige Erscheinung verleiht. Mitosen sind äuBerst spärlich, Nekroseareale existieren nicht [106].

In Ausnahmefällen ist eine Entartung eines Schwannoms möglich. Nach vollständiger Tumorresektion sind Rezidive sehr selten. Aufgrund des sehr langsamen Tumorwachstums ist eine subtotale Tumorresektion in Fällen von starker Adhärenz zu kritischen neurovaskulären Strukturen möglich [144]. Innerhalb des Tumors verlaufende Fasern des betroffenen Nerven sind in der Regel funktionslos, weshalb eine Resektion zu keinen neurologischen Ausfällen führt [146]. In Fällen von zervikalen Schwannomen wird die intrakapsuläre Dissektion empfohlen, um die Nervenfaszikel, welche den Tumor umgeben, nicht zu zerstören [147]. Aufgrund der beengten Platzverhältnisse und der engen Zugangswege ist dies bei Schwannomen der Nasennebenhöhlen allerdings nur sehr eingeschränkt möglich. 


\subsection{Neurofibrome}

Neurofibrome sind gutartige periphere Nervenscheidentumore aus Schwann-Zellen, perineuralartigen Zellen und intraneuralen Fibroblasten. Synonym wird der Begriff Fibroneurom verwendet.

Sinunasale Manifestationen von Neurofibromen sind äußerst selten und können in allen Altersklassen auftreten. Der Altersgipfel betroffener Patienten liegt bei 50 Jahren. Für Patienten mit einer Neurofibromatose Typ I liegt er bei 35 Jahren [148]. Die Prävalenz der Neurofibromatose liegt bei 21:100 000. Letztere sind für ca. $10 \%$ der sinunasalen Neurofibrome verantwortlich.

Häufigste Lokalisationen sind Naseneingang und Sinus maxillaris bei überwiegend unilateraler Manifestation. Beschwerden betroffener Patienten sind Nasenatmungsbehinderung, Epistaxis und Schmerzen über den betroffenen Arealen [148, 149].

Neurofibrome zeigen eine glänzende, fusiforme und manchmal polypoide Oberfläche und sind fest palpabel [148, 149].

Auch Neurofibrome sind unbekapselte Tumore, die eng mit Nervenästen assoziiert sind. Modifizierte Schwannzellen, intraneurale Fibroblasten und perineurale Hybridzellen mit gröberen Kollagensträngen sowie Mastzellen in einem mukopolysaccharid-reichen Stroma bestimmen das histopathologische Bild. Ovaläre bis spindelförmige Zellen mit undulierenden, spitz zulaufenden Zellkernen mit dünnen zytoplasmatischen Prozessen, die sich in das Stroma ausdehnen, sind vorhanden.

Die Prognose ist bei vollständiger Tumorresektion sehr gut. Rezidive treten in $5 \%$ v. a. bei inkompletten Resektionen auf. Eine Malignisierung ist äußerst selten [150].

\subsection{Meningeome}

Meningeome sind gutartige Tumore meningothelialen Ursprungs. Sinunasale Meningeome gehen von extrakraniellen, versprengten arachnoiden Zellen innerhalb von Nervenscheiden oder Gefäßen aus.

Sinunasale Meningeome sind äußerst selten und für weniger als $0,1 \%$ aller primären sinunasalen Neoplasien, $2 \%$ aller Meningeome und $24 \%$ aller extrakraniellen Meningeome verantwortlich. Differenziert werden müssen sie von intrakranialen Befunden mit extrakranieller Ausbreitung in den Sinunasal-Trakt.

Patienten jeden Alters sind betroffen und es existiert - entgegen den intrakraniellen Meningeomen - keine Prädilektion für das weibliche Geschlecht. Das mittlere Erkrankungsalter beträgt 48 Jahre bei einer Altersspanne von 13-88 Jahren.

Manifestationen finden sich häufig in der Nasenhaupthöhle als auch den Nasennebenhöhlen. Eine Manifestation in nur einem der beiden Orte ist noch seltener. Interessanterweise sind die meisten derartigen Tumore linksseitig lokalisiert [151-153].

Die Patienten fallen häufig mit einer endonasalen, polypös anmutenden Raumforderung, mit Nasenatmungsbehinderung, Epistaxis, sinunasalen Beschwerden, Schmerzen, Cephalgien, Exophthalmus, periorbitalen Ödemen oder Visusstörungen auf [106].

Knocheninfiltrationen und Schleimhautulzerationen sind möglich. Die Schnittfläche des Tumors zeigt eine grau-weißliche, bräunliche oder rötliche Farbe. Kalzifikationen und Knochenfragmente können häufig identifiziert werden.

Mikroskopisch können extrakranielle Meningeome äußerst unterschiedliche Erscheinungsbilder aufweisen. Häufig zeigen sie me- ningotheliomatöses Wachstum mit undeutlichen Zellgrenzen. Intranukleäre Pseudoeinschlüsse und Psammomkörper sind häufig.

Von den 15 beschriebenen histologischen Typen von Meningeomen kommen im sinunasal-Trakt meningotheliale, transitionale, metaplastische und psammomatöse Tumore vor. Die meisten Tumore können dem WHO Grad I zugeteilt werden. Sinunasale Manifestationen von Meningeomen Grad II (atypische Meningeome mit schnellem Wachstum) oder Grad III (anaplastische Meningeome, infiltratives Wachstum) sind extrem selten [154, 155].

Differenzialdiagnosen schließen Karzinome, Melanome, aggressive psammomatöse ossifizierende Fibrome ein.

Die vollständige chirurgische Exzision ist Therapie der Wahl, auch wenn Rezidivraten von bis zu 30 \% berichtet werden. Bei Meningeomen, die nicht vollständig resektabel sind, kann eine Radiotherapie zur Wachstumshemmung führen $[156,157]$. Die insgesamte Prognose sinunasaler Meningeome ist gut. Metastasierungen und maligne Transformationen werden nicht beschrieben [106].

\subsubsection{Ossäre Tumore}

\subsection{Osteome und Gardner Syndrom}

Osteome sind gutartige, langsam wachsende Tumore des Schädelknochens, die sich häufig in den Nasennebenhöhlen und der Schädelbasis manifestieren. Am häufigsten finden sich die Knochenwucherungen im Sinus frontalis (70-80\%), dem Sinus ethmoidalis (20-25\%), dem Sinus maxillaris (5\%) und extrem selten dem Sinus sphenoidalis. Die Inzidenz von Osteomen in den Nasennebenhöhlen liegt bei ca. $3 \%[118,158,159]$. Damit sind Osteome per definitionem keine seltene Erkrankung der Nasennebenhöhlen. Sie können allerdings ein Symptom im Rahmen des Gardner Syndroms sein, weshalb sie in der vorliegenden Arbeit trotzdem thematisiert werden.

Die Ätiologie der Tumore ist nicht gänzlich geklärt. Aktuellen Theorien vermuten embryologische Fehlbildungen, traumatische oder entzündliche Trigger, genetische Prädisposition und Störungen des Calcium-Stoffwechsels als Ursache $[118,158,160]$.

Nur ca. $10 \%$ aller Osteome der Nasennebenhöhlen werden symptomatisch. Beschwerden von betroffenen Patienten sind häufig assoziiert mit Obstruktionen der Drainagewege der Nebenhöhlen, also rezidivierenden akuten Sinusitiden und auch chronisch sinunasalen Beschwerden. Druckgefühl, Gesichtsschmerzen und Rhinorrhoe sind klassische Symptome. Bei Beteiligung benachbarter Strukturen der Nasennebenhöhlen kann es zu Kompressionen der Orbita oder des Nervus opticus sowie bei intrakranieller Beteiligung zu einem Pneumatocephalon kommen [158, 161].

Die Computertomografie zeigt hyperdense, homogene, gut abgrenzbare Areale. Die Magnetresonanztomografie kann helfen, ossifizierende Fibrome oder eine fibröse Dysplasie differentialdiagnostisch auszuschließen [118].

Asymptomatische Osteome sollten entsprechend aktuellem Konsens mittels „wait and scan“ behandelt werden [162-164]. Regelmäßige computertomografische Kontrollen alle 2 Jahre geben Aufschluss über Wachstumsgeschwindigkeit des Tumors [165]. Bei symptomatischen Osteomen ist die möglichst vollständige Resektion Methode der Wahl. Je nach Lokalisation kommen endonasale oder offene chirurgische Verfahren zum Einsatz. 
Gardner-Syndrom: Das Gardner-Syndrom zählt mit einer Inzidenz von 1:8000 zu den seltenen Erkrankungen [166]. Die Prävalenz in den USA liegt derzeit bei ca. 1:1 000000 Einwohnern. Patienten, die vom Gardner Syndrom betroffen sind, zeigen häufig (multiple) Osteome, Weichteiltumore und eine intestinale Polyposis (v. a. im Colon) auf. Das Gardner Syndrom wird autosomal dominant vererbt.

Ein genetischer Zusammenhang mit der Entwicklung des Gardner-Syndroms wurde in einer Mutation des Gens für adenomatöse Polyposis coli (APC) gezeigt, das auf Chromosom 5 liegt. Dieses Tumorsuppressorgen ist für die Produktion des APC-Proteins verantwortlich, welches das Zellwachstum im Zellzyklus reguliert [167169].

Regelmäßige Coloskopien sind bei betroffenen Patienten obligat. Bei Nachweis der APC-Genmutation gilt die Entwicklung eines Colonkarzinoms ab einem Alter von 40 Jahren als sicher, weshalb bei Vorliegen von 20 oder mehr Colon-Polypen eine Colektomie empfohlen wird [166]. Insofern sollte bei Vorliegen multipler Osteome differenzialdiagnostisch immer an das Vorliegen des Gardner Syndroms gedacht werden.

\subsection{Fibröse Dysplasie}

Bei der Fibrösen Dysplasie besteht eine mesenchymale Knochenentwicklungsstörung, die durch postzygotisch somatisch aktivierende Mutationen verursacht wird. Es kommt zu einer Aktivierung der Adenylylzyklase und Erhöhung von zyklischem AMP, das auf die nachgeschalteten Signalwege wirkt und den Ersatz von normalem Knochen durch fibröses Gewebe und abnormal strukturierten Knochen bewirkt [170]. Die Inzidenz wird mit 1:4000-10 000 angegeben $[171,172]$.

Je nach Lokalisation der Knochenherde berichten die Patienten von Cephalgien und Druckgefühl. Bei Lokalisation an der Tabula externa des Schädelknochens kommt es zu sichtbaren Deformitäten und entsprechend kosmetischer Beeinträchtigung. Manifestationen an den Ostien oder Schlüsselstellen der Nebenhöhlen-Drainagewege können zu sinunasalen Beschwerden führen, die die zugrundeliegende Erkrankung lange maskieren.

Aufgrund der Seltenheit der Erkrankung existieren nur wenig Daten zur Therapie der fibrösen Dysplasie. Eine kausale Therapie existiert bislang nicht. Es wurde über Schmerzreduktion durch Gabe von Bisphosphonaten berichtet [173-175]. Eine Supprimierung der Osteoblastenaktivität konnte allerdings nicht nachgewiesen werden [176]. Bei asymptomatischem Verlauf wird die primär observierende Therapie favorisiert. Funktionseinschränkungen und Beschwerden wie Cephalgien rechtfertigen ein operatives Vorgehen in Abhängigkeit der Lokalisation der Manifestation. Eine prophylaktische operative Therapie wird nicht empfohlen, stattdessen sollten entsprechend der verfügbaren Daten regelmäßige bildmorphologische Verlaufskontrollen erfolgen $[177,178]$.

\subsection{McCune-Albright-Syndrom}

Das McCune Albright Syndrom wurde zuerst 1936 als eine Trias von fibröser Dysplasie, Café-au-Lait-Flecken der Haut und Pubertas praecox beschrieben [179]. Der heute bekannte, deutlich variablere Phänotyp macht das McCune Albright Syndrom zu einer interdisziplinäreren Herausforderung.
Ursächlich für die Ausbildung des Syndroms ist eine Mutation des GNAS1-Gens (Guanine nucleotide binding protein alpha stimulating activity polypeptide 1), welches auf Chromosom 20 lokalisiert ist.

Die Seltenheit dieser Erkrankung führt zu einer nur unzureichenden Charakterisierung der sinunasalen Beteiligung von Patienten mit McCune-Albright-Syndrom. Derzeit bekannte Symptome stammen vorwiegend aus Fallberichten, die Komplikationen der Erkrankung schildern. Die Prävalenz der Erkrankung wird auf 0,55:100.000 geschätzt [2].

Patienten mit McCune-Albright-Syndrom schildern primär Schwäche in den Extremitäten oder Schmerzempfindungen. Die am häufigsten betroffene Lokalisation ist der proximale Femur. Frakturen der betroffenen Knochenareale finden häufig in der Kindheit statt mit sinkender Inzidenz in Richtung Adoleszenz [180]. Charakteristisch sind die Deformierungen des Knochens unter Belastung, die zu den für die Erkrankungen typischen kraniofazialen Stigmata führen. Kraniofaziale Ausbildungen der fibrösen Dysplasie weisen ein langsames Wachstum mit schmerzloser Schwellung auf, die zu einer bisweilen deutlichen Asymmetrie des Mittelgesichts führt ( $\triangleright$ Abb. 10 und 11). Milde Verläufe werde häufig zufällig im Rahmen von Röntgenaufnahmen der Zähne und im Rahmen von bei Polytraumen durchgeführten Computertomografien diagnostiziert [170]. Schwerere Verläufe führen häufiger zu Schmerzempfindungen, Parästhesien, Okklusionsstörungen, Hörbeeinträchtigungen und Visusstörungen [170, 178, 181, 182]. Betroffene Patienten zeigen in bis zu $50 \%$ Beeinträchtigungen der Schilddrüsenfunktion, meist eine Hyperthyreose. GNAS führt in ca. $15 \%$ der Patienten zu einer Steigerung von Prolaktin und GH in der Hypophyse. Letzteres führt zu den charakteristischen kraniofazialen Veränderungen, die bei den meisten Patienten ersichtlich sind [183].

DeKlotz et al. konnten in einem Kollektiv von 130 Patienten mit McCune-Albright Syndrom bei 112 Patienten kraniofaziale Veränderungen nachweisen [182]. 33\% berichteten von Cephalgien oder Gesichtsschmerzen, Nasenatmung war in $29 \%$ der Fälle und chronisch sinunasale Beschwerden sowie Hyposmie in jeweils $7 \%$ festzustellen. Ein Progress der sinunasalen Beteiligung der Fibrösen Dysplasie nach Abschluss der Adoleszenz ist selten. Schwerwiegen-

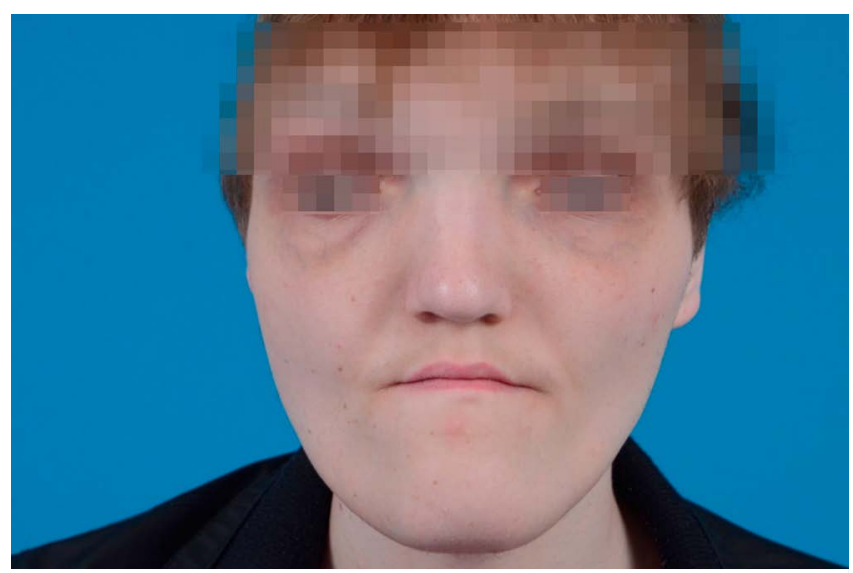

Abb. 10 Typische kraniofaziale Veränderungen eines Patienten mit McCune-Albright-Syndrom. 


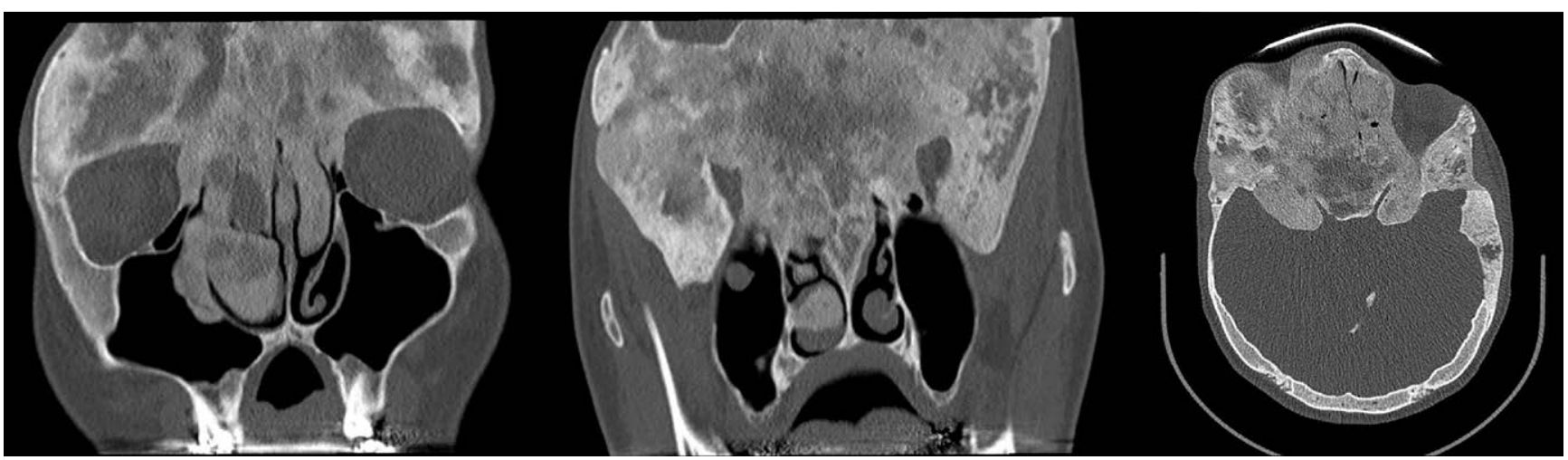

-Abb. 11 Koronare und axiale CT-Schichtung eines Patienten mit McCune-Albright-Syndrom.

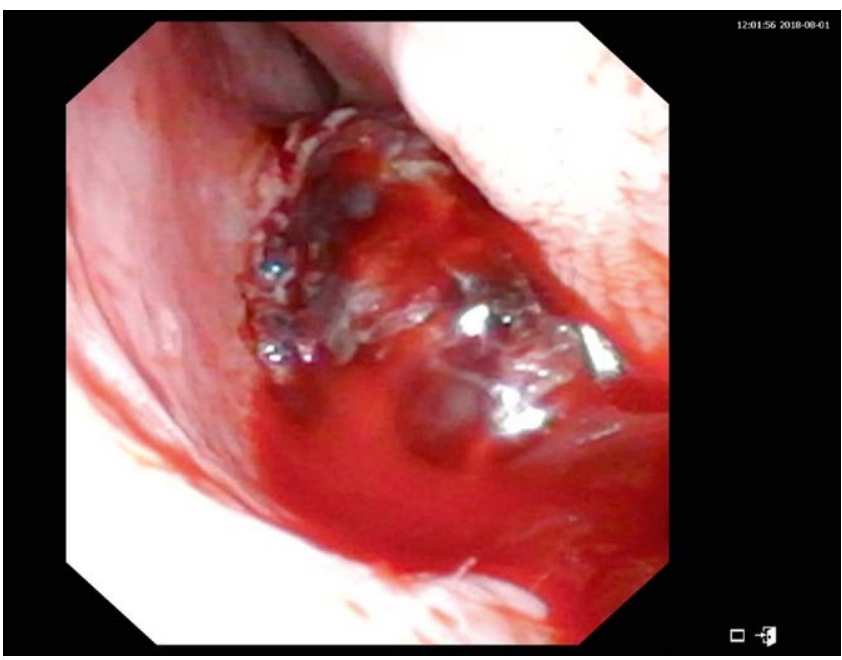

-Abb. 12 Hämangioendotheliom der linken Nasenhauphöhle mit Lokalisation am Nasenseptum (links im Bild zu sehen) als sanguinolente Raumforderung.

de Komplikationen im Rahmen des normalen Fortschreitens der Erkrankung sind ebenfalls selten anzutreffen ( $>$ Abb. 12).

Wie bei der Fibrösen Dysplasie existiert keine kausale Therapie. Bisphosphonate zeigten keinen relevanten Therapieerfolg [184186]. Gemäß allgemeinem Konsens wird das konservative Vorgehen häufiger favorisiert, wohingegen chirurgische Maßnahmen bei signifikanten Symptomen oder bei Kompression vitaler Strukturen zum Einsatz kommen [187-190].

\subsubsection{Andere Weichteiltumore}

In der folgenden Sektion werden seltene benigne Entitäten des Sinunasaltrakts vorgestellt, die epithelialen, odontogenen, neuroglialen Ursprungs sind.

- Respiratorisches epitheliales adenomatoides Hamartom

- Sinunasales Ameloblastom

- Chondromesenchymales Hamartom

- Nasales Gliom

- Cholesteatom

\subsection{Respiratorisches epitheliales adenomatoides} Hamartom (REAH)

Das respiratorische epitheliale adenomatoide Hamartom wurde erstmals 1995 beschrieben [191]. Im Rahmen dieser Erkrankung kommt es zu einer tumorartigen Proliferation von Drüsen im Stroma, welches von mehrreihigem Flimmerepithel bedeckt ist. Manifestationen finden sich in den Nasennebenhöhlen, der Nasenhaupthöhle und dem Nasenrachen. Uni- oder bilaterale Manifestationen sowie Assoziation mit chronisch polypöser Rhinosinusitis sind möglich. Die Zahl der weltweit beschriebenen Fälle schwankt zwischen 60 [191-196], bis ca. 200 [197, 198]. Das Syndrom zählt aufgrund der niedrigen Inzidenz zu den seltenen Erkrankungen.

Vor allem Männer zwischen 30 und 90 Jahren sind von der Neubildung betroffen [191, 195]. Die Symptome entsprechen üblicherweise denen einer chronischen Rhinosinusitis, also Druckgefühl und Nasenatmungsbehinderung, Epistaxis und Rhinorrhoe, Gesichtsschmerzen und Hyposmie [191-193, 199, 200].

Am häufigsten manifestiert sich das epitheliale adenomatoide Hamartom in der Nasenhaupthöhle, vor allem am posterioren $\mathrm{Na}$ senseptum. Nicht selten kommt es zu einem Befall beider Seiten [191-196, 199]. Häufig wird es im Rahmen einer Polyposis nasi diagnostiziert. Bei Manifestation an der Fossa olfactoria kann es zu einer deutlichen Erweiterung derselben kommen, was differenzialdiagnostisch hinsichtlich einer Polyposis nasi relevant ist [201, 202]. Eine Erweiterung der Fossa olfactoria bei einem lokalen Befall, fehlende Kontrastmittelanreicherung in der Computertomografie und ansonsten bildmorphologisch unauffällige Nasennebenhöhlen sollten daher unbedingt an ein epitheliales adenomatoides Hamartom denken lassen.

Aufgrund des primären Eindrucks wird die Diagnose häufig im Rahmen einer Biopsie gesichert. Therapeutisch ist die vollständige Exzision anzustreben. Rezidive sind in den verfügbaren Studien innerhalb eines Zeitraums von 5 Jahren nicht beobachtet worden [191, 193, 199, 203, 204].

\subsection{Sinunasales Ameloblastom}

Ameloblastome sind gutartige, aber aggressive odontogene Tumore, die in den meisten Fällen den Unterkiefer betreffen. Nur etwa $15 \%$ treten am Oberkiefer auf. Als eine Untergruppe sind die sinunasalen Ameloblastome zu betrachten, die vermutlich von der 
epithelialen Auskleidung der Nasennebenhöhlen abstammen. Manifestationsorte sind die Nasennebenhöhlen, in einigen Fällen auch mit Beteiligung der Nasenhaupthöhle.

Es zeigt sich eine meist schmerzlose Raumforderung, die im weiteren Verlauf zu Nasenatmungsbehinderung und Druckgefühl führen kann. Im Unterschied zu Ameloblastomen des Kiefers zeigt die Sinunasale Variante radiografisch ein solides Bild mit teilweisen Verschattungen [205].

Histologisch gesehen sind sinonasale Ameloblastome identisch mit Manifestationen der Mundhöhle, mit klassischen Merkmalen palisadierter säulenförmiger Basalzellen, die eine zentrale Proliferation umgeben, die dem sternförmigen Retikulum eines sich entwickelnden Zahnes ähnelt. In den Nasennebenhöhlen kann eine ameloblastomartige Proliferation unter intakter Mukosa dargestellt werden. Dieser Befund ist - bei gleichzeitig nicht vorhandener Verbindung zum Kiefer - eine Bestätigung für einen primär sinunasalen Ursprung des Tumors. Im Gegensatz zu den gnathischen Variante ist die Prävalenz des sinonasalen Ameloblastoms bei Männern höher. Die Inzidenz wird insgesamt auf ca. 0,5:100 000000 geschätzt [206, 207]. Der Altersgipfel liegt bei ca. 60 Jahren [208] und damit etwa 15-20 Jahr höher als bei der am Kiefer lokalisierten Variante [106].

Der Behandlungserfolg und damit die Rezidivfreiheit ist abhängig von der vollständigen chirurgischen Exzision des Befundes. Detaillierte bildgebende Darstellungen sind essentiell, um Residuen zu vermeiden. Rezidive treten in den meisten Fällen innerhalb von 1-2 Jahren auf, können allerdings auch nach deutlich längeren Zeiträumen entstehen [205]. Beschreibungen von Mortalität durch sinunasale Ameloblastome, Metastasierungen oder maligne Transformationen existieren in der aktuellen Literatur nicht.

\subsection{Chondromesenchymales Hamartom}

Das chondromesenchymale Hamartom ist eine gutartige, langsam wachsende Raumforderung mit lokal destruktivem, tumorähnlichem Wachstum und unterschiedlichen mesenchymalen Anteilen. Synonym werden die Begriffe nasales chondromesenchymales $\mathrm{Ha}$ martom und Mesenchymom verwendet.

Der Tumor ist sehr selten und tritt meist bei Kindern auf, nur selten auch bei älteren Kindern und Erwachsenen mit einer leichten Bevorzugung des männlichen Geschlechts. Es existieren in der derzeitigen Literatur ca. 60 publizierte Fälle [209].

Nasennebenhöhlen, Nasenhaupthöhle und Orbita können betroffen sein. Ausdehnungen entlang der Schädelbasis und nach intrakraniell sind möglich [209, 210].

Symptome betroffener Patienten sind Nasenatmungsbehinderung und Druckgefühl über der betroffenen Region. In der Bildgebung kann aufgrund des destruktiven Wachstums mit Knochenarrosionen der Eindruck eines malignen Geschehens entstehen.

Makroskopisch erinnert das feste und weißliche Gewebe an Knorpel. Mikroskopisch zeigt sich ein lobuläres Proliferationsmuster aus reifem und unreifem hyalinem Knorpel mit unterschiedlichem zellulärem und fibrösem Hintergrund. Die Knorpel- und Stroma-Anteile können mit knöchernen trabekulären Strukturen durchsetzt sein, oder knöcherne Inseln umgeben [106, 211].

Nach vollständiger Tumorresektion ist die Rezidivrate sehr gering und die Prognose entsprechend gut.

\subsection{Nasales Gliom}

Nasale Gliome (Synonym: heterotopes, ZNS-Gewebe) sind Ansammlungen von heterotopem neuroglialen Gewebe. Manifestationen können in der Nase und an der äußeren Nase auftreten. In $60 \%$ zeigt sich die Raumforderung am Nasenrücken, in $30 \%$ innerhalb der Nasenhaupthöhle. Noch seltener, in ca. $10 \%$ der Fälle, werden Raumforderungen an beiden genannten Stellen diagnostiziert, die durch einen Defekt im Knochen miteinander in Verbindung stehen [212].

Bei den meisten Patienten besteht die Raumforderung bereits bei der Geburt. Ca. 90 \% der Fälle werden im Alter von ca. 2 Jahren diagnostiziert bei einer gleichmäßigen Verteilung über beide Geschlechter.

Klinisch zeigt sich eine gut abgrenzbare, glatte Raumforderung, die submukös lokalisiert und nicht kompressibel ist.

Bei innerhalb der Nasenhaupthöhle gelegenen Befunden kann es zu Nasenatmungsbehinderung kommen, die - neben der ästhetischen Beeinträchtigung eines am Nasenrücken gelegenen Befundes - Hauptsymptom des nasalen Glioms ist.

Weitaus seltenere Manifestationen finden sich in den Nasennebenhöhlen, Pharynx, Nasopharynx, Zunge, Gaumen, Tonsillen und innerhalb der Orbita [213].

Im Gegensatz zu paranasalen Zelen nehmen Gliome bei venöser Stauung nicht an Größe zu bzw. pulsieren nicht. Dies kann mit dem Fürstenberg-Test, bei dem eine Kompression der V. jugularis durchgeführt wird, differenziert werden. Zusätzlich zeigt sich in der Computer- oder Magnetresonanztomografie eine Weichgewebsmasse ohne intrakraniellen Anteil oder einen knöchernen Defekt am Übergang zur vorderen Schädelgrube.

Makroskopisch zeigt sich die Raumforderung als polypoide, weiche, graubräunliche Masse mit einer Größe von 1-3 cm. Mikroskopisch ist der Tumor unbekapselt und aus unterschiedlich großen Inseln von Gliagewebe zusammengesetzt. Dazwischen finden sich Astrozyten und bandartige Stränge vaskularisierten Bindegewebes. Das Gliagewebe geht fließend in das Stroma der Dermis über. Mitosen zeigen sich nicht.

Differenzialdiagnostisch müssen nasale Enzephalozelen ausgeschlossen werden, in denen sich im Vergleich zu nasalen Gliomen allerdings ZNS-Gewebe mit leicht aufzufindenden Neuronen befindet. Trotzdem kann es bei Rezidiven zu fibrösen Veränderungen des Tumors kommen, die eine genaue Differenzierung von einem nasalen Gliom stark erschweren.

Die vollständige Exzision des nasalen Glioms ist Therapie der Wahl. Bei inkompletten Resektionen kann es in bis zu 30 \% zu Rezidiven kommen. Lokal aggressives Verhalten oder eine Tendenz zur Entartung bestehen nicht [212].

\subsection{Cholesteatom}

Cholesteatome sind chronisch-eitrige Entzündungen durch versprengtes verhornendes Plattenepithel, welches zu Knochendestruktionen führt. Typischerweise findet sich diese Pathologie im Mittelohr, allerdings finden sich in der aktuellen Literatur auch knapp 30 Fallberichte mit Ausprägung innerhalb der Nasennebenhöhlen [214, 215]. Häufigster Manifestationsort ist die Stirnhöhle, gefolgt von Kieferhöhle und Siebbeinzellen. Ein aktueller Bericht präsentiert eine Manifestation in der Keilbeinhöhle [216]. In > Abb. 13 ist ein großes Cholesteatom der Keilbeinhöhle in einer magnetre- 


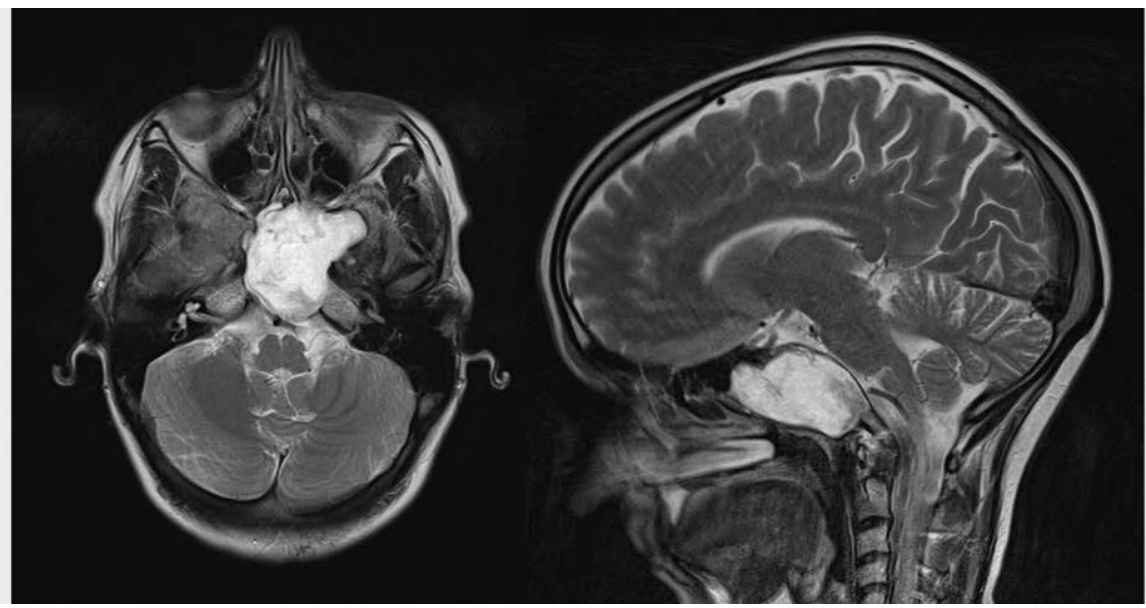

- Abb. 13 T2 gewichtete MRT eines Cholesteatoms der Keilbeinhöhle (links axiale, rechts sagittale Schichtung) (mit freundlicher Genehmigung von Prof. Dr. S. Kösling, Radiologie, Universitätsklinikum Halle).

sonanztomographischen Darstellung zu erkennen. \ Abb. 14 zeigt den intraoperativen, endoskopischen Befund.

Ursächlich können entweder kongenitale Zellversprengungen im Rahmen der Embryogenese oder sekundäre Versprengungen z. B. durch chirurgische Interventionen sein. Auch Metaplasien im Rahmen chronischer Entzündungen werden als Ursache diskutiert [215].

Die Beschwerden sind abhängig von der Lokalisation und können Cephalgien, Visusstörungen, Druckgefühl, Rhinorrhoe und Hiernnervenausfällen umfassen.

Therapie der Wahl ist die operative und möglichst vollständige Resektion, die aber je nach Lage nicht immer möglich ist. Ziel der Operation sollte zudem eine möglichst weite Drainagemöglichkeit der betroffenen Kavität sein, um postoperative Kontrollen und ggf. Reinigungen bei nicht vollständiger Resektion des Cholesteatoms zu ermöglichen.

\subsubsection{Maligne Tumore}

Malignome der Nasenhaupthöhle und der Nasennebenhöhlen repräsentieren 0,2-0,8\% aller malignen Neoplasien des menschlichen Körpers [10]. Die Inzidenz von Malignomen in der Nasenhaupthöhle und den Nasennebenhöhlen wird mit unter 1,5:100 000 bei Männern und unter 1:100 000 bei Frauen angegeben. Folglich sind alle malignen Entitäten dieser anatomischen Region zu den seltenen Erkrankungen zu zählen.

\subsubsection{Maligne epitheliale Tumore \\ 2.4.2.1.1 Plattenepithelkarzinom}

\subsection{Verhornendes Plattenepithelkarzinom}

Sinunasale Plattenepithelkarzinome sind maligne Neoplasien, die von der Oberfläche des Epithels der Nasenhaupthöhle und der Nasennebenhöhlen ausgehen und eine Plattenepithel-Differenzierung aufweisen.

Der Befall des Sinunasaltrakts durch Plattenepithelkarzinome ist selten. Er stellt die am wenigsten von dieser Entität betroffene Lokalisation der Kopf-Hals-Region dar [217]. Das Erkrankungsalter liegt zwischen dem 6. und 7. Lebensjahrzehnt mit deutlich mehr männlichen Patienten (m:w=2:1) [106, 217-219].
Tabakkonsum erhöht das Risiko des Auftretens eines Plattenepithelkarzinoms im Sinunasaltrakt, allerdings deutlich weniger als in anderen Lokalisationen der Kopf-Hals-Region [220-222]. High-risk HPV Infektionen sind meistens mit dem Auftreten des nichtverhornenden Plattenepithelkarzinoms assoziiert. In seltenen Fällen können sinunasale Papillome nach maligner Transformation in ein verhornendes oder in ein nicht verhornendes Plattenepithel übergehen [223].

Häufigster Manifestationsort ist der Sinus maxillaris, gefolgt von der Nasenhaupthöhle und dem Sinus ethmoidalis. Ein Befall des Sinus sphenoidalis oder frontalis ist äußerst selten [106].

Betroffene Patienten weisen initial unspezifische Beschwerden wie Nasenatmungsbehinderung, Epistaxis und Rhinorrhoe bzw. sinunasale Beschwerden auf. Schmerzen über der betroffenen Region, Protrusio bulbi oder Diplopie und Paralysen sind Symptome bei ausgedehnterem Befall. Bei älteren Patienten kann sich die Manifestation durch eine nicht mehr passende Oberkiefer-Zahnprothese bemerkbar machen, wenn der Hartgaumen infiltriert ist.

Makroskopisch wächst der Tumor exo- oder endophytisch mit variablen Ulzerationen, Nekrosearealen und hämorrhagischen Anteilen. Mikroskopisch zeigt der Tumor identische Merkmale zu Manifestationen in anderen Kopf-Hals-Regionen. Dazu gehören irreguläre Nestbildungen und bandartige Anordnungen eosinophiler Zellen, die eine starke Verhornung ausprägen und eine desmoplastische Stromareaktion induzieren. Unterschieden wird zwischen gut, moderat und gering differenzierten verhornenden Plattenepithelkarzinomen.

Therapie der Wahl ist die Tumorresektion mit adjuvanter Radiotherapie. Bei inoperablen Befunden ist eine primäre Radiochemotherapie anzustreben. Die 5-Jahres Gesamt-Überlebensrate für das sinunasale Plattenepithelkarzinom liegt zwischen 50 und $60 \%$ und ist stark abhängig vom Tumorstadium bei Diagnosestellung. Karzinome der Nasenhaupthöhle haben eine bessere Prognose als bei Manifestationen innerhalb der Nasennebenhöhlen, da diese erst in größeren Tumorstadien zu Beschwerden führen [217$219,224,225]$. 


\subsection{Nichtverhornendes Plattenepithelkarzinom}

Das nichtverhornende Plattenepithelkarzinom des Sinunasaltrakts wird charakterisiert durch ein ausgeprägtes bandförmiges Wachstumsmuster mit fehlender oder eingeschränkter Reifung.

Synonym werden die Begriffe Schneidersches Karzinom, Zylinderzellkarzinom oder Übergangs-Karzinom verwendet.

Das nichtverhornende Plattenepithelkarzinom repräsentiert ca. $10-27 \%$ der sinunasalen Plattenepithelkarzinome. Es betrifft Patienten im 6.-7. Lebensjahrzehnt, darunter deutlich mehr männliche Patienten [226-229].

Die Risikofaktoren sind ähnlich denen des verhornenden Plattenepithelkarzinoms des Sinunasaltrakts, allerdings können in 30-50\% der Fälle transkriptional aktive high-risk HPV Viren nachgewiesen werden. Zwischen 2-10\% der sinunasalen Papillome können durch eine maligne Transformation in ein verhornendes und noch seltener in ein nicht verhornendes Plattenepithel übergehen $[106,223]$.

Makroskopisch zeigt der Tumor ein variables exophytisches und/ oder invertiertes Wachstumsmuster mit brüchig wirkender Struktur und Nekrose- sowie hämorrhagischen Arealen. Mikroskopisch wächst der Tumor als sich ausdehnende Nester oder anastomosierende, bandartige Anordnungen von Zellen in der Submukosa mit einer Auflage aus glattem Stroma. Papilläre Eigenschaften können innerhalb oder auf der Oberfläche des Tumors identifiziert werden [106].

Ähnlich dem verhornenden sinunasalen Plattenepithelkarzinom ist die endonasale oder offene Tumorresektion anzustreben, gefolgt von einer adjuvanten Radiotherapie, alternativ zu einer primären Radiochemotherapie für inoperable Befunde. Die 5-Jahres Gesamt-Überlebensrate liegt für nichtverhornende Plattenepithelkarzinome bei ca. $60 \%$. HPV-assoziierte Karzinome haben bessere Überlebenschancen, obwohl die prognostische Signifikanz nicht so stark untermauert ist wie bei Tumoren des Oropharynx [227, 230]. Lymphknotenmetastasen liegen in 3,3 bis $26 \%$ der Fälle bei Erstdiagnose vor [231, 232].

\subsection{Spindelzell-/Sarkomatoides Plattenepithelkarzinom}

Das Spindelzell-Plattenepithelkarzinom oder sarkomatoides Karzinom des Sinunasaltrakts ist eine Sonderform des Plattenepithelkarzinoms, die durch das Vorhandensein vorwiegend maligner Spindelzellen und/oder pleomorpher Zellen definiert ist.

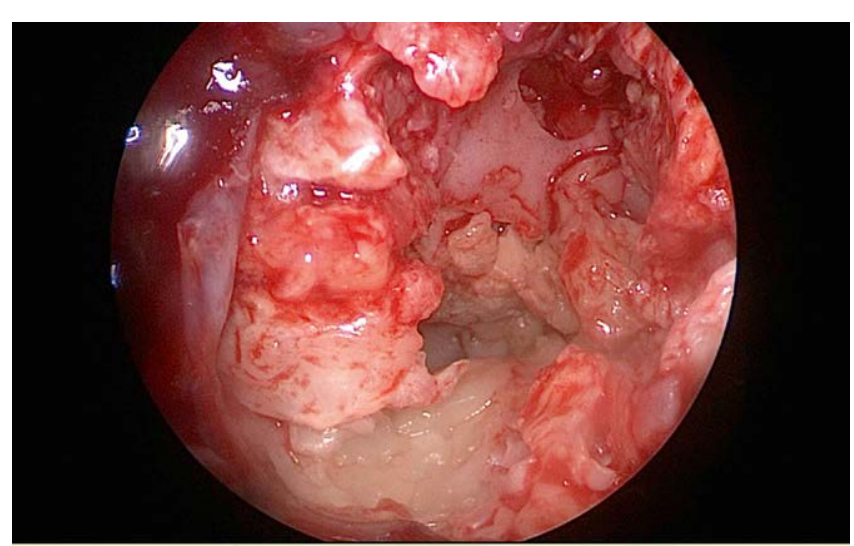

- Abb. 14 Endoskopisches Bild des intraoperativen Befundes des Cholesteatoms der Keilbeinhöhle (mit freundlicher Genehmigung von A. Gey, Prof. Dr. S. Plontke, Dr. A. Glien, HNO Universitätsklinikum Halle)
Diese Sonderform manifestiert sich vorwiegend bei älteren, männlichen Patienten. Der Tumor tritt äußerst selten im Sinunasaltrakt auf und repräsentiert weniger als $5 \%$ aller Plattenepithelkarzinome dieser Region [227, 233-235].

Die Entstehung des Spindelzell-Plattenepithelkarzinoms ist eng assoziiert mit Tabakkonsum und Strahlenexposition. In den wenigen, bisher bekannten Fällen konnte keine HPV-Infektion nachgewiesen werden [227, 236, 237].

Symptome betroffener Patienten sind zunächst unspezifisch und äußern sich meist in Nasenatmungsbehinderung und Epistaxis. In höheren Tumorstadien können Gesichtsschwellungen und Diplopie sowie Schmerzen der betroffenen Areale hinzukommen [106].

Spindelzell-Plattenepithelkarzinome wachsen als polypöse Raumforderungen mit ulzerierender Oberfläche und ähneln dem makroskopischen Bild der häufiger vorkommenden laryngealen Befunde. Sie stammen vom Plattenepithel ab und zeigen eine abweichende Differenzierung mit epithelial-mesenchymaler Transition auf. Die Tumore können Residuen von dysplastischem Plattenepithel enthalten und zeigen häufig Areale mit Transitionen hin zu malignen Spindel- oder pleomorphen Tumorzellen [106].

Hinsichtlich der Prognose und prädiktiver Faktoren bei sinunasaler Manifestation existieren aufgrund der extrem geringen Fallzahlen keine genaueren Daten.

\subsection{Lymphoepitheliales Karzinom}

Das lymphoepitheliale Karzinom ist ein gering differenziertes Plattenepithelkarzinom oder ein histologisch undifferenziertes Karzinom. Ein prominentes lymphoplasmatisches Infiltrat, welches dem Nasopharynx-Karzinom ähnelt, ist typisch für das mikroskopische Erscheinungsbild des Tumors.

Die Entität ist sehr selten und tritt - ähnlich dem NasopharynxKarzinom - meist in südostasiatischen Ländern auf. Der Altersgipfel liegt zwischen 50 und 70 Jahren, bevorzugt bei Männern (m:w 3:1). Ätiologisch ist bei den lymphoepithelialen Karzinomen eine Assoziation mit dem Epstein-Barr Virus nachweisbar [10, 238].

Manifestationen lassen sich meist in der Nasenhaupthöhle feststellen, die Nasennebenhöhlen sind seltener in den Nasennebenhöhlen verortet. Infiltratives Wachstum in den Gaumen, die Orbita oder die Schädelbasis sind möglich.

Symptome betroffener Patienten sind Druckgefühl, Nasenatmungsbehinderung, Epistaxis und bei Infiltration der Orbita eine Protrusio bulbi. Nervenausfälle können bei intrakranieller Infiltration auftreten $[238,239]$.

Lymphknoten- und Fernmetastasierung sind möglich. Eine gründliche Endoskopie und Biopsie des Nasopharynx sollten vorgenommen werden, um eine lokoregionäre Ausbreitung eines $\mathrm{Na}$ sopharynx-Karzinoms auszuschließen.

Aufgrund der geringen Fallzahl existiert keine Standard-Therapie. Aufgrund der hohen Radiosensitivität wird in den meisten Fällen eine lokoregionäre Radiotherapie durchgeführt, die selbst bei Vorliegen von Halslymphknoten-Mestastasierung ein sehr gutes Ansprechen zeigt. Eine Radiochemotherapie gefolgt von SalvageChirurgie ist bei großen Befunden möglich [240]. Die Datenlage ist allerdings aufgrund der sehr geringen Fallzahl schlecht beurteilbar. 


\subsection{Sinunasales undifferenziertes Karzinom (SNUC)}

Das sinunasale undifferenzierte Karzinom wurde erstmals 1986 von Frierson et al. beschrieben [241]. Es handelt sich um ein hochaggressives Karzinom, welches lokal extensives Wachstum zeigt. Pleomorphe Tumorzellen und zahlreiche Tumornekrose-Areale prägen das Erscheinungsbild. Es handelt sich um eine high-grade epitheliale Neoplasie mit unsicherer Histogenese mit oder ohne neuroendokriner Differenzierung. Eine genaue Abgrenzung hinsichtlich des lymphoepithelialen Karzinoms und des Olfaktoriusneuroblastoms ist entscheidend [10, 241].

Der Altersbereich liegt zwischen 30 und 90 Jahren mit einer höheren Inzidenz bei Männern (M:W 2-3:1) [238, 242].

Es existiert keine Assoziation mit dem Epstein-Barr Virus. Einige Fälle traten nach vorangegangener Radiotherapie im Rahmen eines Nasopharynx-Karzinoms auf [238].

Das SNUC manifestiert sich meist in der Nasenhaupthöhle, dem Sinus maxillaris und ethmoidalis mit häufiger Infiltration benachbarter Strukturen. So zeigen bis zu 50 \% der Patienten zum Zeitpunkt der Diagnosesicherung bereits Infiltrationen der Dura und $30 \%$ Infiltrationen der Orbita [243, 244]. In einer Studie, welche die prozentuale Häufigkeit des T-Stadiums in Relation zu den untersuchten Karzinomhistologien analysierte, zeigten sich für das SNUC $69 \%$ der Patienten im Stadium T4 [245].

Ähnlich dem lymphoepithelialen Karzinom kommt es bei betroffenen Patienten initial zu Nasenatmungsbehinderung, Epistaxis, später zu Protrusio bulbi, periorbitalen Schwellungen sowie Gesichtsschmerzen und bei intrakranieller Infiltration zu Ausfällen von Hirnnerven.

Das SNUC zeigt eine hohe Rate von Lokalrezidiven und Fernmetastasierung mit häufiger Gefäß- und Nerveninfiltration [246, 247]. Die 5-Jahres Überlebensrate liegt laut einer aktuellen Studie, die insgesamt 318 Patienten mit SNUC in den USA analysiert hat, bei 34,9\% und die 10-Jahres Überlebensrate bei 31,3\% [248]. Die schlechte Prognose ist in den meisten Fällen durch das bereits hohe Tumorstadium zum Zeitpunkt der Diagnosestellung und die hierdurch bedingte Inoperabilität verursacht. Ein weiterer Grund ist die Tatsache, dass die Mehrzahl der publizierten Fallserien weniger als 20 Patienten enthalten, weshalb kein standardisierter Therapieansatz oder eine Leitlinie zur Therapie des SNUC existiert [243].

In Anbetracht der aktuellen Literatur besteht ein Konsens, dass eine multimodale, aggressive Therapie aus einer Kombination von Chirurgie, Radio- und Chemotherapie erfolgen sollte. Dies wurde durch 2 große SEER (Surveillance, Epidemiology and End Results Program) Datenbank Studien untermauert [248, 249]. Die Resektion des Tumors gefolgt von einer adjuvanten Radiochemotherapie oder die primäre Radiochemotherapie sind mögliche Therapieansätze in Abhängigkeit der Resektabilität des Tumors. Ansätze einer Targeted Therapy mit Lapatinib, welches den Human epidermal growth factor receptor 2 (HER 2) Singalweg sowohl in vitro als auch in vivo unterdrückte, zeigten vielversprechende erste Ergebnisse, die auf effektivere Therapien hoffen lassen [250].

\subsection{Adenokarzinom}

\subsection{Adenokarzinom vom intestinalen Typ}

Sinunasale Adenokarzinome vom intestinalen Typ ähneln dem morphologischen Aufbau des Adenokarzinoms des Darms.
Das Auftreten ist sehr selten und wird auf eine Inzidenzrate von weniger als 1:1000 000 Personenjahren geschätzt. Allerdings variiert die Inzidenz deutlich und steigt hinsichtlich der Prävalenz um den Faktor 500 bei Mitarbeitern von Holz- und Leder-verarbeitenden Betrieben. Das Karzinom ist hierbei eine anerkannte Berufskrankheit (BK4203). Männer sind 3-4 mal häufiger als Frauen betroffen, was vermutlich auf die Beschäftigungsverhältnisse in den entsprechenden Berufen zurückzuführen ist. Das Alter betroffener Patienten liegt meist zwischen dem 6. und 7. Lebensjahrzehnt [106].

Manifestationen sind häufig nahe der lateralen Nasenwand und der mittleren Nasenmuschel zu finden. Schätzungen zufolge entwickeln sich $40 \%$ der Tumore im Sinus ethmoidalis, $28 \%$ in der $\mathrm{Na}$ senhaupthöhle und $23 \%$ im Sinus maxillaris [251, 252].

Symptome sind unilaterale Nasenatmungsbehinderung, Epistaxis und Rhinorrhoe. Seltener treten Schmerzen, Gesichtsschwellungen und Diplopie oder eine Protrusio bulbi auf. Eine Destruktion des umgebenden Knochens und das Einwachsen in benachbarte Regionen ist häufig [106, 252].

Makroskopisch zeigt sich eine polypoide, teilweise papillär und nodulär anmutende Raumforderung mit brüchiger Konsistenz und ulzerierenden, hämorrhagischen sowie seltener gelatineartigen oder mukösen Anteilen [106, 251, 252]. Mikroskopisch lässt sich exophytisches, papilläres und tubuläres oder muzinöses oder vorwiegend aus Siegelringzellen bestehendes Wachstum feststellen. Der Grad der Differenzierung ist stark variabel. In 6-10\% kann eine KRAS Mutation festgestellt werden. Eine BRAF-Mutation ist mit $<10 \%$ deutlich seltener [253-256].

Die radikale Tumorresektion mit freien Resektionsrändern ist aufgrund der eher schlechten Strahlensensibilität der Tumore Therapie der Wahl. Durch die Weiterentwicklung der endoskopischen Technik ist die transnasale Resektion in einigen Fällen auch bei orbitaler und intrakranieller Infiltration möglich [257], mitunter unter Berücksichtigung komplexer rekonstruktiver Verfahren [258]. Low-grade Adenokarzinome vom intestinalen Typ mit niedrigem Tumorstadium können durch eine radikale Tumorresektion alleine therapiert werden. Bei allen anderen Stadien und Entitäten sollten eine adjuvante Radiotherapie erfolgen [259]. Die intensitätsmodulierte Photonenbestrahlung kann als Teil des Therapieregimes diskutiert werden [260]. Bislang existieren keine Phase III Studien hinsichtlich einer Chemotherapie, weshalb die aktuellen Ergebnisberichte hauptsächlich auf Fallberichten und kleinen retrospektiven Fallserien basieren. Im Rahmen einer prospektiven Phase II Studie konnte bei neoadjuvanter Chemotherapie mit PFL (Cisplatin, 5-Fluoruracil und Leucovorin) bei 16\% der behandelten Patienten eine primäre Komplettremission gezeigt werden [261]. In diesen Fällen lag das 3-Jahres Gesamtüberleben bei $100 \%$ gegenüber $43 \%$ bei den restlichen Patienten.

Low-grade papilläre Adenokarzinome haben die besten 3-jahres Überlebensraten mit $<80$ und $<60 \%$ nach 5 Jahren. Tumore der Grade 2 und 3 weisen 3-Jahres Überlebensraten von 54 bzw. 35\% auf. Muzinöse Tumore mit alveolärem Wachstum haben ähnliche Überlebensraten wie papilläre Tumore des Grades 2. Das aggressivste Wachstum weisen Siegelring-Adenokarzinome auf. Bei Infiltration der Orbita, der Haut, des Sinus ethmoidalis oder sphenoidalis sowie der Schädelbasis ist die Prognose deutlich schlechter. Lymphknotenmetastasen können bei Diagnosestellung in $8 \%$ und Fernmetastasen in 13 \% der Fälle diagnostiziert werden [106, 252]. 


\subsection{Adenokarzinom vom nicht intestinalen Typ}

Das sinunasale Adenokarzinom vom nicht intestinalen Typ zeigt keine Eigenschaften von Speicheldrüsenkarzinomen und besitzt keinen intestinalen Phänotyp. Die genannte Tumorkategorie ist heterogen. Trotzdem weist sie spezifische Entitäten auf, die einzigartig sind (z. B. das Nierenzell-ähnliche Karzinom) [106].

Sinunasale low-grade nicht intestinale Adenokarzinome kommen sehr selten vor, weisen keine Prädilektion eines spezifischen Geschlechts auf und können innerhalb einer Altersspanne von 9-89 Jahren diagnostiziert werden. Das mittlere Alter bei Diagnosestellung liegt innerhalb des 6 . Lebensjahrzehnts. High-grade nicht intestinale Adenokarzinome sind selten, betreffen häufiger männliche Patienten, weisen ebenfalls eine breite Altersspanne mit einem Altersgipfel innerhalb des 6. Lebensjahrzehnts auf. Weder für lowgrade noch für high-grade nicht intestinale Adenokarzinome des Sinunasaltrakts ist die Ätiologie bekannt.

Am häufigsten manifestieren sich die Tumore in der Nasenhaupthöhle (64\%), gefolgt vom Sinus ethmoidalis (20\%). Ca. die Hälfte aller high-grade nicht intestinale Adenokarzinome weisen bei Diagnosestellung bereits ein fortgeschrittenes Tumorstadium mit Infiltration der Nasenhaupthöhle und Nasennebenhöhlen auf [262-265].

Symptome der low-grade Variante sind häufig unspezifisch und beinhalten Nasenatmungsbehinderung, Epistaxis und Schmerzempfindungen. High-grade Tumore verursachen häufiger Deformitäten der Gesichtshaut und Protrusio bulbi bei orbitaler Infiltration. Bildmorphologisch präsentieren sich low-grade nicht intestinale Adenokarzinome als solide, die Nasenhaupthöhle oder Nebenhöhlen ausfüllende Masse, wohingegen high-grade nicht intestinale Adenokarzinome deutlich destruktiveres Wachstum mit ossärer Infiltration und Invasion der umgebenden anatomischen Areale zeigen [106].

Makroskopisch imponieren die low-grade Tumore als rote, polypoide oder himbeerartig konfigurierte, feste Struktur. Histologisch zeigen sich papilläre und/oder tubuläre Eigenschaften mit komplexem Wachstumsmuster. Eine einzelne Schicht uniformer muzinöser, kuboider bis säulenförmiger Epithel-Zellen umgibt die Tumore. High-grade Tumore zeigen deutlich mehr histologische Diversität. Solides Wachstum mit gelegentlich eingestreuten glandulären Strukturen sowie vereinzelten Mukozyten sind typisch. Einige Varianten zeigen nestartige Verteilungsmuster mit infiltrativem Verhalten. Zahlreiche Mitoseformen und Nekroseareale sind vorhanden [106].

Therapie der Wahl ist die radikale Tumorresektion. Trotz der spärlichen Datenlage aufgrund der wenigen beschriebenen Fälle erscheint die alleinige chirurgische Therapie - tumorfreie Resektionsränder vorausgesetzt - prognosebestimmend zu sein [266]. Eine kürzlich durchgeführte National Cancer Database Analyse zeigte keinen Einfluss einer Radiotherapie auf das Überleben von Patienten mit low-grade Adenokarzinomen [267]. Patienten mit highgrade Adenokarzinomen zeigen eine deutlich bessere Überlebensrate bei multimodaler Therapie inklusive radikaler Tumorresektion und adjuvanter Radiotherapie. Die Rolle einer systemischen Therapie konnte aufgrund der geringen Fallzahlen bislang nicht abschließend geklärt werden [257].

Rezidive sind bei $25 \%$ der low-grade Variante zu finden und nur etwa $6 \%$ der betroffenen Patienten sterben an der Erkrankung. Die
Prognose für Patienten mit high-grade nicht intestinalem Adenokarzinom ist deutlich schlechter. Die meisten Patienten versterben innerhalb von 5 Jahren nach Diagnosestellung an der Erkrankung. Lokale und Fernmetastasierung tritt gelegentlich auf [262-264].

Bei den wenigen berichteten Fällen eines Nierenzell-ähnlichen Karzinoms gab es weder Rezidive noch Metastasierungen [268].

\subsection{Speicheldrüsenartige Karzinome}

Speicheldrüsen-Neoplasien in der Nase oder den Nasennebenhöhlen sind extrem selten. Die überwiegende Mehrzahl der Fälle besteht aus malignen Entitäten. In einer Analyse von Daniel K. Heffner zeigte sich bei insgesamt 311 Patienten mit sinunasalen speicheldrüsenartigen Tumoren folgende Verteilung der Entitäten [269]:

In der folgenden Darstellung werden die malignen sinunasalen Entitäten dargestellt:

- Adenoidzystisches Karzinom

- Azinuszellkarzinom

- Mukoepidermoidkarzinom

- Epithelial-myoepitheliales Karzinom

\subsection{Adenoidzystisches Karzinom (ACC)}

Das adenoidzystische Karzinom tritt v. a. in den großen und kleinen Speicheldrüsen auf. Eine Manifestation ist aber in allen Bereichen auftreten, in denen sekretorische Drüsen lokalisiert sind (Mamma, Cervix, Colon, Prostata, Nasenhaupthöhle und Nasennebenhöhlen). Es ist das häufigste speicheldrüsenartige Malignom des Sinunasal-Trakts mit einer Altersspanne von 11-92 Jahren. Sinunasale Manifestationen finden sich im Sinus maxillaris (60\%) und in der Nasenhaupthöhle (25\%). Adenoidzystische Karzinome repräsentieren $5 \%$ aller sinunasalen malignen Neoplasien mit einer Inzidenz von $25 \%$ bezogen auf alle Speicheldrüsenkarzinome [270274]. Es wächst langsam, aber infiltrativ entlang beteiligter Hirnnerven in umgebende Strukturen ein. Hämatogene Metastasierung ist häufig und kann selbst Jahre nach der Erstdiagnose auftreten. Aufgrund des späten Auftretens von Symptomen weisen die betroffenen Patienten häufig hohe Tumorstadien auf, was zu entsprechender Morbidität bei Tumorresektionen oder primärer Radiotherapie führt. Aufgrund der geringen Strahlensensitivität sind Dosen $>80$ Gy erforderlich, was zu Kollateralschäden benachbarter Strukturen (Orbita, Nervus opticus, Cerebrum) führt [275-277].

Therapie der Wahl ist die radikale Tumorresektion und postoperative Radiotherapie für R1/R2 Resektionen, bei perinodaler Infiltration und in fortgeschrittenen Tumorstadien (T3/T4), obwohl einige Studien für alle Tumorstadien (T1-4) ein besseres Outcome nachweisen konnten [275, 278-281].

Aufgrund der hohen Tumorstadien bei Erstdiagnose und der häufigen Spätrezidive ist die Prognose des adenoidzystischen Karzinoms schlecht. Die 5-Jahres Überlebensrate wird mit 38-64\% bei konventioneller Bestrahlung angegeben. Die lokale Tumorkontrolle erreichte bei Anwendung von Protonenbestrahlung $50-70 \%$ und sogar bis zu $93 \%$ bei Neutronenbestrahlung [272, 275, 276, 282286].

\subsection{Azinuszellkarzinom}

Das Azinuszellkarzinom ist ein seltenes Malignom der Speicheldrüsen, welches vorwiegend in der Glandula parotis anzutreffen ist. 
Nach Tumorresektion mit oder ohne postoperativer Radiotherapie werden 20-Jahres Überlebensraten nahe $90 \%$ erreicht [287]. Eine Manifestation im Sinus maxillaris oder ethmoidalis, an den Nasenmuscheln oder dem Nasenseptum ist außerordentlich seltenen. Die derzeitige englischsprachige Literatur beschreibt 19 Fälle, deren Follow Up von 1 bis 22 Jahren reicht. 5-Jahres und 10-Jahres Überlebensraten lieben über $90 \%$ [288-291].

\subsection{Mucoepidermoidkarzinom}

Sinunasale Mucoepidermoidkarzinome sind Malignome der kleinen Speicheldrüsen, die sich in der Mundhöhle und dem Oropharynx manifestieren und an diesen Manifestationsorten eine 5-Jahres Überlebensrage von $87 \%$ aufweisen [292]. Lymphknotenmetastasten treten in bis zu 15\% der Fälle auf.

Sinunasale Mucoepidermoidkarzinome repräsentieren ca. 1,5\% aller sinunasalen Malignome und sind damit sehr selten. Häufigste Manifestationsorte sind Sinus maxillaris und die Nasenhaupthöhle [293], in denen sich in $46 \%$ high grade Mucoepidermoidkarzinome diagnostizieren lassen. Symptome befallener Patienten sind Nasenatmungsbehinderung, chronisch sinunasale Beschwerden, Gesichtsschmerzen, Epistaxis und Cephalgien. Kleine monozentrische Studien zeigten 5-Jahres Überlebensraten von 35,9\% bis $44,1 \%$ bei sinunasaler Manifestation [294, 295]. Die Tumorresektion mit adjuvanter Radiatio ist Therapie der Wahl, allerdings fehlen aufgrund der geringen Fallzahlen Daten hinsichtlich der Effektivität [293].

\subsection{Epithelial-myoepitheliales Karzinom}

Das epithelial-myoepitheliale Karzinom repräsentiert eine außerordentlich seltene maligne Entität, welche sich vorwiegend in den großen Speicheldrüsen manifestiert und ca. 1 \% aller Speicheldrüsenmalignome ausmacht. Noch seltener ist die Manifestation in der Nasenhaupthöhle oder den Nasennebenhöhlen, von der nur wenige Fallberichte existieren [296]. Die größte Kohortenstudie umfasst 468 Patienten mit epithelial-myoepithelialem Karzinom. 18 dieser Patienten zeigten eine Manifestation im sinunasalen Bereich [297]. $80 \%$ der Patienten waren älter als 50 Jahre alt. Weibliche Patienten waren häufiger betroffen (W:M 1,5-6:1) [297]. Aufgrund der niedrigen Fallzahlen ist die Beschreibung der Pathophysiologie und der Therapiestrategien nicht systematisiert, da ein großer Teil der relevanten Literatur aus Fallberichten besteht.

Der Begriff epithelial-myoepitheliales Karzinom ist ein histopathologischer Terminus, der die Proliferation tubulärer Strukturen mit einer zweischichtigen Zellauskleidung beschreibt. Die innere Schicht besteht aus kubischen oder niedrig zylindrischen Duktalzellen, die äußere Schicht aus hellen epitheloiden Zellen. Das Tumorstruma kann hyalinisiert sein [298].

Je nach Lokalisation präsentieren die Patienten Symptome wie Epistaxis, Druckgefühl und Schmerzen, Schwellungen und Rhinorrhoe. Häufig zeigt sich bei der Endoskopie eine hämorrhagisch anmutende Raumforderung. Computertomografisch ist eine heterogen Kontrastmittel-aufnehmende Weichteil-Struktur in den beteiligten Nasennebenhöhlen darstellbar. Ossäre Destruktionen benachbarter Strukturen sind nicht typisch, können aber auftreten [296].

Aktuelle Berichte zeigten einen nur geringen Glukose-Uptake in der PET-CT, was dem low-grade Potenzial der Malignität zuzu- ordnen ist und eine präoperative, bildgebende Hilfestellung hinsichtlich der Diagnose erschwert [299, 300].

Therapie der Wahl ist die großzügige chirurgische Exzision. Die Effektivität einer adjuvanten Radiotherapie ist aufgrund des inhomogenen biologischen Verhaltens und Ansprechens unklar [301].

Lymphknotenmetastasen sind selten und treten in weniger als $5 \%$ der Fälle auf. Die 5- und 10-Jahres Überlebensrate liegt bei 72,7 und 59,5\% [297].

\subsubsection{Neuroendokrine Neoplasien}

Der Begriff Neuroendokrine Neoplasien umfasst mehrere Entitäten. Neben dem neuroendokrinen Karzinoid und dem klassischen neuroendokrinen Karzinom zählen auch Aesthesioneuroblastome (siehe 2.4.2.6.2) sowie sinunasale undifferenzierte Karzinome (SNUC, siehe 2.4.2.1.3) zu den Neoplasien mit neuroendokriner Differenzierung [302].

Neuroendokrine Neoplasien exprimieren neuroendokrine Marker wie Synaptophysin und Chromogranin A. Große membrangebundene (hormonenthaltende) Vesikel sind charakteristische Merkmale. Epitheliale neuroendokrine Karzinome (gut, mittelgradig oder schlecht differenziertes Karzinoid) bilden sich aus Zellen des diffusen neuroendokrinen Zellsystems, die Zytokeratine exprimieren und in der Schleimhaut lokalisiert sind. Olfaktoriusneuroblastome und Paragangliome hingegen sind neuroektodermaler Herkunft und bilden sich aus der Olfaktoriusmembran bzw. den Kopf- Hals-Paraganglien [303]. Entsprechend der WHO Klassifikation werden neuroendokrine Tumore als Neoplasie Grad I (früher low-grade neuroendokriner Tumor oder typisches Karzinoid), Neoplasie Grad II (früher intermediärer neuroendokriner Tumor oder atypisches Karzinoid) und Neoplasie Grad III, kleinzelliges Karzinom (früher high-grade Neuroendokriner Tumor oder kleinzelliges Karzinom) sowie Neoplasie Grad III, großzelliges Karzinom (früher high-grade neuroendokriner Tumor oder großzelliges neuroendokrines Karzinom) eingeteilt [304].

\section{Neuroendokrine Karzinoide (typisches Karzinoid, Neoplasie Grad I)}

Über $90 \%$ der neuroendokrinen Karzinoide manifestieren sich am Larynx (supraglottisch). Sinunasale Manifestationen sind wesentlich seltener und führen zu gut abgrenzbaren, submukösen und häufig polypoiden Tumoren [305]. Vor allem schlecht differenzierte neuroendokrine Karzinome finden sich in der Nasenhaupthöhle, den Nasennebenhöhlen oder an der Schädelbasis. Die 5-Jahres Überlebensrate liegt bei 5-20\% [106].

Die Symptome hängen vom Manifestationsort ab. Ein Karzinoid-Syndrom ist bei übermäßiger Hormonproduktion möglich, vor allem bei hepatischer Metastasierung und tritt in etwa $10 \%$ aller Patienten mit Karzinoiden auf. Die typische Trias beinhaltet anfallsartige Rötung von Gesicht und Oberkörper, Diarrhoe und kardiale Beteiligung [306].

\section{Neuroendokrine Karzinome}

Das sinunasale neuroendokrine Karzinom ist ein high-grade Karzinom mit morphologischen und immunhistochemischen Merkmalen einer neuroendokrinen Differenzierung [106]. Es wird unterteilt in kleinzellige neuroendokrine Karzinome und großzellige neuroendokrine Karzinome und stellt ca. 3 \% aller sinunasalen Tumore 
und tritt häufiger bei Männern mittleren bis höheren Alters (mittleres Alter 49-65 Jahre) auf. In seltenen Fällen wird über eine Assoziation mit High-Risk humanen Papilloma-Viren berichtet.

Primärer sinunasaler Manifestationsort ist der Sinus ethmoidalis, die Nasenhaupthöhle, gefolgt von den Sinus maxillaris und sphenoidalis.

Symptome einer Manifestation sind weitestgehend unspezifisch (Nasenatmungsbehinderung, Rhinorrhoe und chronische sinunasale Beschwerden). Viele Patienten werden erst in höheren Tumorstadien bei ihrem behandelnden Arzt vorstellig.

Endoskopisch zeigt sich eine meist große, hämorrhagische Tumormasse mit nekrotischen Anteilen. Bildmorphologisch zeigen sich ossäre Destruktionen und Infiltrationen benachbarter anatomischer Regionen.

Histopathologisch ist das sinunasale neuroendokrine Karzinom identisch zu den in Lunge und anderen Kopf-Hals-Lokalisationen vorkommenden neuroendokrinen Karzinomen. Es zeigt sich ein hochgradig infiltratives Wachstum mit häufiger perineuraler und lymphovaskulärer Infiltration. Sinunasale neurendokrine kleinzellige und großzellige Karzinome weisen eine Zytokeratin-Expression auf, was eine Differenzierung z. B. gegenüber dem Olfaktoriusneuroblastom ermöglicht [304].

Therapeutisch wird - sofern möglich - eine Tumorresektion gefolgt von adjuvanter Radiochemotherapie angestrebt. Vor allem für das großzellige neuroendokrine Karzinom scheint eine neoadjuvante Radiochemotherapie gefolgt von einer Tumorresektion bessere Ergebnisse zu erzielen [302].

Die 5-Jahres Überlebensrate beträgt 50-65\%. Eine Lokalisation im Sinus sphenoidalis ist prognostisch günstiger ( $~ 80 \%)$ als eine maxilläre oder ethmoidale Manifestation ( 33\%). Trotz eingeschränkter Datenlage aufgrund der geringen Fallzahlen scheint die Prognose für großzellige neuroendokrine Karzinome günstiger zu sein als für die kleinzellige Variante [106].

\subsubsection{Maligne Weichteiltumore (Sarkome) \\ 2.4.2.3.1 Fibrosarkom}

Das Firbosarkom ist ein maligner spindelzelliger Tumor mit faszikulärer Architektur und variabel ausgeprägter Collagenmatrix-Produktion, welche fibroblastäre/myofibroblastäre Differenzierung aufweist. Weiter zeigt das Fibrosarkom eine niedrige Mitoseraten und seltene nukleäre Pleomorphismen oder anaplastische Eigenschaften.

Manifestationsorte sind meist in den Extremitäten lokalisiert, lediglich $1 \%$ der Fibrosarkome ist im Kopf-Hals-Bereich zu finden. Es ist für weniger als 3 \% aller nichtepithelialen Malignome des KopfHals-Bereichs verantwortlich, stellt allerdings die zweithäufigste Entität von Kopf- Hals-Sarkomen dar [106, 307].

Symptome ähneln denen anderer Neoplasien der Nasenhaupthöhle und Nasennebenhöhlen. Unspezifische Beschwerden wie Nasenatmungsbehinderung und Epistaxis, Druckgefühl, Schmerzen und Schwellungen können auftreten.

Das Fibrosarkom hat ein hohes Lokalrezidiv-Risiko, allerdings ein geringes Risiko für Fernmetastasierung [140, 308]. Trotz der sehr geringen Fallzahlen wird eine großzügige Tumorresektion empfohlen, da ein geringer Sicherheitsabstand das Risiko des Lokalrezidivs unverhältnismäßig erhöht [140]. Eine U.S. National Cancer Institute's Surveillance, Epidemiology, and End Results (SEER) Datenbankanalyse untersuchte den Verlauf von 51 Patienten mit sinunasalen Fibrosarkomen über einen Zeitraum von 1973 bis 2012 [307]. Das mittlere Alter lag bei 54.5 Jahren ohne Überwiegen eines Geschlechts. Interessanterweise waren 83,7\% der Patienten hellhäutig und nur 8,2\% dunkelhäutig. Die häufigste Lokalisation war mit 54,9\% der Sinus maxillaris gefolgt von der Nasenhaupthöhle (23,5\%). Der häufigste histologische Typ war das mittelgradig differenzierte $(59,5 \%)$, gefolgt vom gut differenzierten Fibrosarkom (16,2\%). Im Follow up zeigte sich bei $28,2 \%$ der Patienten ein Lokalrezidiv, in 64,1\% kam es zu einer regionalen Metastasierung und 7,7\% wiesen Fernmetastasen auf.

Häufigste Therapiemodalität war die alleinige Tumorresektion (61,2\%), gefolgt von Tumorresektion mit adjuvanter Radiotherapie (32,7\%). Auch Lokalrezidive wurden primär durch erneute Tumorresektion therapiert $(71,4 \%)$ gefolgt von Tumorresektion mit adjuvanter Radiotherapie (7,1\%). Die 5-Jahres Überlebensrate lag für alle nachverfolgbaren Fälle bei 71,7\%. Aktuelle Studien zeigen deutliche Vorteile bei Patienten, die eine adjuvante Radiotherapie erhalten [308, 309].

\subsection{Undifferenziertes pleomorphes Sarkom/Malignes fibröses Histiozytom}

Das undifferenzierte pleomorphe Sarkom (Synonym: malignes fibröses Histiozytom) ist ein high-Grade Weichteilsarkom ohne Differenzierungslinie. Es tritt bei Erwachsenen auf, eine sinunasale oder Schädelbasis-Manifestation ist sehr selten, obwohl es nach dem Rhabdomyosarkom und dem Fibromyosarkom das dritthäufigste Sarkom in diese Lokalisationen darstellt [106].

Vorangegangene Radiotherapien werden für das Entstehen des undifferenzierten pleomorphen Sarkoms verantwortlich gemacht [310, 311].

Vor allem unspezifische Symptome wie schmerzlose Schwellungen, Nasenatmungsbehinderung, Protrusio bulbi und Diplopie sowie Epistaxis können auftreten. Eher selten kommt es zu regionaler oder Fernmetastasierung [106].

Endoskopische zeigt sich eine lobulierte, gräulich-weißliche, teils fleischige Masse mit hämorrhagischen Anteilen. Die meisten Befunde erscheinen umschrieben. Mikroskopisch präsentiert das Malignom Spindel- und pleomorphe Zellen in einer variabel kollagenisierten, extrazellulären Matrix. Pleomorphismen, atypische Mitosen, Tumornekroseareale, Histozytenartige und Schaumzellen zeigen sich häufig. Viele Tumorzellen weisen Eigenschaften von Fibroblasten, Myofibroblasten oder Histiozyten auf.

Das undifferenzierte pleomorphe Sarkom ist eine Ausschlussdiagnose, welche nach Ausschluss von Schleimhautmelanomen, Karzinomen, Lymphomen und anderen Sarkomen gestellt werden kann.

Die Tumorresektion scheint trotz der geringen Datenlage und unabhängig von der Randsituation essentiell zu sein. Eine Radiotherapie erhöht die Chance auf lokale Tumorkontrolle [106, 311]. Die 5-Jahres Überlebensrate liegt zwischen 60 und $70 \%$.

Gerrand et al. zeigten für Sarkome der Extremitäten in einer Studie ein unterschiedliches Outcome für Patienten abhängig von histologischem Subtyp, der Anwendung einer Radiotherapie, der lokalen Anatomie und ungeplanter Exzision vor Überweisung in ein Zentrum [312] und postulierten, Patienten bei dem Verdacht auf ein Weichteilsarkom in ein spezialisiertes Diagnostik- und Thera- 
pie-Zentrum mit multidisziplinären Sarkom-Spezialisten zu überweisen [311].

\subsection{Leiomyosarkom}

Das Leiomyosarkom ist ein maligner Tumor, der von der glatten Muskulatur ausgeht. Typische Manifestationsorte sind Uterus oder Intestinaltrakt. Die sinunasale Manifestation oder Lokalisation an der Schädelbasis sind extrem selten. Betroffen sind vorwiegend Erwachsene, nur in Ausnahmefällen Kinder. Auch für das Leiomyosarkom spielt eine vorangegangene Radiotherapie eine große Rolle für die Genese [106].

Aufgrund nur unspezifischer Symptome werden die Patienten meist erst in späten Tumorstadien bei ihrem behandelnden Arzt vorstellig, was zu schlechteren Prognosen bei sinunasalen Manifestation im Vergleich zu anderen Lokalisationen führt [313]. Klinisch zeigt sich eine weiche, vorwiegend polypöse Tumormasse, die Schmerzen, Nasenatmungsbehinderung und Epistaxis verursachen kann. Die Läsionen können auch den kraniofazialen Knochen betreffen und je nach Infiltration weiterführende Beschwerden wie Diplopie, Protrusio bulbi, usw. verursachen.

Eine hämatogene Metastasierung in Lunge, Leber, andere Weichteilareale, Knochen oder zerebrale Strukturen sind möglich. Metastasen anderer Regionen sollten vor der definitiven Tumortherapie ausgeschlossen werden.

Makroskopisch ist die Tumormasse polypoid. Sowohl klare Abgrenzungen zum umgebenden Gewebe als auch schwer abgrenzbare Befunde sind möglich. Mikroskopisch zeigt sich infiltratives Wachstum oder scharf demarkierte Grenzen. Spindelzellen, die in vernetzten Faszikeln angeordnet sind, prägen das Erscheinungsbild. Das eosinophile Zytoplasma zeigt oft kleine perinukleäre Vakuolen [106].

Computertomografische Darstellungen sind häufig unspezifisch und zeigen expansive zystische oder nekrotische, heterogene Läsionen innerhalb des Weichgewebes. Im MRT zeigt sich in der T1und T2-Wichtung nur moderate Hyperintensität, was die Diagnosefindung erschwert [314].

Die Tumorresektion ist Methode der Wahl, allerdings ist aufgrund der Lokalisation und vitaler benachbarter Strukturen eine Resektion mit großem Sicherheitsabstand nur eingeschränkt möglich. Adjuvante Chemotherapie und/oder Radiotherapie kommen bei Patienten mit lokal fortgeschrittenem Wachstum, Rezidiven oder Metastasierungen zum Einsatz [313, 315]. Circa ein Drittel der Patienten mit sinunasaler Manifestation stirbt entweder an Fernmetastasierung oder Lokalrezidiven, die in vitale benachbarte Strukturen einwachsen [106].

\subsection{Rhabdomyosarkom}

Rhabdomyosarkome sind maligne mesenchymale Tumore mit Skelettmuskeldifferenzierung.

Unterschieden werden

- embryonale Rhabdomyosarkome

- alveoläre Rhabdomyosarkome

- pleomorphe Rhabdomyosarkome

- spindelzellige Rhabdomyosarkome

Die Begriffe Myosarkom und malignes Rhabdomyom werden synonym mit Rhabdomyosarkom verwendet.
Die Inzidenz von sinunasalen Rhabdomyosarkomen beträgt 0,034:100 000 mit primärer Manifestation in den Nasennebenhöhlen gefolgt von der Nasenhaupthöhle. Es ist das häufigste sinunasale Sarkom sowohl bei Kindern als auch bei Erwachsenen. Der Altersgipfel liegt innerhalb des ersten Lebensjahrzehnts [106, 311,316]. Eine strahleninduzierte Genese wird diskutiert.

Makroskopisch zeigt sich eine polypoide, schlecht abgrenzbare Tumorformation mit Ausdehnung in benachbarte Strukturen und fleischiger, gelatineartiger, bräunlich bis grauer Oberfläche.

Das embryonale Rhabdomyosarkom ist die am häufigsten im Sinunasaltrakt vorkommende Entität. Sie weist primitive bis spindelförmige Zellen mit spärlichem Zytoplasma und hyperchomatischen Nuklei sowie verstreute Rhabdomyoblasten mit deutlich eosinophilem Zytoplasma auf. Die Anzahl der Rhabdomyoblasten steigt typischerweise nach Radiotherapie deutlich an.

Bei Erwachsenen findet sich häufiger das sinunasale alveoläre Rhabdomyosarkom [311], welches fibrovaskuläre Septen aufweist, die Herde von runden, neoplastischen Zellansammlungen voneinander trennen. Riesenzellen mit mehreren, peripher lokalisierten Zellkernen können präsent sein [106].

Das Outcome der Patienten scheint für Patienten, bei denen eine Vorabexzision oder Probeexzision zur Histologie-Sicherung durchgeführt wurde, schlechter zu sein als für Patienten, bei denen unmittelbar eine vollständige Tumorresektion durchgeführt wurde [311, 312]. Die Überweisung bei Verdacht auf ein Sarkom in ein auf Sarkome spezialisiertes Zentrum mit interdisziplinärer Zusammenarbeit erscheint deshalb besonders wichtig.

Therapeutisch ist die Tumorresektion mit weitem Sicherheitsabstand anzustreben. Auch für die unvollständige Tumorresektion scheint die chirurgische Resektion ein prädiktiver Faktor zu sein [311]. Die Kombination von Operation, Chemotherapie und Bestrahlung werden 5-Jahres Überlebensraten von 40-45\% berichtet, die für Patienten unter 18 Jahren und bei weiblichem Geschlecht etwas höher liegen. Bei Infiltration der Schädelbasis ist die Prognose deutlich schlechter [106, 311, 317].

\subsection{Angiosarkom}

Das Angiosarkom ist eine vaskuläre, maligne Neoplasie. Synonyme Begriffe sind epitheloides Hämangioendoetheliom, malignes Hämangioendotheliom, malignes Angioendotheliom oder Hämangiosarkom.

Der Tumor entwickelt sich in über der Hälfte der Fälle innerhalb der Haut und oberflächlichen Gewebsschichten des Kopf-Hals-Bereichs. Epidemiologisch ist das sinunasale Angiosarkom für weniger als $0,1 \%$ aller Kopf-Hals-Malignome und weniger als $1 \%$ aller sinunasalen Malignome verantwortlich [106].

Als mögliche, allerdings selten berichtete Risikofaktoren für die Entstehung werden Strahlenexposition, Vinylchlorid- und Kohlestaubexposition diskutiert [318-320].

Das Angiosarkom ist eher in der Nasenhaupthöhle und dem Sinus maxillaris lokalisiert. Dort führt es zu initial unspezifischen Beschwerden, allen voran Epistaxis und Nasenatmungsbehinderung. Einige Patienten berichten zudem über sinunasale Beschwerden, Epiphora, Schmerzen und Druckgefühl.

Häufig ist bei Angiosarkomen eine Knocheninfiltration zu beobachten, die sich in der Computertomografie darstellen lässt. In der MRT-Darstellung ist in der T2-Wichtung eine kräftige Signalinten- 
sität darstellbar. Die präoperative Angiografie kann hilfreich sein, um zuführende Gefäße darzustellen und eine präoperativ Embolisation zu ermöglichen [106, 321]. Lymphknoten- und Fernmetastasierung sind bei Erstmanifestation ungewöhnlich.

Makroskopisch präsentiert sich das Angiosarkom mit einer nodulär bis polypoiden, weichen und lividen bis rötlichen Oberfläche mit Ulzerationen, die zu Blutungen neigen. Mikroskopisch entwickelt sich das Malignom unter einer intakten Epithelschicht mit neoplastischen Gefäßbildungen, die sich in das Weichgewebe und den angrenzenden Knochen erstrecken. Hämorrhagische und nekrotische Areale begleiten das Erscheinungsbild. Innerhalb der Neubildungen zeigen sich kapilläre, kavernöse und rudimentär angelegte Gefäße, die mit Erythrozyten angefüllt und mit vergrößerten, atypischen spindelförmigen oder epitheloiden Endothelzellen ausgekleidet sind. Ein Grading wird für das Angiosarkom nicht vorgenommen [106, 321].

Aufgrund der sehr niedrigen Inzidenz existiert keine Standardtherapie für das sinunasale Angiosarkom. In den meisten Fällen ist die Tumorresektion gefolgt von einer Radiotherapie beschrieben. Weitere Therapieansätze, die in einzelnen Fällen beschrieben wurden, sind Chemotherapie, Gamma-Knife-Therapie und die Anwendung von Interleukinen [321-324]. Rezidive sind mit ca. $40 \%$ häufig. Metastasierungen treten innerhalb der ersten 24 Monate auf [323] und finden sich in Lunge, Leber, Niere und Knochen [321]. Die Prognose ist insgesamt schlecht und zeigt eine Gesamtüberlebensrate von ca. $60 \%$ [106].

\subsection{Biphänotypisches Sinunasalsarkom (BSS)}

Das biphänotypische Sinunasalsarkom wurde in die WHO-Klassifikation der Tumore des Sinunasalsystems von 2017 als neue Entität aufgenommen. Begründet ist dies durch die definierende PAX3/ MAML3-Translokation, welche es zu einer eigenen Entität macht. Bisher wurde das Malignom als Leiomyosarkom „fehlklassifiziert“ [325]. Das BSS wurde bisher nur im Sinunasaltrakt beschrieben.

Das BSS ist ein low-grade Spindelzellsarkom. Es tritt bevorzugt bei Frauen auf ( $w: m=3: 1$ ) und erstreckt sich über eine Altersspanne von 24-85 Jahren mit einem Altersdurchschnitt von 52 Jahren [106].

Dominierende Manifestationsorte sind Siebbeinzellen (57\%) und Nasenhaupthöhle (54\%), häufig mit grenzüberschreitendem Wachstum [326] und auch Infiltration der Orbita oder Fossa olfactoria.

Die Symptome sind unspezifisch. Patienten berichten von Nasenatmungsbehinderung, Druckgefühl und Gesichtsschmerzen. Makroskopisch zeigt sich eine polypoide, teils festere, rötlich und graue Tumormasse. Mikroskopisch ist die Zellularität mittelgradig mit fokalen zelldichteren Abschnitten im Tumor mit oberflächlich hamartomartiger Proliferation eingeschlossener ortsständiger Schleimhautdrüsen. Fokal zeigen sich vermehrte ektatische Gefäße mit Einblutungen und hämangioperizytomartigem Aspekt [326].

Das Malignom ist aufgrund der erst 2012 beschriebenen [327] und 2017 in die WHO-Klassifikation aufgenommen eigenständigen Entität weitestgehend unbekannt, dürfte aber häufiger als bisher angenommen sein, da viele Fälle bislang malignen peripheren Nervenscheiden- oder muskulären Tumoren zugeordnet wurden.

Langsames Wachstum und lokale Infiltration benachbarter Strukturen sind Charakteristika des BSS. Circa 50\% der Patienten der ursprünglich beschriebenen Kohorte zeigten Lokalrezidive innerhalb eines Zeitraums von 9 Jahren. Von Fernmetastasierung wurde bisher nicht berichtet [327]. Auch existiert bislang nur ein dokumentierter Todesfall durch die Erkrankung [328].

Therapie der Wahl ist wie bei anderen Sarkomen die Tumorresektion mit ausreichendem Sicherheitsabstand. Adjuvante Radiound Chemotherapie ist in Fällen mit fortgeschrittenem Tumorstadium einsetzbar. Die Effizienz der adjuvanten Radio- und Chemotherapie ist aufgrund der sehr geringen Fallzahlen unbekannt $[329,330]$.

\subsection{Maligner peripherer Nervenscheidentumor/Neurofi- brosarkom}

Der maligne periphere Nervenscheidentumor (MPNST) entsteht an peripheren Nerven oder aus Transformationen gutartiger Tumore peripherer Nerven. In der Regel weist er eine Differenzierung zu einer der Komponenten der Nervenscheiden auf (z. B. SchwannZellen (malignes Schwannom), Fibroblasten oder perineurale Zellen).

Die Malignome treten vorwiegend bei erwachsenen Patienten mit einer großen Altersspanne und einem Altersgipfel innerhalb des 5. Lebensjahrzehnts auf. In ca. 20-25\% der Fälle ist der maligne periphere Nervenscheidentumor mit einer Neurofibromatose Typ I assoziiert. In diesen Fällen sind die Patienten häufig jünger (zwischen 3. Und 4. Lebensjahrzehnt) [106, 331]. Eine Assoziation mit vorangegangener Radiotherapie wird diskutiert [332].

Die Inzidenz beträgt bei Patienten mit einer Neurofibromatose Typ | 1:3 500. Auf die gesamte Bevölkerung berechnet ist die Inzidenz 1:100 000 [333, 334]. Circa $20 \%$ aller malignen peripheren Nervenscheidentumore sind im Kopf-Hals-Bereich lokalisiert. Eine sinunasale Manifestation ist wesentlich seltener.

Manifestationsorte sind entlang von Hirnnerven, vorwiegend dem N. vestibularis und N. vagus lokalisiert [106, 331].

Klinische Symptome betroffener Patienten sind rasch progrediente, schmerzhafte Schwellungen und neurologische Ausfälle betroffener Nerven.

Maligne periphere Nervenscheidentumore sind unbekapselt und weisen ein höchst infiltratives Wachstum auf. Unterschiedlichste Zellmorphologien sind vorhanden, darunter spindelförmige, epitheloide und pleomorphe Zellen). Histologisch wird zwischen spindelzelligen und glandulären malignen peripheren Nervenscheidentumoren differenziert, die sich in der faszikelartigen Anordnung oder dem Vorhandensein von Becherzellen unterscheiden [106]. Die Malignome werden in Low- oder High-grade Entitäten entsprechend der Mitoserate, dem Vorhandensein atypischer Mitosen, Pleomorphismen und Nekrosen eingeteilt [332].

In der Regel sind diese Tumoren sehr aggressiv und haben eine schlechte Prognose. Die Tumorexzision mit ausreichendem Sicherheitsabstand ist Therapie der Wahl. Die Mehrzahl der malignen peripheren Nervenscheidentumore sind High-grade Sarkome, die zu Lokalrezidiven und Fernmetastasen neigen. 40-65\% der betroffenen Patienten weisen Lokalrezidive auf, Fernmetastasierungen treten in 30-60\% der Fälle auf, v. a. in Lunge, Leber, Gehirn, Knochen und Nebennieren. Regionale Lymphknotenmetastasierung ist selten, weshalb eine Neck dissection nicht standardmäßig durchgeführt werden sollte [333]. Eine adjuvante Radiotherapie, ggf. in 
Kombination mit einer Chemotherapie wirkt sich positiv auf das 5-Jahres Gesamtüberleben aus (65 vs. 38\%) [335].

\subsection{Sinunasales Synovialsarkom}

Das Synovialsarkom ist ein mesenchymaler Tumor mit variabler epithelialer Differenzierung und enthaltenen Drüsenformationen. Typisch ist eine spezifische chromosomale Translokation ( $t(X ; 18)$ ( $p 11 ; q 11)$ ), die zu einer Bildung eines SS18-SSX Fusionsgens führt [106, 336].

Das Synovialsarkom ist das häufigste Nicht-RhabdomyosarkomWeichteilsarkom bei Kindern, Heranwachsenden und jungen Erwachsenen mit einer Altersspanne zwischen dem 3. und 4. Lebensjahrzehnt.

Die Ätiologie ist stark assoziiert mit vorangegangener Radiotherapie [337-339]. Eine Manifestation im Sinunasaltrakt oder der Schädelbasis tritt äußerst selten auf.

Klinisch präsentiert sich eine palpable, meist tiefergelegene Raumforderung mit oder ohne Druckdolenz. Makroskopisch ist der Tumor gelb bis grau oder weißlich gestaltet. Langsam wachsende Synovialsarkome sind in der Regel gut abgegrenzt. Mikroskopisch könne monophasische (spindelzellförmig, kalzifizierend/ossifizierend, myxoid und schlecht differenziert) sowie biphasische Subtypen mit glandulären oder soliden Epithelzellen unterschieden werden. Schlecht differenzierte Tumore können Areale mit häufigen Mitosen und Nekrosen enthalten [106].

Die Therapie hat sich innerhalb der letzten Jahrzehnte nur wenig verändert und beinhaltet die Tumorresektion für umschriebene Befunde, häufig kombiniert mit einer Radio- oder Chemotherapie. Kombinierte Therapien werden je nach Stadium der Erkrankung angewandt. In einer großen Studie einer großen Studie kam bei Stadium I und II die Tumorresektion mit postoperativer Radiotherapie, bei Stadium III die Tumorresektion in Kombination mit einer Radiochemotherapie zum Einsatz [340]. Eine neoadjuvante Chemotherapie kann bei Patienten mit lokal fortgeschrittenem Tumorwachstum zum Einsatz kommen, bei denen eine mutilierende Operation erforderlich wäre. Erste Ergebnisse der Immuntherapie, die eine Aktivität bei NY-ESO-1, Trabectedin und einer Vielzahl von Angiogenese-Inhibitoren zeigen, sind vielversprechend [341].

\subsubsection{Borderline- und niedrig maligne Entitäten des Weichgewebes}

\subsection{Aggressive Fibromatose vom Desmoid-Typ}

Die aggressive Fibromatose ist eine klonale, spindelzellige Neoplasie mit infiltrativem Wachstum. Fernmetastasen treten nicht auf. Die Begriffe Desmoid-Fibromatose und aggressive Fibromatose werden synonym mit der aggressiven Fibromatose vom DesmoidTyp verwendet.

Die Inzidenz wird auf 1:250 000 bis 1:500 000 geschätzt. Das Erkrankungsalter reicht von 15-60 Jahren, ca. 30\% der Fälle treten im Kindesalter auf. Die Manifestation im Kopf-Hals-Bereich betrifft ca. $15 \%$ aller aggressiven Fibromatosen. Die sinunasale Manifestation ist noch wesentlich seltener [106, 342, 343].

Die Ätiologie ist ungeklärt. Eine Assoziation mit dem GardnerSyndrom (siehe 2.4.1.2.1) und der familiären kolorektalen Polyposis besteht $[344,345]$.

Aggressive Fibromatosen vom Desmoidtyp zeigen schlecht abgrenzbare Läsionen mit fokal infiltrativem Wachstum, die sich ma- kroskopisch als feste, weißliche Läsionen mit trabekulärem Schnittmuster präsentieren. Immunhistochemisch zeigen Desmoide eine nukleäre Anfärbung mit $\beta$-Catenin und häufig zusätzlichem zytoplasmatischem Hintergrund [326]. Faszikuläres Wachstum mit spindelförmigen Zellen und milden Kernpleomorphismen können visualisiert werden. Atypische Mitosen und Nekrosen sind nicht vorhanden. Das Stroma kann variabel kollagenisiert und myxoid oder mukös anmutend konfiguriert sein.

Eine adäquate Schmerztherapie ist für Patienten mit aggressiver Fibromatose erforderlich. Emori et al. konnten in einer Sammlung von 16 Fällen zeigen, dass der Desmoid-Tumor-assoziierte Schmerz mit einer Überexpression an Cyclooxygenase 2 assoziiert ist [346].

Grundsätzlich ist die vollständige chirurgische Resektion Therapie der Wahl. Aufgrund der anatomischen Nähe zu kritischen Strukturen kann bei Lokalisation im Sinunasaltrakt eine systemische medikamentöse Therapie (Anti-Östrogen-Therapie, nichtsteroidale Antiphlogistika), Chemotherapie (Vinblastin/Vinorelbine, pegyliertes liposomales Doxorubicin), Tyrosin-Kinase.Inhibitoren (z. B. Imatinib, Sorafenib) oder eine Radiotherapie zurückgegriffen werden [326, 343, 347]. Innerhalb der letzten Jahre wurde allerdings zunehmend eine „wait and scan“ Strategie propagiert, da verfügbare Daten zeigten, dass nur ein geringer Anteil von aggressiven Fibromatosen eine Progression aufweist [348] und diese meist innerhalb der ersten 36 Monate nach Diagnosestellung [349].

Die Prognose ist gut bei R0-Resektionen. Bei R1-Resektionen kommt es in der Regel innerhalb von<2 Jahren zu einem Rezidiv [350].

\subsection{Sinunasales Glomangioperizytom}

Das Sinunasale Glomangioperizytom ist eine Spindelzellneoplasie, die in der WHO-Klassifikation der Kopf-Hals-Tumore als neue Entität aufgenommen wurde. Zuvor wurde die Entität als sinunasales Hämangioperizytom bezeichnet. Innerhalb der letzten 60 Jahre war der Begriff Hämangioperizytom gebräuchlich, um eine Vielzahl von Neoplasien zu beschreiben, die ähnliche morphologische Eigenschaften aufwiesen. Diese Eigenschaften betrafen ca. $15 \%$ aller Weichgewebs-Neoplasien [351], was zu Konfusion bei der Etablierung eines spezifischen Therapieregimes führte [352]. Heute bezeichnet der Terminus Hämangioperizytom keine eigene Neoplasie sondern eher ein Wachstumsmuster, das von mehreren Neoplasien geteilt wird, die allerdings sehr unterschiedlich sind [353].

Glomangioperizytome repräsentieren ca. 0,5\% aller sinunasalen Neoplasien. Bisher sind etwas mehr als 100 Fälle beschrieben [352]. Der Altersgipfel liegt im 7. Lebensjahrzehnt mit einer leichten Prädilektion bei weiblichen Patienten [106].

Häufigster Manifestationsort ist die Nasenhaupthöhle mit Ausdehnung in die angrenzenden Nasennebenhöhlen. Isolierte Fälle in den Nasennebenhöhlen sind selten. Das Glomangioperizytom tritt meist unilateral auf.

Betroffen Patienten berichten von Nasenatmungsbehinderung mit Druckgefühl und Epistaxis. Die Beschwerdedauer bis zur Diagnose beträgt häufig mehr als ein Jahr [354].

Makroskopisch zeigt der Tumor ein polypoides, kräftig rotes bis pinkes Bild. Die Oberfläche ist weich und fleischig. Durchschnittlich beträgt die Tumorgröße bei Diagnosestellung $3 \mathrm{~cm}$. Mikroskopisch zeigt sich ein unbekapseltes Wachstum unter einer intakten Epithelschicht mit nur selten Erosionen v. a. bei größeren Tumoren. 
Charakteristisch ist ein musterloser, diffuser Aufbau mit partiell faszikulärer Zellanordnung, getrennt von Gefäßplexus aus Kapillaren bis hin zu großen Kavernen und eine prominente, azelluläre Hyalinisierung [106]. Zellatypien fehlen. B-Catenin ist im Gegensatz zu den Desmoiden (siehe 2.4.2.4.1) in fast allen Tumorzellen kräftig nachweisbar [326].

Glomangioperizytome wachsen langsam und weisen eine sehr gute Überlebensrate auf. Rezidive treten in bis zu 40 \% der Fälle auf und sind meist Folge einer unzureichenden Resektion. Invasives Wachstumsverhalten tritt in der Regel ab einer Tumorgröße über $5 \mathrm{~cm}$ auf [354, 355].

Die Tumorresektion gilt trotz der geringen Fallzahlen als Therapiestandard. Radio- und Chemotherapie kann bei unresektablen Tumoren oder Fernmetastasierung zum Einsatz kommen. Adjuvante Radiotherapie ist möglich, um die lokale Tumorkontrolle zu verbessern. Je nach Ausprägung der Vaskularisation ist eine präoperative Embolisation empfehlenswert, um den intraoperativen Blutverlust zu reduzieren [356-358].

\subsection{Sinunasaler solitärer fibröser Tumor}

Der solitäre fibröse Tumor basiert auf einer Fusion der Gene NAB2 und STAT6 und weist einen fibroblastischen Phänotyp mit sich stark verzweigenden Gefäßstrukturen auf.

Synonym wird der Begriff Hämangioperizytom oder RiesenzellAngiofibrom verwendet.

Der solitäre fibröse Tumor ist eine Rarität und ist für weniger als $0,1 \%$ aller sinunasalen Neoplasien verantwortlich. Vor allem Erwachsene sind betroffen ohne eindeutige Präferenz für ein Geschlecht [106].

Der Tumor tritt hauptsächlich in der Nasenhaupthöhle auf und führt bei betroffenen Patienten zu Nasenatmungsbehinderung und Epistaxis sowie unspezifischen Beschwerden wie Druckgefühl.

Makroskopisch zeigt sich ein polypoider, fest strukturierter, weißlicher Tumor, der aufgrund des vorgegebenen engen Raums im Sinunasaltrakt üblicherweise klein ist [359, 360]. Histologisch zeigen sich submukös liegende, pseudobekapselte Tumore mit variablen Zellformationen, darunter spindelförmige Zellformationen, die wahllos angeordnet erscheinen. Die Gefäße sind sternförmig bis hirschgeweihartig angeordnet [106, 325].

Therapie der Wahl ist die vollständige Tumorresektion, welche üblicherweise zu einer kurativen Situation führt. Patientenalter über 55 Jahre, Tumorgröße über $15 \mathrm{~cm}$, nekrotische Tumorareale und mehr als 4 Mitosen pro 10 hochauflösenden Gesichtsfeldern legen aggressiveres Wachstum nahe [361, 362]. Eine adjuvante Radiotherapie scheint in diesen Fällen v. a. bei unvollständiger Resektion und Lokalrezidiven als zusätzliche Behandlung möglich zu sein [363]. Die Effizienz dieser Therapie ist allerdings aufgrund der extrem niedrigen Fallzahlen nicht abschließend zu bewerten.

\subsection{Epitheloides Hämangioendotheliom}

Das epitheloide Hämangioendotheliom ist eine low- bis intermediate-grade Neoplasie aus Zellen, die einen endothelialen Phänotyp, epitheloide Morphologie und ein hyalinisiertes, chondroides oder basophiles Stroma aufweisen [106].

Betroffen sind v. a. Erwachsene. Aufgrund des extrem seltenen Auftretens und der schwierigen Differenzialdiagnostik ist eine Inzidenz-Abschätzung nur schwer möglich.
Das Vorkommen im Kopf-Hals-Bereich ist sehr selten. Der Entstehungsort liegt meist im Weichgewebe, der Haut oder dem Knochen. Extrem selten können Lymphknoten als primäre Manifestationsorte vorkommen [364-367].

Epitheloide Hämangioendotheliome wachsen sehr langsam, infiltrieren umgebende Strukturen und metastasieren selten [368]. Die Symptome sind meist unspezifisch. Epistaxis kann je nach Lokalisation auftreten.

Makroskopisch zeigt sich eine noduläre Tumormasse mit blasser, teils rötlicher und teils hämorrhagischer Schnittfläche. Histologisch zeigen sich endotheliale und histiozytäre Zellen, die in kurzen, fadenartigen Formationen in einem myxohyalinene Stroma angeordnet sind. Die mitotische Aktivität ist niedrig. Multizelluläre vaskuläre Kanäle können vorhanden sein. Endotheliale Marker sind nachweisbar (CD31, ERG, FLI1). In den meisten Fällen ist eine WWTR1-CAMTA1 Genfusion vorhanden [106].

Die meisten Fälle verlaufen indolent. Fallberichte mit tumorbedingter Mortalität existieren [369-371].

Die Therapie der Wahl ist die radikale Tumorresektion [372], die in bis zu 85 \% zu Rezidivfreiheit führt [373]. Eine medikamentöse Therapie kann kurativ oder adjuvant durchgeführt werden. Sie beinhaltet eine Kombination aus Corticosteroiden, zytotoxische Wirkstoffe, Thrombozytenaggregationshemmer und Antifibrinolytika und Interferon-alpha. Für Fälle, in denen eine R0-Resektion aufgrund hoher Morbidität nicht erreichbar ist, kann zudem eine Radiotherapie diskutiert werden [373, 374].

\subsubsection{Hämatolymphoide Tumore \\ 2.4.2.5.1 Extranodales NK/T-Zell Lymphom}

Das extranodale NK/T-Zell Lymphom ist ein extranodales Lymphom mit zytotoxischem Phänotyp und einer zwingenden Assoziation mit dem Epstein-Barr-Virus. Synonym werden die Begriffe angiozentrisches Lymphom und letales Mittellinien-Granulom verwendet.

Das Malignom hat eine höhere Prävalenz in Südostasien und der indigenen Bevölkerung von Mexiko und Zentral- sowie Südamerika. Hier repräsentiert es bis zu 10\% der Non-Hodgkin Lymphome. Im Gegensatz hierzu ist dieser Anteil in Nordamerika und Europa unter $1 \%$. Die Prävalenz der Erkrankung wird in Europa auf unter 9:1 000000 Einwohner geschätzt [375].

Das extranodale NK/T-Zell Lymphom wächst destruierend im oberen Aerodigestivtrakt und manifestiert sich in der Nasenhaupthöhle, den Nasennebenhöhlen und entlang des Waldeyerschen Rachenrings [106].

Erste Symptome sind Nasenatmungsbehinderung und Epistaxis. Das infiltrative Wachstum führt häufig zu Perforationen des Nasenseptums oder des harten Gaumens und zu Einwachsen in die Haut, an der bei Durchbruch ulzerierende Läsionen entstehen. Bei Lokalisation innerhalb der Nasennebenhöhlen können Symptome einer chronischen Rhinosinusitis die eigentliche Erkrankung kaschieren [106]. Funktionseinschränkungen stellen sich bei okulärer oder zerebraler Infiltration ein.

Histopathologisch zeigt sich ein diffus in das Gewebe infiltrierender Tumor mit angiozentrischem bzw. angioinvasivem Wachstumsmuster und großen Tumornekrose-Arealen. Die neoplastischen Zellen variieren in Größe und Anzahl der irregulär geformten 
Zellkerne. Immunhistochemisch exprimiert der Tumor CD3, zytotoxische Marker und CD56 [376, 377].

Aufgrund der strikten EBV-Assoziation und der klaren ethnischen Prädisposition wird ein Gendefekt der Immunantwort betroffener Patienten gegenüber einer EBV-Infektion vermutet [378, 379].

Die Prognose ist im Vergleich zu anderen T-Zell Lymphomen schlecht mit einer medianen Überlebensrate von 7,8 Monaten und einer 5-Jahres Überlebensrate von $40 \%$ [15]. Die plasmatische EBVDNA Last ist von diagnostischer und prognostischer Signifikanz. Sie wurde zusammen mit den PET CT Ergebnissen in die prognostischen Algorithmen integriert [106, 380]. Aktuelle Chemotherapieregimes erreichen langfristige Remissionen in 70-80 \% der Fälle in Stadium I/II und ca. 50\% in Stadium III/IV [381,382].

\subsection{Extraossäres Plasmozytom}

Das extraossäre Plasmozytom stellt eine raumfordernde Proliferation monoklonaler Plasmazellen mit extraossärer Manifestation ohne das zugrundeliegende multiple Myelom dar. Wichtig ist die Unterscheidung von B-Zell Lymphomen mit plasmozytischer/plasmablastischer Differenzierung, speziell vom MALT Lymphom und dem plasmoblastischen Lymphom [106].

Das mediane Patientenalter bei Diagnosestellung beträgt ca. 60 Jahre und es besteht eine erhöhte Prävalenz bei Patienten männlichen Geschlechts (m:w=3-4:1) [106, 383, 384].

Ca. $80 \%$ der extraossären Plasmozytome manifestieren sich innerhalb der oberen Atemwege, vorwiegend der Nasenhaupthöhle und den Nasennebenhöhlen. Die weltweite Inzidenz wird auf 0,021 bis 4:100 000 Einwohner geschätzt [385].

Klinisch zeigen sie solitäre Raumforderungen, die zu Atemwegseinengungen, Epistaxis, Gesichtsschmerzen, chronisch sinunasalen Beschwerden mit Rhinorrhoe und je nach Infiltration zu Hirnnervenausfällen und einer Protrusio bulbi führen können.

Unter $25 \%$ der Patienten weisen ein monoklonales Serum-Paraprotein auf, typischerweise vom IgA-Typ. Diagnostische Merkmale des multiplen Myeloms fehlen [386, 387].

Histologisch kann eine diffuse Infiltration gut, mittelgradig oder nur gering differenzierter Plasmazellen und gelegentlich Amyloidablagerungen festgestellt werden. Mittelgradig und gut differenzierte extraossäre Plasmozytome müssen von B-Zell Lymphomen, insbesondere vom MALT Lymphom mit extensiver plasmozytischer Differenzierung abgegrenzt werden. Gering differenzierte extraossäre Plasmozytome sind von plasmoblastischen Lymphomen zu differenzieren [388, 389]. Die Zellen exprimieren häufig Merkmaler einer plasmozytischen Differenzierung (C138, C38, VS38, MUM1/IRF4) [390]. Monotypische Immunglobulin Leichtketten können typischerweise festgestellt werden.

Therapie der Wahl ist die lokale Radiotherapie, welche eine wesentlich bessere Prognose als bei multiplem Myelom erbringt. Die krankheitsspezifische 5- und 10-Jahres Überlebensrate wird in der aktuellen Literatur mit bis zu 82 bzw. 76\% angegeben [391-393]. Lokalrezidive oder Versprengung in andere extraossäre Lokalisationen sind möglich. Circa 15\% der Patienten entwickeln im Verlauf ein multiples Myelom [383].

\subsection{Langerhans-Zell-Histiozytose}

Im Rahmen der Langerhans-Zell-Histiozytose (LZH) kommt es zu einer Proliferation und Akkumulation von Langerhans-Zellen in unterschiedlichen Gewebearten. Die Prävalenz in der europäischen Bevölkerung wird auf 1-2:100 000 geschätzt. Eine primäre Manifestation der LZH in der Nase, den Nasennebenhöhlen oder an der Schädelbasis ist noch deutlich seltener anzutreffen. Genaue Zahlen hierzu existieren nicht. Besonders häufig ist die Erkrankung bei Kindern zu finden. Der Altersgipfel betroffener Patienten liegt zwischen 1 und 4 Jahren [394, 395]. Typische Manifestationen der LZH finden sich innerhalb des Knochens ( $80 \%$ ), in der Haut (35\%) sowie an der Hypophyse (25\%). Seltener betroffene Organsysteme sind Lunge, Leber und das hämatopoetische System (15-20\%) [396]. Schwere Verläufe können zu einer sklerosierenden Cholangitis oder neurodegenerativen Veränderungen in bis zu $2 \%$ der Fälle führen.

Bei Befall der Nase oder der Nasennebenhöhlen stellen sich zumeist Druckgefühl und Schmerzen über der befallenen Region ein. Bei Befall des Sinus frontalis oder maxillaris kann es zu Schwellungen im Gesichtsbereich kommen [397]. Aufgrund der raumfordernden Wirkung der Manifestation der LZH sind Affektionen benachbarter Strukturen wie z. B. dem Nervus opticus möglich [398].

Bildmorphologisch präsentiert sich die Erkrankung mit gut abgrenzbaren, fast „ausgestanzt“ wirkenden knöchernen Läsionen und Beteiligung des angrenzenden Weichgewebes. Läsionen ohne knöcherne Erosionen wurden ebenfalls demonstriert [399, 400]. In einer Untersuchung von 163 Patienten mit LZH konnte in 55\% der Fälle eine magnetresonanztomografische Beteiligung der $\mathrm{Na}$ sennebenhöhlen oder der Mastoide diagnostiziert werden [401].

Aktuelle Studien haben gezeigt, dass bei Patienten mit disseminierter Erkrankung eine BRAF V600E Mutation nachgewiesen werden kann, die ebenfalls in malignen Melanomen auftritt [402-404]. Die Möglichkeit einer Anwendung einer „Targeted Therapy“ mit Inhibitoren, die bereits im Rahmen eines Malignen Melanoms verwendet werden, wird derzeit untersucht. Nicht zuletzt aufgrund dieser Mutation bleibt die Debatte, ob es sich bei der LZH um eine maligne Erkrankung mit variierender klinischer Manifestation handelt, bestehen.

Aufgrund der nicht gänzlich geklärten Pathogenese der LZH ist die Therapie empirisch und hängt von der jeweiligen Manifestation und dem Grad des systemischen Befalls ab. Die Diagnose wird über eine Gewebeprobe gesichert. Die Exzision oder Kürettage befallener Areale kann eine effektive Therapie für unifokale Manifestationen sein [405]. Die Prognose ist bei unifokaler Manifestation gut. Die Gabe von $125 \mathrm{mg}$ Methylprednisolon wird aufgrund der inhibitorischen Wirkung auf die Osteolyse empfohlen. Radiotherapie wird vorwiegend bei Rezidiven eingesetzt. Bei systemischem Befall mit multifokaler Ausbreitung ist die Prognose deutlich schlechter. Therapeutisch werden medikamentöse Therapien mit Vinblastin, Prednison, Etoposid und Methotrexat in verschiedenen Kombinationen verwendet [406].

\subsubsection{Neuroektodermale und melanozytäre Tumore 2.4.2.6.1 Ewing-Sarkom, primitiver neuroektodermaler Tumor}

Das Ewing Sarkom und der primitive neuroektodermale Tumor sind primitive, rund-/kleinzellige high-grade Sarkome mit variabler neuroektodermaler Differenzierung. Charakteristisch ist eine Translo- 
kation zwischen dem EWSR1 Gen und Chromosom 22 sowie einem Mitglied der ETS-Transkriptionsfamilie [106].

Synonym werden die Begriffe peripherer neuroektodermaler Tumor, peripheres Neuroepitheliom, peripheres Neuroblastom oder adultes Neuroblastom verwendet.

Ewing Sarkome und primitive neuroektodermale Tumore manifestieren sich nur in 2-10\% der Fälle im Kopf-Hals-Bereich und weisen eine höhere Inzidenz beim männlichen Geschlecht auf. Vorwiegend sind Kinder und junge Erwachsene betroffen [106].

Manifestationen im Kopf-Hals-Bereich sind Schädel- und Kieferknochen, deutlich weniger sind die Nasennebenhöhlen oder die Nasenhaupthöhle betroffen. Häufigster Manifestationsort des Sinunasaltrakts ist der Sinus maxillaris und die Nasenhaupthöhle. Infiltrationen in die Orbita oder nach intrakraniell sind möglich [407, 408]. - Abb. 15 zeigt die magnetresonanztomografische Darstellung des Schädels eines 9-jährigen Patienten, der durch eine Abduzensparese linksseitig aufgefallen war.

Schmerzen, progrediente Schwellungen, Nasenatmungsbehinderung mit raschem Progress sind typische Symptome betroffener Patienten.

Makroskopisch zeigen sich polypoide oder multilobuläre, grau/ weißliche, teils hämorrhagische Tumore mit Ulcerationen. Histologisch ist ein ausgesprochen zellulärer Tumor mit diffusem bis lobulärem Wachstum und trabekulärem oder strangartigem Aufbau festzustellen. Einheitliche kleine Zellen mit runden bis ovalen Zellkernen, diskretes nukleäres Chromatin, blasses Zytoplasma und undeutliche Zellgrenzen sind weitere Merkmale. Die mitotische Aktivität ist mit 5-10 Mitosen pro hochauflösenden 10 Gesichtsfeldern variabel ausgeprägt [106]. In 90-95\% der Fälle existiert eine konsistente, reziproke Translokation zwischen den EWSR1 Gen auf Chromosom 22 und dem FLI1 Gen auf Chromosom 11 [409].

Neben der MRT und CT ist die PET-CT zum Staging empfohlen, um Fernmetastasierung auszuschließen bzw. korrekt zu lokalisieren und das eventuell erforderliche chirurgische Vorgehen besser planen zu können [410]. Sofern möglich, ist eine Exzision des Befundes mit ausreichendem Sicherheitsabstand anzustreben.
Obwohl Ewing Sarkome als strahlensensitiv eingestuft werden, ist die Anzahl von Patienten, die innerhalb der letzten 30 Jahre primär radiotherapiert wurden, stetig gesunken. Ein Grund hierfür ist die Spättoxizität und das Risiko von sekundären Malignomen nach Radiotherapie, da besonders Kinder von der Erkrankung betroffen sind. Die Modifikation von Chemotherapien hat innerhalb der letzten Jahrzehnte die Überlebensraten von ursprünglich ca. 10 \% deutlich erhöht. Die derzeitige 5-Jahres Überlebensrate für sinunasale Ewing-Sarkome/primitive neuroektodermale Tumore ohne Metastasierung liegt bei 50-75\% und ist damit besser als für andere Lokalisationen $[408,411]$. Chemotherapie-Schemata sind VACA(Vincristin, Doxorubicin, Cyclophosphamid, Actinomycin), VAIA (Ifosfamid anstelle von Cyclophosphamid) oder EVAIA (zusätzlich Etoposid) und VIDE (ohne Actinomycin). Trotz der guten Prognoseentwicklung ist das Outcome von Patienten mit Metastasen deutlich schlechter [412].

\subsection{Olfaktoriusneuroblastom}

Olfaktoriusneuroblastome sind maligne neuroektodermale Neoplasien. Entsprechend ihrer Genese sind sie häufig in den kranialen Anteilen der Nasenhaupthöhle entlang der Regio olfactoria lokalisiert. Synonym wird der Begriff Aesthesioneuroblastom verwendet.

Die Inzidenz wird mit ca. 4:10 000000 angegeben. Insgesamt repräsentiert die Entität ca. 3 \% aller Nasennebenhöhlenmalignome $[106,413]$. Das Alter betroffener Patienten reicht in den in der Literatur beschriebenen Fällen von 2 bis 90 Jahren mit einem Altersgipfel zwischen dem 5. und 6. Lebensjahrzehnt. Männer sind häufiger betroffen (1,2:1). Eine ethnische oder familiäre Prädilektion existiert nicht.

Der Tumor kann sich entlang der Lamina cribrosa, dem medialen Anteil der mittleren Nasenmuschel oder dem kranialen Anteil des Nasenseptums manifestieren. Ursprungsorte sind das vomeronasale Organ, das Ganglion sphenopalatinum, entsprechend der Embryologie die olfaktorische Plakode oder der Nervus terminalis, der die Ethmoidspalte des anterioren Anteils der Lamina cribrosa

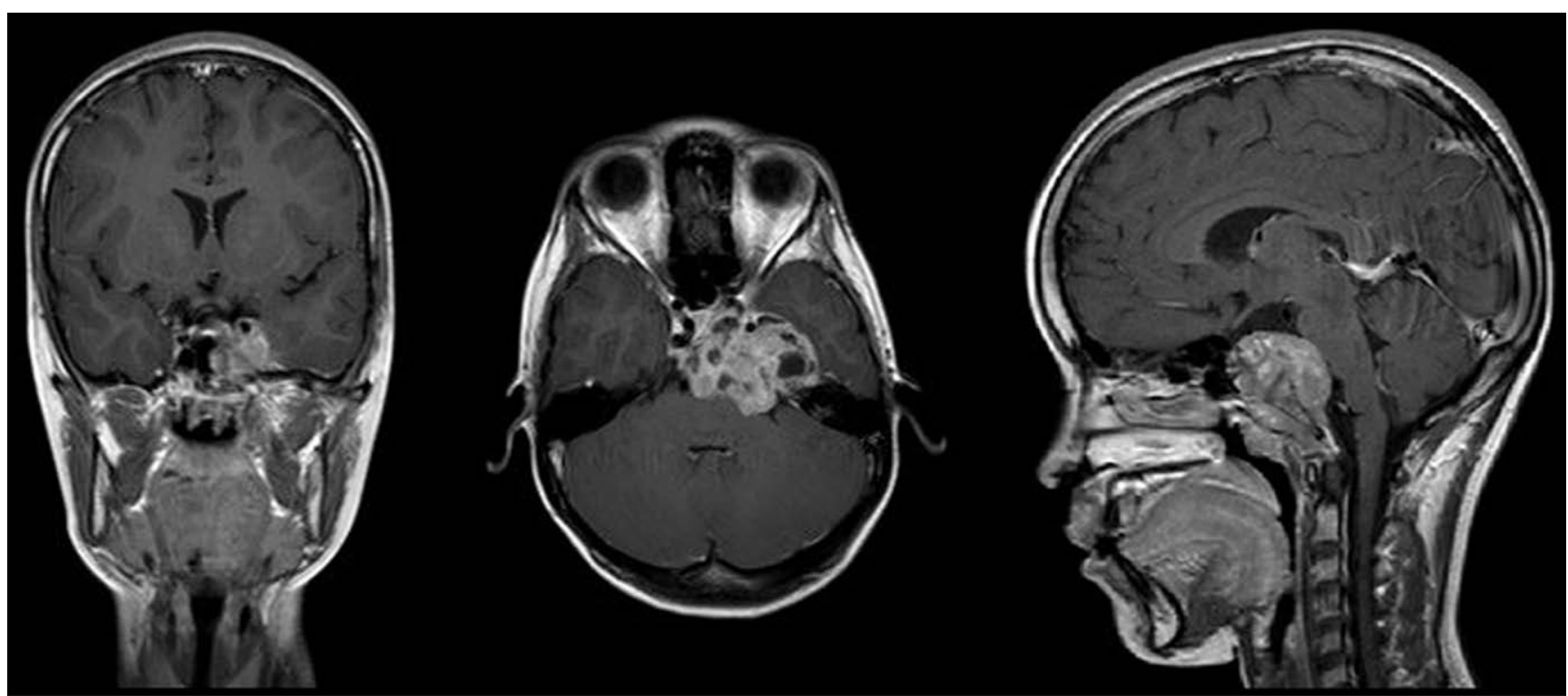

Abb. 15 Ewing Sarkom der Schädelbasis links, ausgehend vom Sinus sphenoidalis mit intrakranieller Infiltration. 


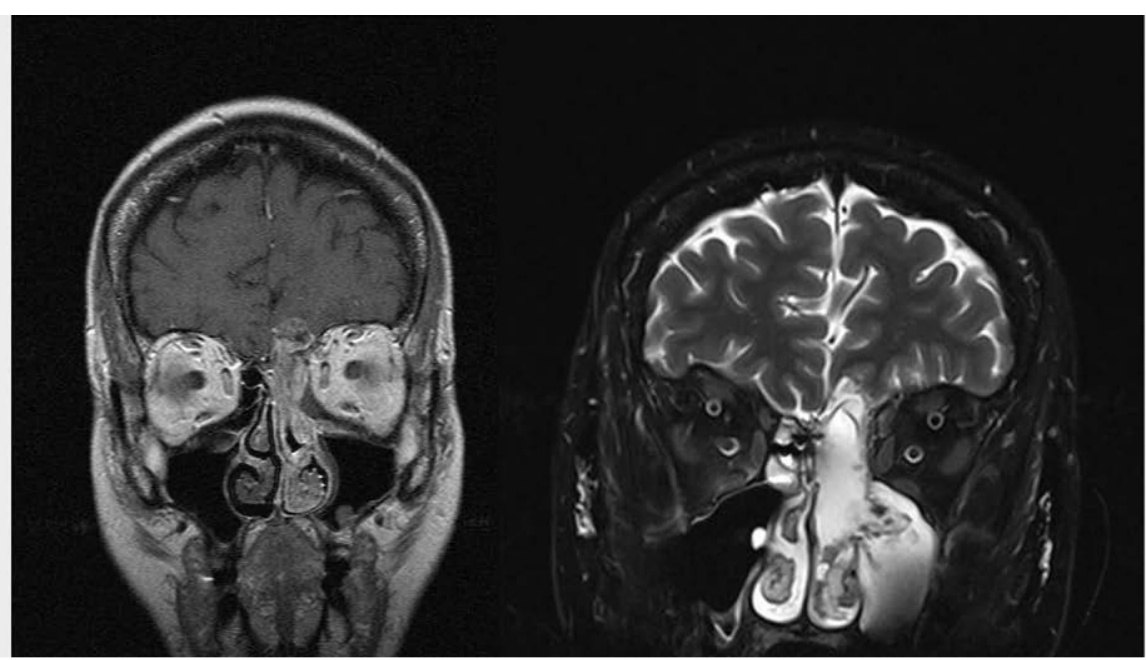

Abb. 16 Links: Koronare T1-gewichtete MRT-Darstellung eines Olfaktoriusneuroblastoms. Zu erkennen ist die intrakranielle Infiltration der linken Frontobasis. Rechts: Koronare T2-gewichtete, intraoperative MRT nach Resektion des Olfaktoriusneuroblastoms. Die Rekonstruktion der Rhinobasis ist zu diesem Zeitpunkt noch nicht erfolgt.

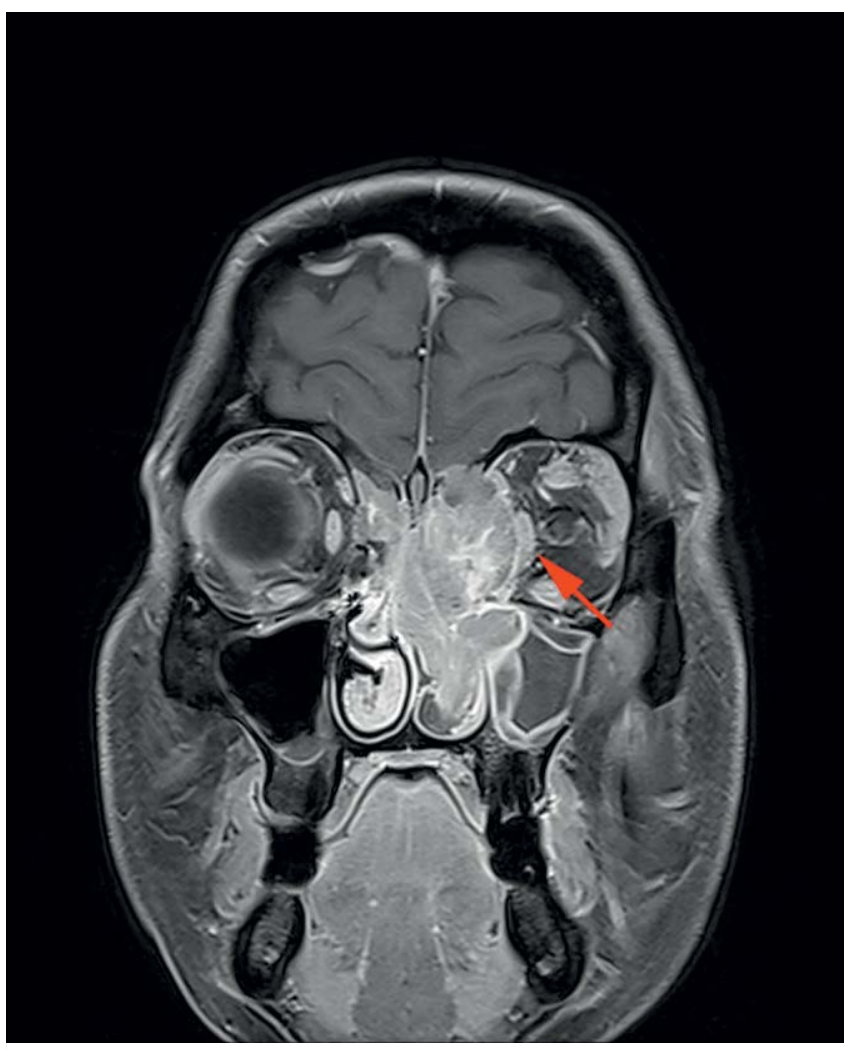

Abb. 17 Koronare T1-gewichtete MRT-Darstellung eines Olfaktoriusneuroblastoms mit Verdrängung und beginnender Infiltration des orbitalen Inhalts (roter Pfeil).

ausfüllt [414]. Ektope Manifestationen im Siebbein sind möglich, allerdings extrem selten für alle anderen Sinus [415, 416]. Aufgrund des Entstehungsortes ist die Schädelbasis grundsätzlich in das Tumorgeschehen involviert.

Initial weisen Olfaktoriusneuroblastome häufig Beschwerden auf, die denen gutartiger Läsionen ähneln, weshalb es häufig zu einer späten Diagnosestellung kommt. Nasenatmungsbehinderung und gelegentlich Epistaxis werden von den Patienten berichtet. Cephalgien, Rhinorrhoe, Epiphora und Visusstörungen sind Symptome eines bereits ausgedehnteren Tumorwachstums. Die Anosmie ist trotz der Lokalisation an der Lamina cribrosa mit $<5 \%$ selten. Paraneoplastische Syndrome treten in ca. 2 \% der Fälle auf.

Klinisch präsentiert sich eine Tumormasse, die von der Lamina cribrosa ausgeht und sich über weite Teile dieser erstreckt. Meist ist das Tumorwachstum unilateral und imponiert polypoid, weich mit rot-grauer Oberfläche bei intakter Mucosa. Computer- und vor allem Magnetresonanztomografie ermöglichen die Ausdehnungsbestimmung ( $\mathbf{A}$ Abb. 16) und Darstellung einer Infiltration der Orbita, was beispielhaft an $\mathbf{A} \mathbf{A b b} \mathbf{1} \mathbf{1 7}$ zu erkennen ist.

Es existieren verschiedene Staging-Systeme (Kadish [417], Morita [418] und nach TNM [419]), wobei die Einteilung nach Kadish die weiteste Verbreitung zeigt.

Olfaktoriusneuroblastome werden in low grade- und high grade-Entitäten unterteilt. Low grade Olfaktoriusneuroblastome zeigen scharf demarkierte, submukös wachsende Zellnester, die oft durch vaskuläres oder hyalinisiertes Bindegewebe voneinander getrennt sind. Sogenannte Homer Wright Rosetten/Pseudorosetten, in denen sich neoplastische Zellen palisadenartig um die zentral liegende neurale Matrix verteilen, sind charakteristisch. High grade Olfaktoriusneuroblastome zeigen Tumornekroseareale, Pleomorphismen, eine gesteigerte Mitoserate sowie ein weniger offensichtliches lobuläres Wachstum [106].

Das bekannteste Grading-System stammt von Hyams et al. [420]. In diesem wird je nach Differenzierungsgrad zwischen Grad I (hochdifferenziert) und Grad IV (niedrig differenziert) unterschieden. Kriterien sind Tumorarchitektur, mitotische Aktivität, nukleäre Polymorphismen, fibrilläre Matrizen und Rosetten, Nekroseareale, glanduläre Proliferation und Kalzifikationen.

In einer 2009 publizierten Arbeit von Mao et al. konnte gezeigt werden, dass der PTCH1, GLI1 und GLI2 Signalweg in die Pathoge- 


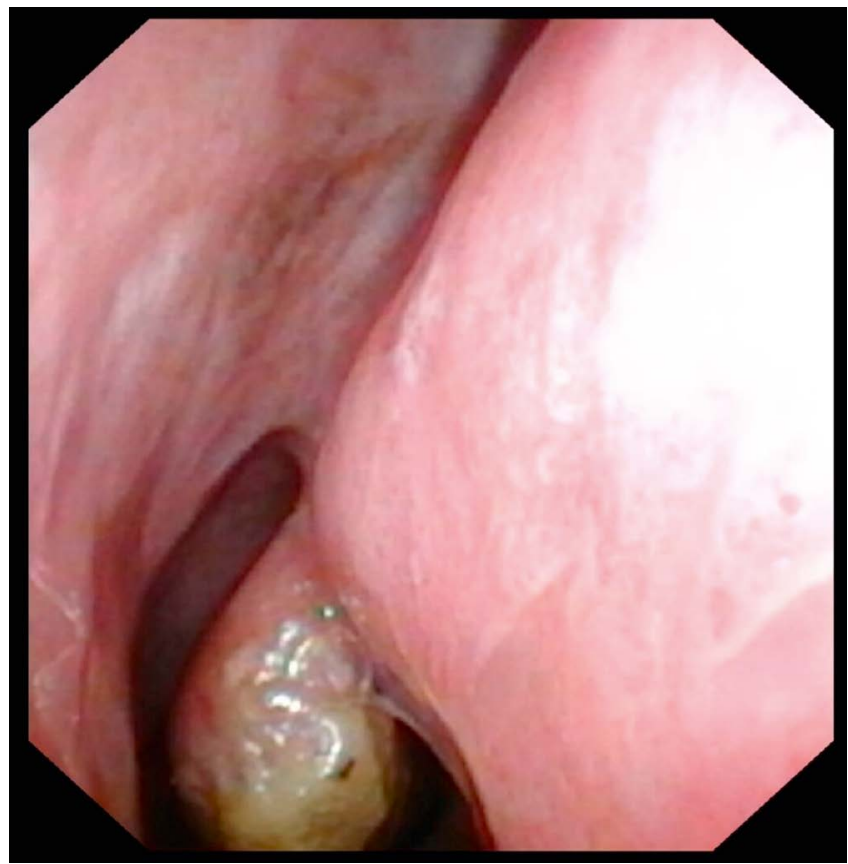

- Abb. 18 Malignes Schleimhautmelanom vor dem Ansatz der mittleren Muschel unmittelbar unterhalb und vor dem Agger nasi rechts. Es zeigt sich eine pigmentierte, nicht erhabene Schleimhautveränderung.

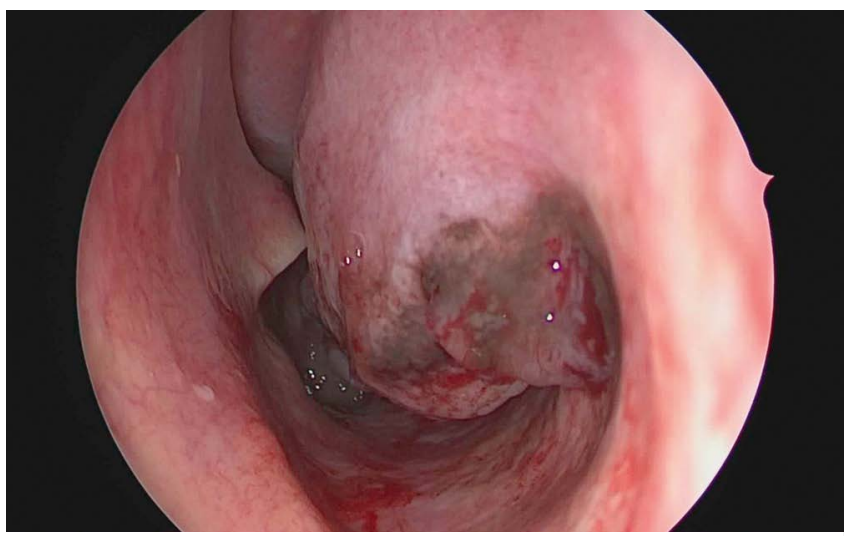

- Abb. 19 Malignes Schleimhautmelanom der unteren Nasenmuschel sowie der lateralen Nasenwand links. Am Muschelkopf zeigt sich ein polypös anmutendes Tumorwachstum.

nese der Olfaktoriusneuroblastome involviert sind, was eine zentrale Rolle des Sonic Hedgehog Signalwegs nahelegt [421].

Primäre Therapieoption ist die Tumorresektion, gefolgt von einer lokalen Radiotherapie. Entgegen der traditionellen, 1963 erstmals beschriebenen kraniofazialen Resektion [422] wird heute die endoskopische Resektion des Tumors favorisiert. Entgegen der ursprünglichen Annahme, dass nur die en-bloc-Resektion des Tumors langfristige Rezidiv-Freiheit gewähren könnte, zeigen endoskopische Verfahren ein ähnlich gutes onkologisches Outcome bei allerdings deutlich weniger invasiven Eingriffen [423]. Fortgeschrittenes Tumorwachstum kann zusätzlich eine Chemotherapie erforderlich machen. High grade Tumore nach Hyams sprechen hierauf

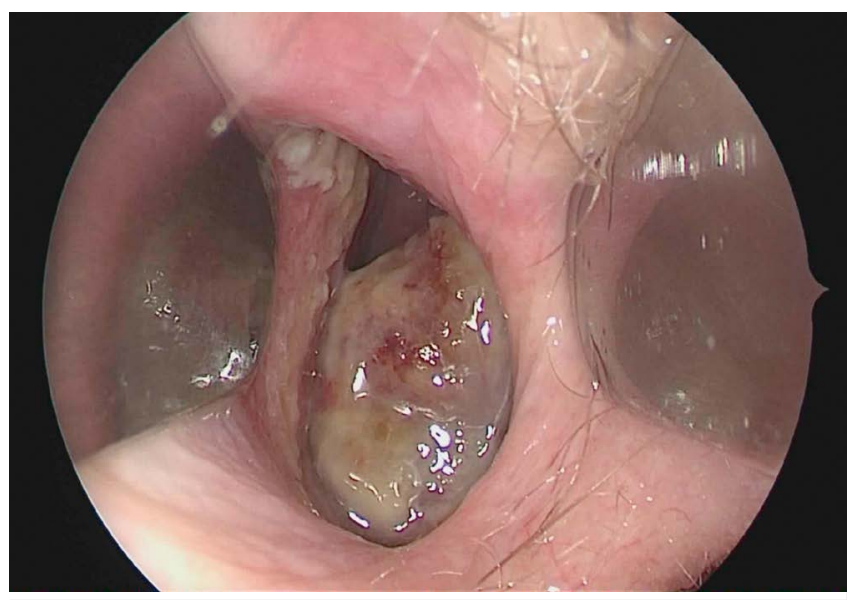

Abb. 20 Malignes Schleimhautmelanom der NasenhaupthöhlenSchleimhaut links mit polypös anmutendem Wachstum.

besser an, weshalb in Einzelfällen auch eine Induktions-Chemotherapie diskutiert werden kann [424].

Eine Meta-Analyse von Dulguerov et al analysierte die Krankheitsverläufe in Abhängigkeit der Therapieschemata und zeigte das beste Outcome für Patienten, die eine Tumorresektion gefolgt von einer lokalen Radiotherapie erhalten hatten. Patienten dieser Gruppe zeigten eine 2-Jahres Überlebensrate von $65 \%$, verglichen mit 48 und $37 \%$ bei alleiniger Tumorresektion bzw. alleiniger Radiotherapie [425]. Aktuelle Studienergebnisse zeigen zudem ein signifikant verbessertes krankheitsspezifisches Überleben für Patienten im Stadium T3/T4, bei denen eine Tumorresektion und Strahlentherapie durchgeführt wurde, im Vergleich zu einer alleinigen chirurgischen Therapie [426].

\subsection{Maligne Schleimhautmelanome}

Schleimhautmelanome sind maligne Neoplasien, die aus Melanozyten der Schleimhaut entstehen und die sich biologisch von kutanen Melanomen unterscheiden. Die Ätiologie ist unbekannt.

Schleimhautmelanome sind für weniger als $1 \%$ aller malignen Melanome verantwortlich [427] und repräsentieren ca. $4 \%$ aller sinunasalen Tumore. Die Altersspanne ist weit gefächert und weist einen Altersgipfel innerhalb des 7. Lebensjahrzehnts auf [106].

Häufigster Manifestationsort ist die Nasenhaupthöhle mit dem Nasenseptum und deutlich seltener der Nasopharynx oder Sinus maxillaris $[428,429]$. Aufgrund der Abschirmung von Sonneneinstrahlung scheint das sinunasale Schleimhautmelanom eine unterschiedliche Biologie gegenüber dem kutanen malignen Melanom zu besitzen. Etwa $20 \%$ der betroffenen Patienten weisen bei Diagnosestellung multifokale Herde auf, etwa $40 \%$ der diagnostizierten Melanome sind amelanotisch [430].

Maligne Schleimhautmelanome können sich als plane, pigmentierte Schleimhautveränderungen ( $\boldsymbol{A} \mathbf{A b b}$. $\mathbf{1 8}$ ) oder als polypöse, raumfordernde Tumorformationen präsentieren ( $\bullet \mathbf{A b b} \mathbf{B} 19$ und 20). Symptome bei der Erstvorstellung sind häufig Epistaxis und Obstruktion der Nase bzw. Nasenatmungsbehinderung. Derart unspezifische Beschwerden führen häufig zu einer Diagnosestellung in höheren Tumorstadien. 
-Tab. 4 Staging-Einteilung des Olfaktoriusneuroblastoms nach Kadish und Morita.

\section{Stadium nach \\ Kadish}

A

B

C

$\mathrm{D}$ (Erweiterung nach Morita [418])
Tumorausdehnung in der Nasenhaupthöhle und den Nasennebenhöhlen

Tumorausdehnung über die Nasenhaupthöhle und Nasennebenhöhlen hinaus

Vorhandensein regionaler Metastasen oder von Fernmetastasen
Tumor auf die Nasenhaupthöhle begrenzt

>Tab. 3 Häufigkeit verschiedener Entitäten sinunasaler speicheldrüsenartiger Tumore nach Heffner [269].

\begin{tabular}{|l|c|c|}
\hline Entität & Anzahl von Fällen & Prozentzahl \\
\hline Pleomorphes Adenom & 73 & $23 \%$ \\
\hline Onkozytärer Tumor & 7 & $2 \%$ \\
\hline $\begin{array}{l}\text { Low-grade Adenokarzinom } \\
\text { (inkl. Azinuszellkarzinom) }\end{array}$ & 67 & $21 \%$ \\
\hline Mukoepidermoidkarzinom & 17 & $5 \%$ \\
\hline Adenoidzystisches Karzinom & 54 & $17 \%$ \\
\hline High-grade Adenokarzinom & 93 & $30 \%$ \\
\hline Summe & 311 & $100 \%$ \\
\hline
\end{tabular}

Makroskopisch weist das Schleimhautmelanom eine polypoide Formation auf. Es kann pigmentiert und brüchig bis hellbraun oder grau und fest konfiguriert sein [106]. Mikroskopisch zeigen sich häufig Ulzerationen der Schleimhautbedeckung mit variabler Zellmorphologie, die von epitheloiden/undifferenzierten Zellen zu spindelformigen, plasmazytoiden und rhabdoiden Zellen mit teilweisen prominenten Kernen reicht. Atypische Mitosen sind häufig zu beobachten. Knapp die Hälfte der Malignome können eine amelanotische Ausprägung zeigen, was die Anzahl der möglichen Differenzialdiagnosen deutlich erhöht (u. a. Olfaktoriusneuroblastom, Rhabdomyosarkom, Sinunasales undifferenziertes Karzinom, schlecht differenziertes Plattenepithel-Karzinom) [106].

Im Gegensatz zu kutanen Melanomen sowie Aderhautmelanomen zeigen sich höhere Raten von KIT- und NRAS-Mutationen. BRAF Mutationen hingegen sind selten [431, 432].

Entscheidend für Staging und Prognose ist die korrekte Differenzierung eines mukosalen Melanoms von einer sinunasalen Metastasierung eines kutanen malignen Melanoms. Fernmetastasierung und fortgeschrittenes Patientenalter sind die entscheidendsten Prognosefaktoren. Entsprechend der 7. Ausgabe des „Cancer Stanging Manuals des American Joint Committee on Cancer" besteht im Stadium T3 und T4 eine 5-Jahres Überlebensrate von unter $30 \%$ [433-435].
Gegenwärtige Behandlungsempfehlungen befürworten die weiträumige lokale Exzision, sofern möglich [436]. Die Rolle der postoperativen Radiotherapie ist umstritten. Eine Meta-Analyse aus dem Jahr 2012 konnte keine höhere Überlebensrate feststellen [437]. Andere Studienergebnisse belegen eine gesteigerte 3-Jahres Überlebensrate von 18 auf $30 \%$ sowie eine reduzierte lokale Rezidivrate nach postoperativer Radiotherapie [438, 439]. Anti-PD-1 Antikörper sowie Anti-CTLA-4 Antikörper Therapien zeigen vielversprechende Ergebnisse bei fortgeschrittenen oder metastasierten Schleimhautmelanomen, allerdings ist die Evidenz zu gering, um die klinische Anwendung zu rechtfertigen [436, 440].

\subsubsection{Keimzelltumore}

\subsection{Sinunasales Teratokarzinosarkom}

Teratokarzinosarkome sind maligne Neoplasien mit histologischen Eigenschaften sowohl von Teratomen als auch Karzinosarkomen ohne bösartige Keimzellbestandteile. Die Begriffe Malignes Teratom, Blastom, Teratokarzinom und teratoides Karzinosarkom werden synonym verwendet.

Teratokarzinosarkome sind sehr seltene Tumore, die hauptsächlich bei männlichen Erwachsenen auftreten (mittleres Patientenalter 60 Jahre).

Am häufigsten tritt der Tumor in der Nasenhaupthöhle, gefolgt von Sinus ethmoidalis und maxillaris auf. In etwa $20 \%$ der Fälle kann eine intrakranielle Beteiligung festgestellt werden [441].

Die Diagnose stellt sich anhand des Nachweises von malignen epithelialen Elementen und 2 oder mehr malignen mesenchymalen Komponenten wie z. B. Fibroblasten, Knorpel, Knochen oder glatter Muskulatur. Diese Kombinationen können primitiven bronchialen oder intestinalen Strukturen ähneln, die im Sinonasaltrakt fremd wirken [442]. Die teratoiden Elemente sind wesentliche diagnostische Faktoren des sinunasalen Teratokarzinosarkoms. Fetal anmutendes, klarzelliges Plattenepithel und tubuläre oder glanduläre Formationen sind weitere Kriterien für die Diagnosestellung. Stammzell-Anteile sind beim Teratokarzinosarkom nicht vorhanden [443-447].

Die Behandlung des sinunasalen Teratokarzinosarkoms ist aufgrund der hohen Malignitätsrate und der schlechten Prognose schwierig. Um realistische Chancen auf ein längerfristiges tumorfreies Überleben zu haben, wird eine radikale Tumorresektion gefolgt von einer Radiotherapie empfohlen [448]. In Fällen einer intrakraniellen Ausdehnung wurden kombinierte intra- und extrakranielle Herangehensweisen beschrieben, um en-bloc Resektionen zu realisieren [449]. Eine Übersichtsarbeit von Misra et al. identifizierte 5 Berichte, in denen die Tumorresektion endoskopisch unterstützt wurde [441]. Die Rolle einer adjuvanten Chemotherapie ist aufgrund nur weniger Fallberichte nicht gesichert. Aufgrund der extremen Seltenheit sind die Charakteristika und optimale Therapieschemata nicht definiert.

Lymphknoten- und Fernmetastasierungen sind häufig. Die berichteten Überlebensraten variieren von $50-70 \%$ in unterschiedlichen Analysen [106, 441]. 


\section{Zusammenfassung}

Die vorliegende Übersicht stellt seltene Erkrankungen der Nase, der Nasennebenhöhlen sowie der vorderen Schädelbasis mit Fokus auf Fehlbildungen, Belüftungs- und Funktionsstörungen wie auch Tumorerkrankungen vor. Ein Anspruch auf Vollständigkeit kann aufgrund der Komplexität des anatomischen Bereichs und der Vielzahl möglicher Erkrankungen (Funktionsstörungen, Fehlbildungen, Tumore) nicht erhoben werden.

In vielen Fällen ist die adäquate Therapie einer seltenen Erkrankung komplex und bedarf umfangreicher Recherche der in der Literatur beschriebenen Erfahrungen. Vor allem bei seltenen benignen und malignen Neoplasien ist der Nutzen einer adjuvanten Therapie oftmals nicht geklärt und erfordert Erfahrung, die allerdings aufgrund der geringen Fallzahlen in vielen Zentren nicht vorgehalten werden kann. Auch muss innerhalb der Gruppe der seltenen Erkrankungen eine Abstufung vorgenommen werden, da extreme Unterschiede in den Inzidenzen der einzelnen Krankheitsbilder vorliegen. Eine Inzidenz von weniger als 5:10 000 erfüllt zwar die Definition einer seltenen Erkrankung, führt aber an einem großen Zentrum für Hals-, Nasen-, Ohrenheilkunde, Kopf- und Halschirurgie zu einer durchaus nennenswerten Anzahl behandelter Fälle. Erkrankungen, für die weltweit weniger als 100 Fallberichte existieren, stellen auch für große Zentren Herausforderungen dar.

Insofern scheint es sinnvoll, Kompetenzzentren für bestimmte seltene Erkrankungen zu bilden. Zudem ist ein reger Austausch zwischen den Zentren unter Berücksichtigung der gewonnenen Daten unerlässlich, um die diagnostischen und therapeutischen Möglichkeiten bei den seltenen Erkrankungen weiter zu entwickeln. Das Krankenhausstrukturgesetz aus dem Jahr 2015, welches u. a. finanzielle Zuschläge für Zentren für seltene Erkrankungen vorsieht, definiert auch deren Aufgaben, darunter die Erstellung von Registern oder Versorgungsatlanten zur Information von betroffenen Patienten. Vor allem für seltene Erkrankungen bilden Registerstudien ein wichtiges Fundament zur Datensammlung und zukünftigen statistischen Analyse von therapeutischem Nutzen, Lebensqualität, Therapiekosten sowie Arzneimittelsicherheit. Hiervon werden in absehbarer Zukunft auch Patienten mit seltenen Erkrankungen der Nase, der Nasennebenhöhlen und der vorderen Schädelbasis profitieren.

\section{Danksagung}

Prof. Dr. Thomas Hoffmann und Prof. Dr. Jörg Lindemann für die kritische Durchsicht des Manuskripts sowie Herrn Prof. Dr. Wolfgang Pirsig für das zur Verfügung gestellte Bildmaterial und die Anregungen zum Kapitel „Fehlbildungen der Nase“. Weiter gilt mein Dank Herrn Prof. Dr. Meinrad Beer, Radiologie Universitätsklinik Ulm, für die zur Verfügung gestellten CT und MRT-Aufnahmen. Für die Bereitstellung der Abbildungen 13 und 14 bedanke ich mich bei Frau Alexandra Gey, Herrn Prof. Stefan Plontke und Dr. Alexander Glien (Klinik für Hals-Nasen-Ohrenheilkunde, Universitätsklinikum Halle) sowie bei Frau Prof. Sabrina Kösling (Radiologie, Universitätsklinikum Halle).
Interessenkonflikt

Die Autorinnen/Autoren geben an, dass kein Interessenkonflikt besteht.

\section{Literaturverzeichnis}

[1] Bundesministerium für Gesundheit Seltene Erkrankungen - Bundesgesundheitsministerium. 2019; Im Internet: https://www.bundesgesundheitsministerium.de/themen/praevention/gesundheitsgefahren/ seltene-erkrankungen.html

[2] Anzahl I. Prävalenzen en und Inzidenzen seltener Krankheiten: Bibliografische Angaben. 2015; 1-52. Im Internet: https://www. orpha.net/orphacom/cahiers/docs/DE/Pravalenzen_seltener_Krankheiten_Alphabetische_Liste.pdf

[3] Pedan H, Janosova V, Hajtman A, Calkovsky V. Non-Reflex Defense Mechanisms of Upper Airway Mucosa: Possible Clinical Application. Physiol Res 2020; 69(Suppl 1): S55-S67. doi:10.33549/physiolres.934404. PMID: 32228012

[4] Sommer F, Scheithauer M, Kröger R et al. Niesen als mechanische Abwehr - Numerische Simulation mit Analyse der durchströmten Nasenbereiche. Laryngorhinootologie 2014; 93: 746-750

[5] Sommer F, Hoffmann TK, Mlynski G et al. Dreidimensionale Analyse nasaler PhysiologieThree-dimensional analysis of nasal physiology. HNO 2017; 66: 280-289

[6] Lindemann ], Reichert M, Kröger R et al. Numerical simulation of humidification and heating during inspiration in nose models with three different located septal perforations. Eur Arch Oto-RhinoLaryngology 2016; 273: 1795-1800

[7] Sommer F, Kröger R, Lindemann J. Numerical simulation of humidification and heating during inspiration within an adult nose. Rhinology 2012; 50: 157-164

[8] Lindemann ], Rettinger G, Kröger R et al. Numerical simulation of airflow patterns in nose models with differently localized septal perforations. Laryngoscope 2013; 123: 2085-2089

[9] Götte K, Hörmann K. Sinonasal malignancy: What's new? Orl 2004; 66: 85-97

[10] Barnes L, Eveson JW, Reichart P et al. World health organization classification of tumours: Pathology and genetics of head and neck tumours. Lyon: International Agency for Research on Cancer; 2005

[11] Slinger CA, McGarry GW. Nose and sinus tumours: Red flags and referral. Br J Gen Pract 2018; 68: 247-248

[12] Le QT, Fu KK, Kaplan M et al. Treatment of maxillary sinus carcinoma: A comparison of the 1997 and 1977 American Joint Committee on Cancer staging systems. Cancer 1999; 86: 1700-1711

[13] Tiwari R, Hardillo JA, Mehta D et al. Squamous cell carcinoma of maxillary sinus. Head Neck 2000; 22: 164-169

[14] Tiwari R, Hardillo JA, Tobi $\mathrm{H}$ et al. Carcinoma of the ethmoid: Results of treatment with conventional surgery and post-operative radiotherapy. Eur J Surg Oncol 1999; 25: 401-405

[15] Laudien M. Ausgewählte seltene rhinologische Krankheitsbilder Pathogenese - Klinik - Therapie. Laryngorhinootologie 2015; 94 : S272-S287

[16] Hauser LJ, Jensen EL, Mirsky DM et al. Pediatric anosmia: A case series. Int J Pediatr Otorhinolaryngol 2018; 110: 135-139

[17] Hummel T, Whitcroft KL, Andrews P et al. Position paper on olfactory dysfunction. Rhinol J 2017; 0: 1-30 
[18] Orphanet: Anosmie, isolierte kongenitale. Im Internet: https://www. orpha.net/consor/cgi-bin/Disease_Search.php?lng=DE\&data_ id $=11807 \&$ Disease_Disease_Search_diseaseGroup $=$ anosmie \& Disease_Disease_Search_diseaseType $=$ Pat\&Krankheite $(n) /$ Krankheitsgruppe = Anosmie--isolierte-kongenitale\&title = Anosmie isolierte kongenit

[19] Mahmood AN, Abulaban O, Janjua A. Bilateral olfactory aplasia: Uncommon cause of congenital anosmia. Clin Case Reports 2019; 7 : 1456-1457

[20] Orphanet: Kallmann Syndrom. Im Internet: https://www.orpha.net/ consor/cgi-bin/OC_Exp.php?Lng $=$ DE\&Expert $=478$

[21] Johnson VP, McMillin JM, Aceto T et al. A newly recognized neuroectodermal syndrome of familial alopecia, anosmia, deafness, and hypogonadism. Am J Med Genet 1983; 15: 497-506

[22] Gebril O, Abdelraouf E, Shafie M et al. Johnson-McMillin microtia syndrome: New additional family. J Fam Med Prim Care 2014; 3: 275

[23] Orphanet: Arrhinie, isolierte. Im Internet: https://www.orpha.net/ consor/cgi-bin/OC_Exp.php?lng = DE\&Expert $=1134$

[24] Thiele H, Musil A, Nagel F et al. Familial arhinia, choanal atresia, and microphthalmia. Am J Med Genet 1996; 63: 310-313

[25] Abukhalaf SA, Zalloum JS, Al Hammouri A et al. Congenital arrhinia: A case report and literature review. Int J Pediatr Otorhinolaryngol 2020; 135: 110083

[26] Jung JW, Ha DH, Kim BY et al. Nasal Reconstruction Using a Customized Three-Dimensional-Printed Stent for Congenital Arhinia: Three-Year Follow-up. Laryngoscope 2019; 129: 582-585

[27] Núñez-Villaveiran T, Frohner BB, Urcelay PR et al. Bifid nose - A mild degree of frontonasal dysplasia. A case report. Int J Pediatr Otorhinolaryngol 2013; 77: 1374-1377

[28] Orphanet: Bifid nose. Im Internet: https://www.orpha.net/consor/ cgi-bin/Disease_Search.php?lng = EN\&data_id = 2457\&Disease_ Disease_Search_diseaseGroup $=$ bifid-nose\&Disease_Disease_Search_ diseaseType $=$ Pat\&Disease $(\mathrm{s}) /$ groupofdiseases $=$ Bifid-nose\&title $=$ Bifid nose\&search = Disease_Search_Simple

[29] Sedano HO, Michael Cohen M, Jirasek J et al. Frontonasal dysplasia. J Pediatr 1970; 76: 906-913

[30] Genç E, Derbent M, Ergin NT. A mild case of frontonasal dysplasia: The rhinologic perspective. Int J Pediatr Otorhinolaryngol 2002; 65: 75-83

[31] Cohen MM. Perspectives on craniosynostosis: Sutural biology, some well-known syndromes, and some unusual syndromes. J Craniofac Surg 2009; 20: 646-651

[32] Orphanet: Kraniorhinie. Im Internet: https://www.orpha.net/consor/ cgi-bin/OC_Exp.php?lng= de\&Expert $=157832$

[33] Rüegg EM, Bartoli A, Rilliet B et al. Management of median and paramedian craniofacial clefts. J Plast Reconstr Aesthetic Surg 2019; 72: 676-684

[34] Orphanet: Paramedian nasal cleft. Im Internet: https://www.orpha. net/consor/cgi-bin/Disease_Search.php?lng=EN\&data_ id=17067\&Disease_Disease_Search_diseaseGroup=paramediannasalcleft\&Disease_Disease_Search_diseasType=Pat\&Disease $(s)$ | groupofdiseases=Paramedian-nasal-cleft\&title=Paramedian $\% 20$ nasal\%20cleft

[35] Williams A, Pizzuto M, Brodsky L et al. Supernumerary nostril: A rare congenital deformity. Int J Pediatr Otorhinolaryngol 1998; 44: 161-167

[36] Orphanet: Polyrhinie. Im Internet: https://www.orpha.net/consor/ cgi-bin/Disease_Search.php?lng = DE\&data_id $=17033 \&$ Disease_Disease_Search_diseaseGroup $=$ Polyrhinie\&Disease_Disease_Search_ diseaseType $=$ Pat\&Krankheite $(n) /$ Krankheitsgruppe $=$ Polyrhinie\&title $=$ Polyrhinie\&search $=$ Disease_Search_Simple
[37] Orphanet: Nasenlöcher, überzählige. Im Internet: https://www.orpha. net/consor/cgi-bin/Disease_Search.php?lng=DE\&data_ id $=17034 \&$ Disease_Disease_Search_diseaseGroup $=$ Nasenloch\&Disease_Disease_Search_diseaseType = Pat\&Krankheite $(n)$ | Krankheitsgruppe $=$ Nasenlocher--uberzahlige $\&$ title $=\mathrm{Na}-$ senl \%F6cher, \%FCberz\%E4hlige

[38] Gulasi S, Turhan AH, Celik Y et al. Accessory nostril: A rare congenital nasal anomaly. J Craniofac Surg 2015; 26: e602-e603

[39] Galiè M, Clauser LC, Tieghi R et al. The arrhinias: Proboscis lateralis literature review and surgical update. J Cranio-Maxillofacial Surg 2019; 47: 1410-1413

[40] Harada T, Muraoka M. Proboscis lateralis: A rare bilateral case [7]. Ann Plast Surg 2001; 47: 350-351

[41] Wolfe SA, Tessier P, Ciminello FS. The Arrhinias. Scand J Plast Reconstr Surg Hand Surg 2009; 43: 177-196

[42] Rosen Z, Gitlin G. Bilateral Nasal Proboscis: Associated with Unilateral Anophthalmia, Unilateral Diffuse Pigmentation of the Conjunctiva, and Anomalies of the Skull and Brain. AMA Arch Otolaryngol 1959; 70: $545-550$

[43] El-fattah AMA, Naguib A, El-Sisi H et al. Midline nasofrontal dermoids in children: A review of 29 cases managed at Mansoura University Hospitals. Int J Pediatr Otorhinolaryngol 2016; 83: 88-92

[44] Orphanet: Nasal dorsum fistula. Im Internet: https://www.orpha.net/ consor/cgi-bin/OC_Exp.php?lng $=$ en\&Expert $=141219$

[45] Jurkov M, Olze H, Klauschen F et al. IgG4-related orbitopathy as an important differential diagnosis of advanced silent sinus syndrome. HNO 2020; 68: 65-68

[46] MONTGOMERY WW. Mucocele of the Maxillary Sinus Causing Enophthalmos. Eye Ear Nose Throat Mon 1964; 43: 41-44

[47] Soparkar CNS, Patrinely JR, Cuaycong M] et al. The Silent Sinus Syndrome: A Cause of Spontaneous Enophthalmos. Ophthalmology 1994; 101: 772-778

[48] Naik RM, Khemani S, Saleh HA. Frontal silent sinus syndrome. Otolaryngol - Head Neck Surg (United States) 2013; 148: 354-355

[49] McArdle B, Perry C. Ethmoid silent sinus syndrome causing inward displacement of the orbit: Case report. J Laryngol Otol 2010; 124 : 206-208

[50] Wise SK, Wojno TH, DelGaudio JM. Silent sinus syndrome: Lack of orbital findings in early presentation. Am J Rhinol 2007; 21: 489-494

[51] Brandt MG, Wright ED. The silent sinus syndrome is a form of chronic maxillary atelectasis: A systematic review of all reported cases. Am J Rhinol 2008; 22: 68-73

[52] Rose GE, Lund V]. Clinical features and treatment of late enophthalmos after orbital decompression: A condition suggesting cause for idiopathic „imploding antrum“ (silent sinus) syndrome. Ophthalmology 2003; 110: 819-826

[53] Numa WA, Desai U, Gold DR et al. Silent sinus syndrome: A case presentation and comprehensive review of all 84 reported cases. Ann Otol Rhinol Laryngol 2005; 114: 688-694

[54] Davidson JK, Soparkar CNS, Williams JB et al. Negative sinus pressure and normal predisease imaging in silent sinus syndrome. Arch Ophthalmol 1999; 117: 1653-1654

[55] Annino D], Goguen LA. Silent sinus syndrome. Curr Opin Otolaryngol Head Neck Surg 2008; 16: 22-25

[56] Hildenbrand T, Klein SB, Schramek N et al. Rare diseases of the maxillary sinus. HNO 2020; 68: 581-589

[57] Facon F, Eloy P, Brasseur P et al. The silent sinus syndrome. Eur Arch Oto-Rhino-Laryngology 2006; 263: 567-571

[58] Hourany R, Aygun N, Della Santina CC et al. Silent sinus syndrome: An acquired condition. Am J Neuroradiol 2005; 26: 2390-2392 
[59] Lee DS, Murr AH, Kersten RC et al. Silent sinus syndrome without opacification of ipsilateral maxillary sinus. Laryngoscope 2018; 128 : 2004-2007

[60] Illner A, Davidson HC, Harnsberger HR et al. The silent sinus syndrome: Clinical and radiografic findings. Am J Roentgenol 2002; 178: 503-506

[61] Rose GE, Sandy C, Hallberg L et al. Clinical and radiologic characteristics of the imploding antrum, or „silent sinus," syndrome. Ophthalmology 2003; 110: 811-818

[62] Weber RK. Aktueller Stand der endonasalen Nasennebenhöhlenchirurgie [Comprehensive review on endonasal endoscopic sinus surgery]. Laryngorhinootologie. 2015; 94 Suppl 1; S64-S142. doi:110.1055/s-0035-1545353. Epub 2015 Apr 10. PMID: 25860497

[63] Sogg A. Endoscopic sinus surgery. 4th Editio Thieme Verlag; 1993

[64] Sommer F, Hoffmann T, Lindemann J et al. Radicality of maxillary sinus surgery and size of the maxillary sinus ostium. HNO 2020; 68: 573-580

[65] Thomas RD, Graham SM, Carter KD et al. Management of the orbital floor in silent sinus syndrome. Am J Rhinol 2003; 17: 97-100

[66] Babar-Craig H, Kayhanian H, de Silva D] et al. Spontaneous silent sinus syndrome (Imploding antrum syndrome): Case series of 16 patients. Rhinology 2011; 49: 315-317

[67] Sivasubramaniam R, Sacks R, Thornton M. Silent sinus syndrome: Dynamic changes in the position of the orbital floor after restoration of normal sinus pressure. J Laryngol Otol 2011; 125: 1239-1243

[68] Adams WM, Jones RI, Chavda SI et al. Pneumosinus dilatans: a discussion of four cases and the possible aetiology. Rhinology 1998; 36: $40-402$

[69] Urken ML, Som PM, Lawson W et al. Abnormally large frontal sinus. II. Nomenclature, pathology, and symptoms. Laryngoscope 1987; 97: 606-611

[70] Kim W], Kim MM. Binasal hemianopia caused by pneumosinus dilatans of the sphenoid sinuses. Indian J Ophthalmol 2019; 67: 1772-1775

[71] Skolnick CA, Mafee MF, Goodwin JA. Pneumosinus Dilatans of the Sphenoid Sinus Presenting With Visual Loss. J Neuro-ophthalmology 2001; 20: 259-263

[72] Alatar AA, AlSuliman YA, Alrajhi MS et al. Maxillary Pneumosinus Dilatans Presenting With Proptosis: A Case Report and Review of the Literature. Clin Med Insights Ear, Nose Throat 2019; 12: 117955061882514

[73] Sweatman J, Beltechi R. Pneumosinus Dilatans: An exploration into the association between Arachnoid Cyst, Meningioma and the pathogenesis of Pneumosinus Dilatans. Clin Neurol Neurosurg 2019; 185

[74] Ricci JA. Pneumosinus Dilatans: Over 100 Years Without an Etiology. J Oral Maxillofac Surg 2017; 75: 1519-1526

[75] Martin AJ, Jarosz JM, Thomas NWM. The strange association of pneumosinus dilatans and arachnoid cyst: Case report and review of the literature. Acta Neurochir (Wien) 2001; 143: 197-201

[76] Gibbons BA, Miele WR, Florman JE, Heilman CB, Horgan MA Pneumosinus dilitans and meningioma: a case series and review of the literature. Neurosurg Focus 2011; 50(5): E13. doi:10.3171/2011. 3.FOCUS1113. PMID: 21529169

[77] Desai NS, Saboo SS, Khandelwal A et al. Pneumosinus dilatans: Is it more than an aesthetic concern? J Craniofac Surg 2014; 25: 418-421

[78] Draf W, Constantinidis ], Weber R et al. Pneumosinus Dilatans Frontalis, Atiologie, Symptomatik Und Operationstechnik. Laryngorhinootologie 1996; 75: 660-664

[79] Cho HS, Hong S], Chae HK et al. Maxillary Sinus Pneumocele Presenting as Aesthetic Deformity: A Case Report With Literature Review. Ear, Nose Throat J 2020; 99: 397-401
[80] Song M, Ahn SM, Reh DR et al. Ethmoid pneumocele presenting with exophthalmos 15 years after endoscopic sinus surgery. Allergy Rhinol 2015; 6: 129-132

[81] Braverman I. Pneumocele of the maxillary sinus with orbital and trigeminal nerve involvement: case report and review of the literature. J Otolaryngol Head Neck Surg 2009; 38(2): E35-E38. PMID: 19442351

[82] Sasaki T, Yamoto T, Fujita K et al. A Case of Orbital Emphysema Associated with Frontal Sinus Pneumocele. J Neurol Surg Reports 2013; 74: 054-056

[83] Bachor E, Weber R, Kahle G et al. Temporary unilateral amaurosis with pneumosinus dilatans of the sphenoid sinus. Skull Base Surg 1994; 4: 169-175

[84] Bell AF, Ivan DJ, Munson RA. Barosinus pneumocele: Transient visual loss due to sphenoid sinus pneumocele in a U.S. Air Force pilot. Aviat Sp Environ Med 1995; 66: 276-279

[85] Choi S], Seo ST, Rha KS et al. Sinonasal organized Hematoma: Clinical features of seventeen cases and a systematic review. Laryngoscope 2015; 125: 2027-2033

[86] Kim JS, Oh JS, Kwon SH. The increasing incidence of paranasal organizing hematoma: a 20 -year experience of 23 cases at a single center. Rhinol J 2016; 54: 176-182

[87] Pang W, Hu L, Wang H et al. Organized Hematoma: An Analysis of 84 Cases with Emphasis on Difficult Prediction and Favorable Management. Otolaryngol - Head Neck Surg (United States) 2016; 154: 626-633

[88] Song HM, Jang Y], Chung YS et al. Organizing hematoma of the maxillary sinus. Otolaryngol - Head Neck Surg 2007; 136: 616-620

[89] Young D. Surgical treatment of male infertility. J Reprod Fertil 1970; 23: $541-542$

[90] Hendry WF, Knight RK, Whitfield HN et al. Obstructive Azoospermia: Respiratory Function Tests, Electron Microscopy and the Results of Surgery. Br J Urol 1978; 50: 598-604

[91] Arya AK, Beer HL, Benton J et al. Does Young's syndrome exist? J Laryngol Otol 2009; 123: 477-481

[92] Hendry WF, Levison DA, Parkinson MC et al. Testicular obstruction: Clinicopathological studies. Ann R Coll Surg Engl 1990; 72: 396-407

[93] Shiraishi K, Ono N, Eguchi S et al. Young's syndrome associated with situs inversus totalis. Arch Androl 2004; 50: 169-172

[94] Hasegawa A, Fujita M, Ohe M et al. A Rare Case of Young's Syndrome in Japan. Intern Med 1994; 33: 649-653

[95] Armengot M, Juan G, Carda C et al. Young's syndrome: A further cause of chronic rhinosinusitis. Rhinology 1996; 34: 35-37

[96] Greenstone MA, Rutman A, Hendry WF et al. Ciliary function in Young's syndrome. Thorax 1988; 43: 153-154

[97] Stern BM, Sharma G. Ciliary Dysfunction (Kartagener Syndrome, Primary Ciliary Dyskinesia). StatPearls Publishing; 2019

[98] Samia H, Khadija B, Agnes H et al. Long-term outcome of tunisian children with primary ciliary dyskinesia confirmed by transmission electron microscopy. Afr Health Sci 2016; 16: 954-961

[99] Schofield LM, Duff A, Brennan C. Airway Clearance Techniques for Primary Ciliary Dyskinesia; is the Cystic Fibrosis literature portable? Paediatr Respir Rev 2018; 25: 73-77

[100] Alanin MC, Aanaes K, Høiby N et al. Sinus surgery can improve quality of life, lung infections, and lung function in patients with primary ciliary dyskinesia. Int Forum Allergy Rhinol 2017; 7: 240-247

[101] Nyilas S, Schlegtendal A, Singer F, Goutaki M, Kuehni CE, Casaulta C, Latzin P, Koerner-Rettberg C. Alternative inert gas washout outcomes in patients with primary ciliary dyskinesia. Eur Respir J 2017; 49(1): 1600466. doi:10.1183/13993003.00466-2016. PMID: 28122863 
[102] Lucas JS, Barbato A, Collins SA, Goutaki M, Behan L, Caudri D, Dell S, Eber E, Escudier E, Hirst RA, Hogg C, Jorissen M, Latzin P, Legendre M, Leigh MW, Midulla F, Nielsen KG, Omran H, Papon JE, Pohunek P, Redfern B, Rigau D, Rindlisbacher B, Santamaria F, Shoemark A, Snijders D, Tonia T, Titieni A, Walker WT, Werner C, Bush A, Kuehni CE. European Respiratory Society guidelines for the diagnosis of primary ciliary dyskinesia. Eur Respir ] 2017; 49(1); 1601090. doi:10.1183/13993003.00466-2016. PMID: PMC6054534

[103] Strippoli MPF, Frischer T, Barbato A et al. Management of primary ciliary dyskinesia in European children: Recommendations and clinical practice. Eur Respir J 2012; 39: 1482-1491

[104] Barbato A, Frischer T, Kuehni CE et al. Primary ciliary dyskinesia: A consensus statement on diagnostic and treatment approaches in children. In: European Respiratory Journal. Eur Respir J 2009; 1264-1276

[105] Lucas JS, Burgess A, Mitchison HM et al. Diagnosis and management of primary ciliary dyskinesia. Arch Dis Child 2014; 99: 850-856

[106] El-Naggar AK, Chan JKC, Grandis JR et al. WHO Classification of Head and Neck Tumours. 4th Edition Lyon: International Agency for Research on Cancer; 2017

[107] Lombardi D, Tomenzoli D, Buttà L et al. Limitations and complications of endoscopic surgery for treatment for sinonasal inverted papilloma: A reassessment after 212 cases. Head Neck 2011; 33: 1154-1161

[108] Stange T, Schultz-Coulon H]. Zum Chirurgischen Behandlungskonzept bei Invertierten Papillomen der Nase und Nasennebenhöhlen. HNO 2008; 56: 614-622

[109] Christensen WN, Smith RRL. Schneiderian papillomas. A clinicopathologic study of 67 cases. Hum Pathol 1986; 17: 393-400

[110] Stammberger $\mathrm{H}$. New aspects in the genesis of inverted papillomas. Laryngol Rhinol Otol (Stuttg) 1983; 62: 249-24955

[111] Leoncini G, Zanetti L. The papillomas of the sinonasal tract. A comprehensive review. Pathologica 2017; 109: 31-34

[112] Sarkar FH, Visscher DW, Kintanar EB et al. Sinonasal Schneiderian papillomas: human papillomavirus typing by polymerase chain reaction. Mod Pathol 1992; 5: 329-332

[113] Barnes L. Schneiderian papillomas and nonsalivary glandular neoplasms of the head and neck. Mod Pathol 2002; 15: 279-297

[114] Cunningham MJ, Brantley S, Barnes L et al. Oncocytic Schneiderian papilloma in a young adult: A rare diagnosis. Otolaryngol Neck Surg 1987; 97: 47-51

[115] Barnes L, Bedetti C. Oncocytic schneiderian papilloma: A reappraisal of cylindrical cell papilloma of the sinonasal tract. Hum Pathol 1984; 15: 344-351

[116] Michaels L, Young M. Histogenesis of papillomas of the nose and paranasal sinuses. Arch Pathol Lab Med 1995; 119: 821-826

[117] Lawson W, Patel ZM. The evolution of management for inverted papilloma: An analysis of 200 cases. Otolaryngol - Head Neck Surg 2009; 140: 330-335

[118] Lund V], Stammberger H, Nicolai P et al. European position paper on endoscopic management of tumours of the nose, paranasal sinuses and skull base. Rhinol Suppl 2010; 1-143

[119] Maitra A, Baskin LB, Lee EL. Malignancies arising in oncocytic schneiderian papillomas: A report of 2 cases and review of the literature. Arch Pathol Lab Med 2001; 125: 1365-1367

[120] Anari S, Carrie S. Sinonasal inverted papilloma: Narrative review. ] Laryngol Otol 2010; 124: 705-715

[121] Attlmayr B, Derbyshire SG, Kasbekar AV et al. Management of inverted papilloma: Review. In: Journal of Laryngology and Otology. Cambridge University Press; 2017: 284-289
[122] Heathcote KJ, Nair SB. The impact of modern techniques on the recurrence rate of inverted papilloma treated by endonasal surgery. Rhinology 2009; 47: 339-344

[123] Diamantopoulos II, Jones NS, Lowe J. All nasal polyps need histological examination: An audit-based appraisal of clinical practice. J Laryngol Otol 2000; 114: 755-759

[124] Lloyd GAS, Lloyd GAS. Epithelial Tumours. In: Diagnostic Imaging of the Nose and Paranasal Sinuses 1988; 95-110

[125] Hildenbrand T, Weber R, Mertens ] et al. Surgery of Inverted Papilloma of the Maxillary Sinus via Translacrimal Approach - LongTerm Outcome and Literature Review. J Clin Med 2019; 8: 1873

[126] Giotakis E, Knipping S, Kühnel T et al. Unilateral diseases of the maxillary sinus. HNO 2020; 68: 623-636

[127] Vrabec DP. The inverted schneiderian papilloma: A 25-year study. Laryngoscope 1994; 104: 582-605

[128] Bielamowicz S, Calcaterra TC, Watson D. Inverting papilloma of the head and neck: The UCLA update. Otolaryngol - Head Neck Surg 1993; 109: 71-76

[129] Kraft M, Simmen D, Kaufmann T et al. Long-term results of endonasal sinus surgery in sinonasal papillomas. Laryngoscope 2003; 113: $1541-1547$

[130] Tanna N, Edwards JD, Aghdam H et al. Transnasal endoscopic medial maxillectomy as the initial oncologic approach to sinonasal neoplasms: The anatomic basis. Arch Otolaryngol - Head Neck Surg 2007; 133: 1139-1142

[131] Busquets JM, Hwang PH. Endoscopic resection of sinonasal inverted papilloma: A meta-analysis. Otolaryngol - Head Neck Surg 2006; 134: 476-482

[132] Veeresh M, Sudhakara M, Girish G et al. Leiomyoma: A rare tumor in the head and neck and oral cavity: Report of 3 cases with review. J Oral Maxillofac Pathol 2013; 17: 281-287

[133] Agaimy A, Michal M, Thompson LDR et al. Angioleiomyoma of the Sinonasal Tract: Analysis of 16 Cases and Review of the Literature. Head Neck Pathol 2015; 9: 463-473

[134] Heyman JNS, Jones LM, Hilton JM et al. Angioleiomyoma of the inferior turbinate: A rare cause of isolated facial pain. Ann R Coll Surg Engl 2020; 102: E20-E22

[135] Lau YW, Tharumalingam V, Tan TY et al. Sinonasal angioleiomyoma. Med J Malaysia 2016; 71: 154-155

[136] Mathieu T, Verbruggen A, Goovaerts G et al. Vascular leiomyoma of the nasal cavity: case report and literature review. Eur Arch Oto-Rhino-Laryngology 2017; 274: 579-583

[137] Poncet A, Dor L. Botryomycose humaine. Rev Chir 1897; 18: 996-1003

[138] Hartzell M. Granuloma pyogenicum (botryomycosis of French authors). J Cutan Dis 1904; 22: 520-523

[139] Mills SE, Cooper PH, Fechner RE. Lobular capillary hemangioma: The underlying lesion of pyogenic granuloma. A study of 73 cases from the oral and nasal mucous membranes. Am J Surg Pathol 1980; 4: 471-479

[140] Fu Y-S, Perzin KH. Nonepithelial tumors of the nasal cavity, paranasal sinuses, and nasopharynx. A clinicopathologic study VI. Fibrous tissue tumors (fibroma, fibromatosis, fibrosarcoma). Cancer 1976; 37 : 2912-2928

[141] Thompson LDR, Fanburg-Smith JC. Update on Select Benign Mesenchymal and Meningothelial Sinonasal Tract Lesions. Head Neck Pathol 2016; 10: 95-108

[142] Sammut S], Tomson N, Corrie P. Pyogenic granuloma as a cutaneous adverse effect of vemurafenib. N Engl J Med 2014; 371: 1265-1267

[143] Smith SC, Patel RM, Lucas DR et al. Sinonasal Lobular Capillary Hemangioma: A Clinicopathologic Study of 34 Cases Characterizing Potential for Local Recurrence. Head Neck Pathol 2013; 7: 129-134 
[144] Sunaryo PL, Svider PF, Husain Q et al. Schwannomas of the sinonasal tract and anterior skull base: A systematic review of 94 cases. Am J Rhinol Allergy 2014; 28: 39-49

[145] Shugar JMA, Son PM, Biller HF et al. Peripheral nerve sheath tumors of the paranasal sinuses. Head Neck Surg 1981; 4: 72-76

[146] Donner TR, Voorhies RM, Kline DG. Neural sheath tumors of major nerves. J Neurosurg 1994; 81: 362-373

[147] Ansari I, Ansari A, Graison AA et al. Head and Neck Schwannomas: A Surgical Challenge - A Series of 5 Cases. Case Rep Otolaryngol 2018; 2018: 1-10

[148] Azani AB, Bishop JA, Thompson LDR. Sinonasal Tract Neurofibroma: A Clinicopathologic Series of 12 Cases with a Review of the Literature. Head Neck Pathol 2015; 9: 323-333

[149] Annino D], Domanowski GF, Vaughan CW. A Rare Cause of Nasal Obstruction: A Solitary Neurofibroma. Otolaryngol Neck Surg 1991; 104: 484-488

[150] Perzin KH, Panyu H, Wechter S. Nonepithelial tumors of the nasal cavity, paranasal sinuses and nasopharynx. A clinicopathologic study. XII: Schwann cell tumors (neurilemoma, neurofibroma, malignant schwannoma). Cancer 1982; 50: 2193-2202

[151] Friedman CD, Costantino PD, Teitelbaum B et al. Primary extracranial meningiomas of the head and neck. Laryngoscope 1990; 100: 41-48

[152] Thompson LDR, Gyure KA. Extracranial sinonasal tract meningiomas: A clinicopathologic study of 30 cases with a review of the literature. Am J Surg Pathol 2000; 24: 640-650

[153] Ho K-L. Primary meningioma of the nasal cavity and paranasal sinuses. Cancer 1980; 46: 1442-1447

[154] Perry A, Scheithauer BW, Stafford SL et al. „Malignancy“ in meningiomas: A clinicopathologic study of 116 patients, with grading implications. Cancer 1999; 85: 2046-2056

[155] Perry A, Stafford SL, Scheithauer BW et al. Meningioma grading: An analysis of histologic parameters. Am J Surg Pathol 1997; 21: 1455-1465

[156] Rushing E], Bouffard JP, McCall S et al. Primary extracranial meningiomas: An analysis of 146 cases. Head Neck Pathol 2009; 3: 116-130

[157] Mnejja M, Hammami B, Bougacha L et al. Primary sinonasal meningioma. Eur Ann Otorhinolaryngol Head Neck Dis 2012; 129: 47-50

[158] Wolf A, Safran B, Pock J et al. Surgical treatment of paranasal sinus osteomas: A single center experience of 58 cases. Laryngoscope. 2019;

[159] Atallah N, Jay MM. Osteomas of the paranasal sinuses. J Laryngol Otol 1981; 95: 291-304

[160] Furlaneto EC, Rocha JRM, Heitz C. Osteoma of the zygomatic arch Report of a case. Int J Oral Maxillofac Surg 2004; 33: 310-311

[161] Summers LE, Mascott CR, Tompkins JR et al. Frontal sinus osteoma associated with cerebral abscess formation: A case report. Surg Neurol 2001; 55: 235-239

[162] Eller R, Sillers M. Common Fibro-osseous Lesions of the Paranasal Sinuses. Otolaryngol Clin North Am 2006; 39: 585-600

[163] Schick B, Steigerwald C, El Tahan AER et al. The role of endonasal surgery in the management of frontoethmoidal osteomas. Rhinology 2001; 39: 66-70

[164] Schick B, Dlugaiczyk J. Benign tumors of the nasal cavity and paranasal sinuses. In: Rhinology and Facial Plastic Surgery 2009; 377-385

[165] Buyuklu F, Akdogan MV, Ozer C et al. Growth characteristics and clinical manifestations of the paranasal sinus osteomas. Otolaryngol Head Neck Surg 2011; 145: 319-323

[166] Golant A, Zeichner JA. Gardner Syndrome. StatPearls Publishing; 2014
[167] Pinto RS, Simons A, Verma R et al. Gardener-associated fibroma: An unusual cause of upper airway obstruction. BMJ Case Rep 2018; 2018

[168] Yang A, Sisson R, Gupta A, Tiao G, Geller Jl. Germline APC mutations in hepatoblastoma. Pediatr Blood Cancer 2018; 65(4); doi:10.1002/ pbc.26892. Epub 2017 Dec 18. PMID: 29251405

[169] Kiessling P, Dowling E, Huang Y, Ho ML, Balakrishnan K, Weigel B], Highsmith WE Jr, Niu Z, Schimmenti LA. Identification of aggressive Gardner syndrome phenotype associated with a de novo APC variant, c.4666dup. Cold Spring Harb Mol Case Stud 2019; 5(2): a003640. doi:10.1101/mcs.a003640. PMID: 30696621; PMCID: PMC6549566

[170] Burke AB, Collins MT, Boyce AM. Fibrous dysplasia of bone: craniofacial and dental implications. Oral Dis 2017; 23: 697-708

[171] Erkmen K, Al-Mefty O, Adada B. Tumors of the skull base.In: Oncology of CNS Tumors. Philadelphia: WB Saunders; 2010: 279-307

[172] Heller AJ, DiNardo LJ, Massey D. Fibrous dysplasia, chondrosarcoma, and McCune-Albright syndrome. Am J Otolaryngol - Head Neck Med Surg 2001; 22: 297-301

[173] Kos M, Luczak K, Godzinski J et al. Treatment of monostotic fibrous dysplasia with pamidronate. J Cranio-Maxillofacial Surg 2004; 32: 10-15

[174] Collins MT, Kushner H, Reynolds JC et al. An instrument to measure skeletal burden and predict functional outcome in fibrous dysplasia of bone. J Bone Miner Res 2005; 20: 219-226

[175] Kelly MH, Brillante B, Collins MT. Pain in fibrous dysplasia of bone: Age-related changes and the anatomical distribution of skeletal lesions. Osteoporos Int 2008; 19: 57-63

[176] Devogelaer JP. New uses of bisphosphonates: Osteogenesis imperfecta. Curr Opin Pharmacol 2002; 2: 748-753

[177] Schreiber A, Villaret AB, Maroldi R et al. Fibrous dysplasia of the sinonasal tract and adjacent skull base. Curr Opin Otolaryngol Head Neck Surg 2012; 20: 45-52

[178] Amit M, Collins MT, FitzGibbon EJ et al. Surgery versus watchful waiting in patients with craniofacial fibrous dysplasia - a meta-analysis. PLoS One 2011; 6

[179] McCune D. Osteitis fibrosa cystica: The case of a nine year old girl who also exhibits precocious puberty, multiple pigmentation of the skin and hyperthyroidism. Am J Dis Child 1936; 52: 743-744

[180] Leet Al, Chebli C, Kushner $\mathrm{H}$ et al. Fracture incidence in polyostotic fibrous dysplasia and the McCune-Albright syndrome. J Bone Miner Res 2004; 19: 571-577

[181] Boyce AM, Brewer C, Deklotz TR et al. Association of hearing loss and otologic outcomes with fibrous dysplasia. JAMA Otolaryngol - Head Neck Surg 2018; 144: 102-107

[182] Deklotz TR, Kim HJ, Kelly M et al. Sinonasal disease in polyostotic fibrous dysplasia and McCune-Albright Syndrome. Laryngoscope 2013; 123: 823-828

[183] Boyce AM, Glover M, Kelly MH et al. Optic neuropathy in McCuneAlbright syndrome: Effects of early diagnosis and treatment of growth hormone excess. J Clin Endocrinol Metab 2013; 98

[184] Plotkin H, Rauch F, Zeitlin L et al. Effect of Pamidronate Treatment in Children with Polyostotic Fibrous Dysplasia of Bone. J Clin Endocrinol Metab 2003; 88: 4569-4575

[185] DiMeglio LA. Bisphosphonate therapy for fibrous dysplasia. Pediatr Endocrinol Rev 2007; 4: 440-445

[186] Dumitrescu CE, Collins MT. McCune-Albright syndrome. Orphanet ] Rare Dis 2008; 3: 12. doi:10.1186/1750-1172-3-12. PMID: 18489744; PMCID: PMC2459161

[187] Feldman MD, Kelly M, Rao VM et al. Fibrous dysplasia of the paranasal sinuses. Otolaryngol Neck Surg 1986; 95: 222-225

[188] Ikeda K, Suzuki H, Oshima T et al. Endonasal endoscopic management in fibrous dysplasia of the paranasal sinuses. Am J Otolaryngol - Head Neck Med Surg 1997; 18: 415-418 
[189] Uzun C, Adali MK, Koten M et al. McCune-Albright syndrome with fibrous dysplasia of the paranasal sinuses. Rhinology 1999; 37 : 122-124

[190] Lee JS, Fitzgibbon E, Butman JA et al. Normal vision despite narrowing of the optic canal in fibrous dysplasia. N Engl J Med 2002; 347: $1670-1676$

[191] Wenig BM, Heffner DK. Respiratory epithelial adenomatoid hamartomas of the sinonasal tract and nasopharynx: A clinicopathologic study of 31 cases. Ann Otol Rhinol Laryngol 1995; 104: 639-645

[192] Delbrouck C, Fernandez Aguilar S, Choufani G et al. Respiratory epithelial adenomatoid hamartoma associated with nasal polyposis. Am J Otolaryngol - Head Neck Med Surg 2004; 25: 282-284

[193] Endo R, Matsuda H, Takahashi M et al. Respiratory epithelial adenomatoid hamartoma in the nasal cavity. Acta Otolaryngol 2002 122: $398-400$

[194] Ingram WF, Noone MC, Gillespie MB. Respiratory epithelial adenomatoid hamartoma: A case report. Ear, Nose Throat J 2006; 85: 190-192

[195] Athre R, Ducic Y. Frontal sinus hamartomas. Am J Otolaryngol - Head Neck Med Surg 2005; 26: 419-421

[196] Flavin R, Russell J, Phelan E et al. Chondro-osseous respiratory epithelial adenomatoid hamartoma of the nasal cavity: A case report. Int J Pediatr Otorhinolaryngol 2005; 69: 87-91

[197] Fitzhugh VA, Mirani N. Respiratory epithelial adenomatoid hamartoma: A review. Head Neck Pathol 2008; 2: 203-208

[198] Braun H, Beham A, Stammberger H. Respiratorisches epitheliales adenomatoides hamartom der nasenhaupthöhle: Fallbericht und literaturübersicht. Laryngorhinootologie 2003; 82: 416-420

[199] Himi Y, Yoshizaki T, Sato K et al. Respiratory epithelial adenomatoid hamartoma of the maxillary sinus. J Laryngol Otol 2002; 116: 317-318

[200] Safi C, Li C, Tabaee A et al. Outcomes and imaging findings of respiratory epithelial adenomatoid hamartoma: a systematic review. Int Forum Allergy Rhinol 2019; 9: 674-680

[201] Lima NB, Jankowski R, Georgel T et al. Respiratory adenomatoid hamartoma must be suspected on CT-scan enlargement of the olfactory clefts. Rhinology 2006; 44: 264-269

[202] Hawley KA, Ahmed M, Sindwani R. CT findings of sinonasal respiratory epithelial adenomatoid hamartoma: $A$ closer look at the olfactory clefts. Am J Neuroradiol 2013; 34: 1086-1090

[203] Metselaar RM, Stel HV, Van Der Baan S. Respiratory epithelial adenomatoid hamartoma in the nasopharynx. J Laryngol Otol 2005; 119: 476-478

[204] Hawley KA, Pabon S, Hoschar AP et al. The presentation and clinical significance of sinonasal respiratory epithelial adenomatoid hamartoma (REAH). Int Forum Allergy Rhinol 2013; 3: 248-253

[205] Schafer DR, Thompson LDR, Smith BC et al. Primary ameloblastoma of the sinonasal tract: A clinicopathologic study of 24 cases. Cancer 1998; 82: 667-674

[206] Shahidi S, Bronoosh P, Daneshbod Y. Follicular ameloblastoma presenting as a sinonasal tumor. Iran Red Crescent Med J 2012; 14: 113-116

[207] Hertog D, van der Waal I. Ameloblastoma of the jaws: A critical reappraisal based on a 40-years single institution experience. Oral Oncol 2010; 46: 61-64

[208] Barrena BG, Phillips B], Moran KJ et al. Sinonasal Ameloblastoma. Head Neck Pathol 2019; 13: 247-250

[209] Golbin DA, Ektova AP, Demin MO, Lasunin N, Cherekaev VA. Nasal Chondromesenchymal Hamartoma with Skull Base and Orbital Involvement: Case Presentation. Cureus 2018; 10(6): e2892. doi:10.7759/cureus.2892. PMID: 30167348; PMCID: PMC6112910
[210] McDermott MB, Ponder TB, Dehner LP. Nasal chondromesenchymal hamartoma: An upper respiratory tract analogue of the chest wall mesenchymal hamartoma. Am J Surg Pathol 1998; 22: 425-433

[211] Ozolek JA, Carrau R, Barnes EL et al. Nasal chondromesenchymal hamartoma in older children and adults: Series and immunohistochemical analysis. Arch Pathol Lab Med 2005; 129: 1444-1450

[212] Chan TY. World Health Organization classification of tumours: Pathology \& genetics of tumours of the urinary system and male genital organs. Urology 2005; 65: 214-215

[213] Seibert RW, Seibert JJ, Jimenez JF et al. Nasopharyngeal brain heterotopia - a cause of upper airway obstruction in infancy. Laryngoscope 1984; 94: 818-819

[214] Kanjanawasee D, Chaowanapanja P, Keelawat S et al. Sphenoid Sinus Cholesteatoma - Complications and Skull Base Osteomyelitis: Case Report and Review of Literature. Clin Med Insights Case Reports 2019; 12

[215] Hansen S, Sørensen CH, Stage J et al. Massive cholesteatoma of the frontal sinus: Case report and review of the literature. Auris Nasus Larynx 2007; 34: 387-392

[216] Gey A, Plontke SK, Scheller C, Kösling S, Fathke C, Glien A. Seltene Diagnose einer knochendestruierenden Läsion der Keilbeinhöhle [Rare diagnosis of a bone-destructive lesion of the sphenoid sinus]. HNO. 2020 Dec 14. German. doi:10.1007/s00106-020-00974-2. Epub ahead of print. PMID: 33315128

[217] Ansa B, Goodman M, Ward K et al. Paranasal sinus squamous cell carcinoma incidence and survival based on surveillance, epidemiology, and end results data, 1973 to 2009. Cancer 2013; 119: 2602-2610

[218] Turner JH, Reh DD. Incidence and survival in patients with sinonasal cancer: A historical analysis of population-based data. Head Neck 2012; 34: 877-885

[219] Sanghvi S, Khan MN, Patel NR et al. Epidemiology of sinonasal squamous cell carcinoma: A comprehensive analysis of 4994 patients. Laryngoscope 2014; 124: 76-83

[220] Youlden DR, Cramb SM, Peters S et al. International comparisons of the incidence and mortality of sinonasal cancer. Cancer Epidemiol 2013; 37: 770-779

[221] Hayes RB, Kardaun JWPF, De Bruyn A. Tobacco use and sinonasal cancer: A case-control study. Br J Cancer 1987; 56: 843-846

[222] Brinton LA, Blot W], Becker JA et al. A case-control study of cancers of the nasal cavity and paranasal sinuses. Am J Epidemiol 1984; 119: 896-906

[223] Nudell J, Chiosea S, Thompson LDR. Carcinoma Ex-Schneiderian Papilloma (Malignant Transformation): A Clinicopathologic and Immunophenotypic Study of 20 Cases Combined with a Comprehensive Review of the Literature. Head Neck Pathol 2014; 8: 269-286

[224] Dulguerov P, Jacobsen M, Allal A et al. Nasal and paranasal sinus carcinoma: are we making progress? A series of 220 patients and a systematic review. Cancer 2001; 92: 3012-3029

[225] Thorup C, Sebbesen L, Danø H et al. Carcinoma of the nasal cavity and paranasal sinuses in Denmark 1995-2004. Acta Oncol (Madr) 2010; 49: 389-394

[226] El-Mofty SK, Lu DW. Prevalence of high-risk human papillomavirus DNA in nonkeratinizing (cylindrical cell) carcinoma of the sinonasal tract: A distinct clinicopathologic and molecular disease entity. Am J Surg Pathol 2005; 29: 1367-1372

[227] Bishop JA, Guo TW, Smith DF et al. Human papillomavirus-related carcinomas of the sinonasal tract. Am J Surg Pathol 2013; 37: 185-192

[228] Osborn DA. Nature and behavior of transitional tumors in the upper respiratory tract. Cancer 1970; 25: 50-60 
[229] Robin PE, Powell D], Stansbie JM. Carcinoma of the nasal cavity and paranasal sinuses: incidence and presentation of different histological types. Clin Otolaryngol Allied Sci 1979; 4: 431-456

[230] Larque AB, Hakim S, Ordi J et al. High-risk human papillomavirus is transcriptionally active in a subset of sinonasal squamous cell carcinomas. Mod Pathol 2014; 27: 343-351

[231] Mirghani H, Hartl D, Mortuaire G et al. Nodal recurrence of sinonasal cancer: Does the risk of cervical relapse justify a prophylactic neck treatment? Oral Oncol 2013; 49: 374-380

[232] Castelnau-Marchand P, Levy A, Moya-Plana A et al. Sinunasales Plattenepithelkarzinom ohne klinische Lymphknotenbeteiligung: Welches Halsmanagement ist das Beste? Strahlentherapie und Onkol 2016; 192: 537-544

[233] Hosokawa S, Okamura J, Sakai N, Mineta H. Primary spindle cell carcinoma of the frontal sinus. J Oral Maxillofac Surg 2012;70(11): e674-e678. doi:10.1016/j.joms.2012.07.025. Epub 2012 Sep 6. PMID: 22959877

[234] Furuta A, Kudo M, Kanai Kl et al. Typical carcinoid tumor arising in the nose and paranasal sinuses - Case report. Auris Nasus Larynx 2010; 37: 381-385

[235] Guan M, Li Y, Shi ZG et al. Sarcomatoid carcinoma involving the nasal cavity and paranasal sinus: A rare and highly progressive tumor. Int J Clin Exp Pathol 2014; 7: 4489-4492

[236] Thompson LDR, Wieneke JA, Miettinen $M$ et al. Spindle cell (sarcomatoid) carcinomas of the larynx: A clinicopathologic study of 187 cases. Am J Surg Pathol 2002; 26: 153-170

[237] Lewis JE, Olsen KD, Sebo TJ. Spindle cell carcinoma of the larynx: Review of 26 cases including DNA content and immunohistochemistry. Hum Pathol 1997; 28: 664-673

[238] Jeng YM, Sung MT, Fang CL et al. Sinonasal undifferentiated carcinoma and nasopharyngeal-type undifferentiated carcinoma: Two clinically, biologically, and histopathologically distinct entities. Am J Surg Pathol 2002; 26: 371-376

[239] Leung Suet Yi, Yuen Siu Tsan, Chung Lap Ping et al. Epstein-Barr virus is present in a wide histological spectrum of sinonasal carcinomas. Am J Surg Pathol 1995; 19: 994-1001

[240] Takakura H, Tachino H, Fujisaka M, Nakajima T, Yamagishi K, Ishida M, Shojaku $\mathrm{H}$. Lymphoepithelial carcinoma of the maxillary sinus: A case report and review of the literature. Medicine (Baltimore) 2018; 97(28): e11371. doi:10.1097/MD.0000000000011371. PMID: 29995775; PMCID: PMC6076030

[241] Frierson HF, Mills SE, Fechner RE et al. Sinonasal undifferentiated carcinoma. An aggressive neoplasm derived from Schneiderian epithelium and distinct from olfactory neuroblastoma. Am J Surg Pathol 1986; 10: 771-779

[242] Cerilli LA, Holst VA, Brandwein MS et al. Sinonasal undifferentiated carcinoma: Immunohistochemical profile and lack of EBV association. Am J Surg Pathol 2001; 25: 156-163

[243] Abdelmeguid AS, Bell D, Hanna EY. Sinonasal Undifferentiated Carcinoma. Curr Oncol Rep 2019; 21(3): 26. doi:10.1007/s11912019-0776-4. PMID: 30806835

[244] Musy PY, Reibel JF, Levine PA. Sinonasal undifferentiated carcinoma; The search for a better outcome. Laryngoscope 2002; 112: 1450-1455

[245] Schröck A, Göke F, van Bremen T et al. Maligne erkrankungen des sinunasaltrakts. Eine monoinstitutionelle erfahrung von 1996 bis 2010. HNO 2012; 60: 1041-1046

[246] Rosenthal DI, Barker JL, El-Naggar AK et al. Sinonasal malignancies with neuroendocrine differentiation: Patterns of failure according to histologic phenotype. Cancer 2004; 101: 2567-2573

[247] Bell D, Hanna EY. Sinonasal undifferentiated carcinoma: Morphological heterogeneity, diagnosis, management and biological markers. Expert Rev Anticancer Ther 2013; 13: 285-296
[248] Chambers K], Lehmann AE, Remenschneider A et al. Incidence and survival patterns of sinonasal undifferentiated carcinoma in the United States. J Neurol Surgery, Part B Skull Base 2015; 76: 94-100

[249] Kuan EC, Arshi A, Mallen-St Clair J, Tajudeen BA, Abemayor E, St John MA. Significance of Tumor Stage in Sinonasal Undifferentiated Carcinoma Survival: A Population-Based Analysis. Otolaryngol Head Neck Surg 2016; 154(4): 667-673. doi:10.1177/01945998 16629649. Epub 2016 Feb 23. PMID: 26908559

[250] Takahashi Y, Lee J, Pickering C et al. Human epidermal growth factor receptor 2/neu as a novel therapeutic target in sinonasal undifferentiated carcinoma. Head Neck 2016; 38: E1926-E1934

[251] Sanchez-Casis G, Devine KD, Weiland LH. Nasal adenocarcinomas that closely simulate colonic carcinomas. Cancer 1971; 28: 714-720

[252] Barnes L. Intestinal-type adenocarcinoma of the nasal cavity and paranasal sinuses. Am J Surg Pathol 1986; 10: 192-202

[253] Szablewski V, Solassol J, Poizat F et al. EGFR expression and KRAS and BRAF mutational status in intestinal-type sinonasal adenocarcinoma. Int J Mol Sci 2013; 14: 5170-5181

[254] Saber AT, Nielsen LR, Dictor M et al. K-ras mutations in sinonasal adenocarcinomas in patients occupationally exposed to wood or leather dust. Cancer Lett 1998; 126: 59-65

[255] Franchi A, Innocenti DRD, Palomba A et al. Low prevalence of K-RAS, EGF-R and BRAF mutations in sinonasal adenocarcinomas. Implications for anti-EGFR treatments. Pathol Oncol Res 2014; 20: 571-579

[256] Projetti F, Durand K, Chaunavel A et al. Epidermal growth factor receptor expression and KRAS and BRAF mutations: Study of 39 sinonasal intestinal-type adenocarcinomas. Hum Pathol 2013; 44: 2116-2125

[257] Ferrari M, Bossi P, Mattavelli D, Ardighieri L, Nicolai P. Management of sinonasal adenocarcinomas with anterior skull base extension. J Neurooncol 2020;150(3): 405-417. doi:10.1007/s11060-01903385-8. Epub 2020 Jan 3. PMID: 31897925

[258] Hoffmann TK, El Hindy N, Müller OM et al. Vascularised local and free flaps in anterior skull base reconstruction. Eur Arch Oto-Rhino-Laryngology 2013; 270: 899-907

[259] Hoeben A, van de Winkel L, Hoebers F et al. Intestinal-type sinonasal adenocarcinomas: The road to molecular diagnosis and personalized treatment. Head Neck 2016; 38: 1564-1570

[260] Turri-Zanoni M, Battaglia P, Lambertoni A et al. Treatment strategies for primary early-stage sinonasal adenocarcinoma: A retrospective bi-institutional case-control study. J Surg Oncol 2015; 112: 561-567

[261] Licitra L, Locati LD, Cavina R et al. Primary chemotherapy followed by anterior craniofacial resection and radiotherapy for paranasal cancer. Ann Oncol 2003; 14: 367-372

[262] Jo VY, Mills SE, Cathro HP et al. Low-grade sinonasal adenocarcinomas: The association with and distinction from respiratory epithelial adenomatoid hamartomas and other glandular lesions. Am J Surg Pathol 2009; 33: 401-408

[263] Neto AG, Pineda-Daboin K, Luna MA. Sinonasal tract seromucous adenocarcinomas: A report of 12 cases. Ann Diagn Pathol 2003; 7: 154-159

[264] Heffner DK, Hyams V], Hauck KW et al. Low-grade adenocarcinoma of the nasal cavity and paranasal sinuses. Cancer 1982; 50: 312-322

[265] Stelow EB, Jo VY, Mills SE et al. A histologic and immunohistochemical study describing the diversity of tumors classified as sinonasal high-grade nonintestinal adenocarcinomas. Am J Surg Pathol 2011; 35: 971-980

[266] Bignami M, Lepera D, Volpi L et al. Sinonasal Non-Intestinal-Type Adenocarcinoma: A Retrospective Review of 22 Patients. World Neurosurg 2018; 120: e962-e969

[267] Shay A, Ganti A, Raman A et al. Survival in low-grade and high-grade sinonasal adenocarcinoma: A national cancer database analysis. Laryngoscope 2020; 130: E1-E10 
[268] Shen T, Shi Q, Velosa C et al. Sinonasal renal cell-like adenocarcinomas: Robust carbonic anhydrase expression. Hum Pathol 2015; 46: 1598-1606

[269] Heffner DK. Sinonasal and laryngeal salivary gland lesions.In: Surgical Pathology of the Salivary Glands. Philadelphia: WB Saunders; 1991: 544-559

[270] Akbaba S, Ahmed D, Mock A, Held T, Bahadir S, Lang K, Syed M, Hoerner-Rieber J, Forster T, Federspil P, Herfarth K, Plinkert P, Debus J, Adeberg S. Treatment Outcome of 227 Patients with Sinonasal Adenoid Cystic Carcinoma (ACC) after Intensity Modulated Radiotherapy and Active Raster-Scanning Carbon Ion Boost: A 10-Year Single-Center Experience. Cancers (Basel) 2019; 111(11): 1705-417. doi:10.3390/cancers11111705. PMID: 31683896; PMCID: PMC6895865

[271] Spiro RH, Huvos AG, Strong EW. Adenoid cystic carcinoma of salivary origin. A clinicopathologic study of 242 cases. Am J Surg 1974; 128: 512-520

[272] Spiro RH. Salivary neoplasms: Overview of a 35-year experience with 2,807 patients. Head Neck Surg 1986; 8: 177-184

[273] Michel G, Joubert M, Delemazure AS et al. Adenoid cystic carcinoma of the paranasal sinuses: Retrospective series and review of the literature. Eur Ann Otorhinolaryngol Head Neck Dis 2013; 130: 257-262

[274] Kim GE, Park HC, Keum KC et al. Adenoid cystic carcinoma of the maxillary antrum. Am J Otolaryngol - Head Neck Med Surg 1999; 20 : $77-84$

[275] Chen AM, Bucci MK, Weinberg V et al. Adenoid cystic carcinoma of the head and neck treated by surgery with or without postoperative radiation therapy: Prognostic features of recurrence. Int J Radiat Oncol Biol Phys 2006; 66: 152-159

[276] Terhaard CH], Lubsen $\mathrm{H}$, Rasch CRN et al. The role of radiotherapy in the treatment of malignant salivary gland tumors. Int J Radiat Oncol Biol Phys 2005; 61: 103-111

[277] Garden AS, Weber RS, Ang KK et al. Postoperative radiation therapy for malignant tumors of minor salivary glands. Outcome and patterns of failure. Cancer 1994; 73: 2563-2569

[278] Chen AM, Granchi PJ, Garcia J et al. Local-regional recurrence after surgery without postoperative irradiation for carcinomas of the major salivary glands: Implications for adjuvant therapy. Int J Radiat Oncol Biol Phys 2007; 67: 982-987

[279] Mendenhall WM, Morris CG, Amdur RJ et al. Radiotherapy alone or combined with surgery for adenoid cystic carcinoma of the head and neck. Head Neck 2004; 26: 154-162

[280] Terhaard CH], Lubsen H, Van Der Tweel I et al. Salivary gland carcinoma: Independent prognostic factors for locoregional control, distant metastases, and overall survival: Results of the Dutch Head and Neck Oncology Cooperative Group. Head Neck 2004; 26 : 681-693

[281] Katz TS, Mendenhall WM, Morris CG et al. Malignant tumors of the nasal cavity and paranasal sinuses. Head Neck 2002; 24: 821-829

[282] Laramore GE, Krall JM, Griffin TW et al. Neutron versus photon irradiation for unresectable salivary gland tumors: Final report of an RTOG-MRC randomized clinical trial. Int J Radiat Oncol Biol Phys 1993; 27: 235-240

[283] Douglas JG, Koh W], Austin-Seymour M et al. Treatment of salivary gland neoplasms with fast neutron radiotherapy. Arch Otolaryngol - Head Neck Surg 2003; 129: 944-948

[284] Stannard C, Vernimmen F, Carrara $\mathrm{H}$ et al. Malignant salivary gland tumours: Can fast neutron therapy results point the way to carbon ion therapy? Radiother Oncol 2013; 109: 262-268

[285] Huber PE, Debus ], Latz D et al. Radiotherapy for advanced adenoid cystic carcinoma: Neutrons, photons or mixed beam? Radiother Oncol 2001; 59: 161-167
[286] Pommier P, Liebsch N], Deschler DG et al. Proton beam radiation therapy for skull base adenoid cystic carcinoma. Arch Otolaryngol Head Neck Surg 2006; 132: 1242-1249

[287] Patel NR, Sanghvi S, Khan MN et al. Demografic trends and disease-specific survival in salivary acinic cell carcinoma: An analysis of 1129 cases. Laryngoscope 2014; 124: 172-178

[288] Haerle SK, Gullane PJ, Witterick IJ et al. Sinonasal Carcinomas. Epidemiology, Pathology, and Management. Neurosurg Clin N Am 2013; 24: 39-49

[289] Neto AG, Pineda-Daboin K, Spencer ML et al. Sinonasal acinic cell carcinoma: A clinicopathologic study of four cases. Head Neck 2005; 27: 603-607

[290] Wong A, Leong JL, Ho B. Primary acinic cell carcinoma of the ethmoid sinus. Ear, Nose Throat J 2010; 89

[291] Biron VL, Lentsch E], Gerry DR et al. Case-control analysis of survival outcomes in sinonasal acinic cell carcinoma. Int Forum Allergy Rhinol 2014; 4: 507-511

[292] Ellis MA, Graboyes EM, Day TA et al. Prognostic factors and occult nodal disease in mucoepidermoid carcinoma of the oral cavity and oropharynx: An analysis of the National Cancer Database. Oral Oncol 2017; 72: 174-178

[293] Auger SR, Patel T, Ganti A et al. Effect of margin status and pathological grade in treatment of sinonasal mucoepidermoid carcinoma. Laryngoscope. 2020;

[294] Bhattacharyya N. Survival and staging characteristics for non-squamous cell malignancies of the maxillary sinus. Arch Otolaryngol Head Neck Surg 2003; 129: 334-337

[295] Wolfish EB, Nelson BL, Thompson LDR. Sinonasal Tract Mucoepidermoid Carcinoma: A Clinicopathologic and Immunophenotypic Study of 19 Cases Combined with a Comprehensive Review of the Literature. Head Neck Pathol 2012; 6: 191-207

[296] Lee YS, Ha SM, Paik SW et al. Epithelial-myoepithelial carcinoma originating from a minor salivary gland in the nasal septum: A case report and literature review. Medicine (Baltimore) 2020; 99: e19072

[297] Gore MR. Epithelial-myoepithelial carcinoma: A population-based survival analysis. BMC Ear, Nose Throat Disord 2018; 18

[298] Morresi-Hauf AT, Reu S, Fertl A. Epithelial-myoepitheliales Karzinom der Trachea: Fallbericht und Literaturübersicht. Pathologe 2013; 34: 56-64

[299] Roh JL, Chang HR, Choi SH et al. Clinical utility of 18F-FDG PET for patients with salivary gland malignancies. J Nucl Med 2007; 48: 240-246

[300] Kim CH, Jeong JS, Kim SR et al. Endobronchial epithelial-myoepithelial carcinoma of the lung. Thorax 2018; 73: 593-594

[301] Kim SH, Park SE, Bae HG et al. Epithelial-myoepithelial carcinoma of the nasopharynx: A case report and review of the literature. Oncol Lett 2015; 10: 927-930

[302] Fried D, Zanation AM, Huang B et al. Management of nonesthesioneuroblastoma sinonasal malignancies with neuroendocrine differentiation. Laryngoscope 2012; 122: 2210-2215

[303] Hong SL, Kim SD, Roh HJ et al. The sphenoid sinus: An unusual presentation of a typical carcinoid tumor. J Craniofac Surg 2014; 25: e483-e485

[304] Konukiewitz B, Agaimy A, Weichert W et al. Neuroendokrine Neoplasien der Kopf-Hals-Region. Pathologe 2018; 39: 27-34

[305] Ferlito A, Silver CE, Bradford CR et al. Neuroendocrine neoplasms of the larynx: An overview. Head Neck 2009; 31: 1634-1646

[306] Lee DH, Cho HH, Cho YB. Typical carcinoid tumor of the nasal cavity. Auris Nasus Larynx 2007; 34: 537-539

[307] Patel TD, Carniol ET, Vázquez A et al. Sinonasal fibrosarcoma: Analysis of the Surveillance, Epidemiology, and End Results database. Int Forum Allergy Rhinol 2016; 6: 201-205 
[308] Lartigau E, Lusinchi A, Schwaab G. Sarcomas of nasal cavity and paranasal sinuses: Chondrosarcoma, osteosarcoma and fibrosarcoma. J Laryngol Otol 1994; 108: 947-953

[309] Koshy M, Rich SE, Mohiuddin MM. Improved Survival With Radiation Therapy in High-Grade Soft Tissue Sarcomas of the Extremities: A SEER Analysis. Int J Radiat Oncol Biol Phys 2010; 77: 203-209

[310] Wang CP, Chang YL, Ting LL et al. Malignant fibrous histiocytoma of the sinonasal tract. Head Neck 2009; 31: 85-93

[311] Szablewski V, Neuville A, Terrier P et al. Adult sinonasal soft tissue sarcoma: Analysis of 48 cases from the French Sarcoma Group database. Laryngoscope 2015; 125: 615-623

[312] Gerrand CH, Bell RS, Wunder JS et al. The influence of anatomic location on outcome in patients with soft tissue sarcoma of the extremity. Cancer 2003; 97: 485-492

[313] Kwok MMK, Lee S, Hosking P. Leiomyosarcoma: A rare sinonasal malignancy. BMJ Case Rep 2018; 2018

[314] Tanaka H, Westesson PL, Wilbur DC. Leiomyosarcoma of the maxillary sinus: $\mathrm{CT}$ and MRI findings. $\mathrm{Br}$ J Radiol 1998; 71: 221-224

[315] Dobben GD. Leiomyosarcoma of the Nasopharynx. AMA Arch Otolaryngol 1958; 68: 211-213

[316] Sanghvi S, Misra P, Patel NR et al. Incidence trends and long-term survival analysis of sinonasal rhabdomyosarcoma. Am J Otolaryngol - Head Neck Med Surg 2013; 34: 682-689

[317] Wurm J, Constantinidis J, Grabenbauer GG et al. Rhabdomyosarcomas of the nose and paranasal sinuses: Treatment results in 15 cases. Otolaryngol - Head Neck Surg 2005; 133: 42-50

[318] Narula AA, Vallis MP, El-Silimy OE et al. Radiation induced angiosarcomas of the nasopharynx. Eur J Surg Oncol 1986; 12: 147-152

[319] Maddox JC, Evans HL. Angiosarcoma of skin and soft tissue: A study of forty-four cases. Cancer 1981; 48: 1907-1921

[320] Williamson IG, Ramsden RT. Angiosarcoma of maxillary antrum-association with vinyL chloride exposure. J Laryngol Otol 1988; 102: 464-467

[321] Nelson BL, Thompson LDR. Sinonasal tract angiosarcoma: A clinicopathologic and immunophenotypic study of 10 cases with a review of the literature. Head Neck Pathol 2007; 1: 1-12

[322] Fukushima K, Dejima K, Koike S et al. A case of angiosarcoma of the nasal cavity successfully treated with recombinant interleukin-2. Otolaryngol - Head Neck Surg 2006; 134: 886-887

[323] Treviño-González JL, Santos-Lartigue R, González-Andrade B et al. Angiosarcoma of the nasal cavity: A case report. Cases J 2009; 2

[324] Es-Sbissi F, Nitassi S, Boulaadas M et al. Sinonasal angiosarcoma. Eur Ann Otorhinolaryngol Head Neck Dis 2015; 132: 161-163

[325] Agaimy A, Hartmann A. Kopf-Hals-Tumoren: Neues aus der WHO-Klassifikation 2017. Pathologe 2018; 39

[326] Agaimy A, Haller F, Hartmann A. Sinunasale Tumoren: Neues aus der WHO mit besonderem Fokus auf neue mesenchymale Entitäten. Pathologe 2018; 39: 18-26

[327] Lewis JT, Oliveira AM, Nascimento AG et al. Low-grade sinonasal sarcoma with neural and myogenic features: A clinicopathologic analysis of 28 cases. Am J Surg Pathol 2012; 36: 517-525

[328] Rooper LM, Huang SC, Antonescu CR et al. Biphenotypic sinonasal sarcoma: An expanded immunoprofile including consistent nuclear $\beta$-catenin positivity and absence of SOX10 expression. Hum Pathol 2016; 55: 44-50

[329] Carter CS, East EG, McHugh JB. Biphenotypic sinonasal sarcoma: A review and update. In: Archives of Pathology and Laboratory Medicine. College of American Pathologists 2018; 1196-1201

[330] Fritchie KJ, Jin L, Wang $X$ et al. Fusion gene profile of biphenotypic sinonasal sarcoma: an analysis of 44 cases. Histopathology 2016; 69: 930-936
[331] Ducatman BS, Scheithauer BW, Piepgras DG et al. Malignant peripheral nerve sheath tumors. A clinicopathologic study of 120 cases. Cancer 1986; 57: 2006-2021

[332] Rodriguez F], Folpe AL, Giannini C et al. Pathology of peripheral nerve sheath tumors: Diagnostic overview and update on selected diagnostic problems. Acta Neuropathol 2012; 123: 295-319

[333] James AW, Shurell E, Singh A et al. Malignant Peripheral Nerve Sheath Tumor. Surg Oncol Clin N Am 2016; 25: 789-802

[334] Bradtmöller M, Hartmann C, Zietsch J et al. Impaired Pten expression in human malignant peripheral nerve sheath tumours. PLoS One 2012; 7: e47595

[335] Kar M, Suryanarayana Deo SV, Shukla NK et al. Malignant peripheral nerve sheath tumors (MPNST) - Clinicopathological study and treatment outcome of twenty-four cases. World J Surg Oncol 2006; 4: 55

[336] Jo VY, Fletcher CDM. WHO classification of soft tissue tumours: An update based on the 2013 (4th) edition. Pathology 2014; 46: 95-104

[337] Van De Rijn M, Barr FG, Xiong Q Bin et al. Radiation-associated synovial sarcoma. Hum Pathol 1997; 28: 1325-1328

[338] Deraedt K, Debiec-Rychter M, Sciot R. Radiation-associated synovial sarcoma of the lung following radiotherapy for pulmonary metastasis of Wilms' tumour [7]. Histopathology 2006; 48: 473-475

[339] Egger JF, Coindre JM, Benhattar J et al. Radiation-associated synovial sarcoma: Clinicopathologic and molecular analysis of two cases. Mod Pathol 2002; 15: 998-1004

[340] Sherman KL, Wayne JD, Chung J et al. Assessment of multimodality therapy use for extremity sarcoma in the United States. J Surg Oncol 2014; 109: 395-404

[341] Vlenterie M, Jones RL, Van Der Graaf WTA. Synovial sarcoma diagnosis and management in the era of targeted therapies. Curr Opin Oncol 2015; 27: 316-322

[342] De Bree E, Zoras O, Hunt JL et al. Desmoid tumors of the head and neck: A therapeutic challenge. Head Neck 2014; 36: 1517-1526

[343] Orphanet: Desmoid type fibromatosis. Im Internet: https://www. orpha.net/consor/cgi-bin/Disease_Search.php?lng = DE\&data_ id = 8665\&Disease_Disease_Search_diseaseType = ORPHA\&Disease_ Disease_Search_diseaseGroup $=873 \&$ Disease $(\mathrm{s}) /$ groupofdiseases $=$ Desmoid-type-fibromatosis\&title = Desmoid-typefibromatosis\&search $=$ Dise

[344] Colombo C, Foo WC, Whiting D et al. FAP-related desmoid tumors: A series of 44 patients evaluated in a cancer referral center. Histol Histopathol 2012; 27: 641-649

[345] Coffin CM, Hornick JL, Zhou H et al. Gardner fibroma: A clinicopathologic and immunohistochemical analysis of 45 patients with 57 fibromas. Am J Surg Pathol 2007; 31: 410-416

[346] Emori M, Kaya M, Mitsuhashi T et al. Desmoid tumor-associated pain is dependent on mast cell expression of cyclooxygenase-2. Diagn Pathol 2014; 9

[347] Kasper B, Baumgarten C, Garcia J et al. An update on the management of sporadic desmoid-type fibromatosis: A European Consensus Initiative between Sarcoma PAtients EuroNet (SPAEN) and European Organization for Research and Treatment of Cancer (EORTC)/Soft Tissue and Bone Sarcoma Group (STBSG). Ann Oncol 2017; 28: 2399-2408

[348] Bonvalot S, Eldweny H, Haddad V et al. Extra-abdominal primary fibromatosis: Aggressive management could be avoided in a subgroup of patients. Eur J Surg Oncol 2008; 34: 462-468

[349] Penel N, Chibon F, Salas S. Adult desmoid tumors: Biology, management and ongoing trials. Curr Opin Oncol 2017; 29: 268-274

[350] Huang PW, Tzen CY. Prognostic factors in desmoid-type fibromatosis: A clinicopathological and immunohistochemical analysis of 46 cases. Pathology 2010; 42: 147-150 
[351] Granter SR, Badizadegan K, Fletcher CDM. Myofibromatosis in adults, glomangiopericytoma, and myopericytoma: A spectrum of tumors showing perivascular myoid differentiation. Am J Surg Pathol 1998; 22: $513-525$

[352] Asimakopoulos P, Syed MI, Andrews T et al. Sinonasal glomangiopericytoma: Is anything new? Ear, Nose Throat J 2016; 95: E1

[353] Gengler C, Guillou L. Solitary fibrous tumour and haemangiopericytoma: Evolution of a concept. Histopathology 2006; 48: 63-74

[354] Thompson LDR, Miettinen M, Wenig BM. Sinonasal-type hemangiopericytoma: A clinicopathologic and immunophenotypic analysis of 104 cases showing perivascular myoid differentiation. Am J Surg Pathol 2003; 27: 737-749

[355] Catalano PJ, Brandwein M, Shah DK et al. Sinonasal hemangiopericytomas: A clinicopathologic and immunohistochemical study of seven cases. Head Neck 1996; 18: 42-53

[356] Billings KR, Fu YS, Calcaterra TC et al. Hemangiopericytoma of the head and neck. Am J Otolaryngol - Head Neck Med Surg 2000; 21: 238-243

[357] Carew JF, Singh B, Kraus DH. Hemangiopericytoma of the head and neck. Laryngoscope 1999; 109: 1409-1411

[358] Weber W, Henkes H, Metz KA et al. Haemangiopericytoma of the nasal cavity. Neuroradiology 2001; 43: 183-186

[359] Witkin GB, Rosai J. Solitary fibrous tumor of the upper respiratory tract: A report of six cases. Am J Surg Pathol 1991; 15: 842-848

[360] Batsakis JG, El-Naggar AK, Hybels RD. Pathology consultation solitary fibrous tumor. Ann Otol Rhinol Laryngol 1993; 102: 74-76

[361] Künzel J, Hainz M, Ziebart T et al. Head and neck solitary fibrous tumors: a rare and challenging entity. Eur Arch Oto-Rhino-Laryngology 2016; 273: 1589-1598

[362] Demicco EG, Park MS, Araujo DM et al. Solitary fibrous tumor: A clinicopathological study of 110 cases and proposed risk assessment model. Mod Pathol 2012; 25: 1298-1306

[363] Xue Y, Chai G, Xiao F et al. Post-operative radiotherapy for the treatment of malignant solitary fibrous tumor of the nasal and paranasal area. Jpn J Clin Oncol 2014; 44: 926-931

[364] Piccaluga PP, De Falco G, Kustagi M et al. Gene expression analysis uncovers similarity and differences among Burkitt lymphoma subtypes. Blood 2011; 117: 3596-3608

[365] Chi AC, Weathers DR, Folpe AL et al. Epithelioid hemangioendothelioma of the oral cavity: Report of two cases and review of the literature. Oral Surgery, Oral Med Oral Pathol Oral Radiol Endodontology 2005; 100: 717-724

[366] Errani C, Zhang L, Sung YS et al. A novel WWTR1-CAMTA1 gene fusion is a consistent abnormality in epithelioid hemangioendothelioma of different anatomic sites. Genes Chromosom Cancer 2011; 50: 644-653

[367] Flucke U, Vogels RJC, de Saint Aubain Somerhausen N et al. Epithelioid Hemangioendothelioma: Clinicopathologic, immunhistochemical, and molecular genetic analysis of 39 cases. Diagn Pathol 2014; 9

[368] Bruder E, Alaggio R, Kozakewich HPW et al. Vascular and perivascular lesions of skin and soft tissues in children and adolescents. Pediatr Dev Pathol 2012; 15: 26-61

[369] Weiss SW, Enzinger FM. Epithelioid hemangioendothelioma a vascular tumor often mistaken for a carcinoma. Cancer 1982; 50: 970-981

[370] Mentzel T, Beham A, Calonje E et al. Epithelioid hemangioendothelioma of skin and soft tissues: Clinicopathologic and immunohistochemical study of 30 cases. Am J Surg Pathol 1997; 21: 363-374

[371] Deyrup AT, Tighiouart M, Montag AG et al. Epithelioid hemangioendothelioma of soft tissue: A proposal for risk stratification based on 49 cases. Am J Surg Pathol 2008; 32: 924-927
[372] Beger M, Antoni C, Haas S et al. Epitheloides Hämangioendotheliomdrei Patienten, drei Therapieoptionen. Z Gastroenterol 2006; 44: A5_04

[373] Wong BLK, Lee VNY, Tikka T et al. Kaposiform haemangioendothelioma of the head and neck. Crit Rev Oncol Hematol 2016; 104: $156-168$

[374] Sun Z], Zhang L, Zhang WF et al. Kaposiform hemangioendothelioma involving the neck. Oral Oncol Extra 2006; 42: 60-65

[375] Lima M. Aggressive mature natural killer cell neoplasms: from epidemiology to diagnosis. Orphanet J Rare Dis 2013; 8: 95

[376] Pongpruttipan T, Sukpanichnant S, Assanasen T et al. Extranodal $\mathrm{NK} / \mathrm{T}$-cell lymphoma, nasal type, includes cases of natural killer cell and $\alpha \beta$, $\gamma \delta$, and $\alpha \beta / \gamma \delta$ T-cell origin: A comprehensive clinicopathologic and phenotypic study. Am J Surg Pathol 2012; 36: 481-499

[377] Jhuang JY, Chang ST, Weng SF et al. Extranodal natural killer/T-cell lymphoma, nasal type in Taiwan: A relatively higher frequency of T-cell lineage and poor survival for extranasal tumors. Hum Pathol 2015; 46: 313-321

[378] De Campos-Lima PO, Gavioli R, Zhang Q] et al. HLA-A11 epitope loss isolates of Epstein-Barr virus from a highly A11 + population. Science (80-) 1993; 260: 98-100

[379] Lima PODC, Levitsky V, Brooks J et al. T cell responses and virus evolution: Loss of hla all-restricted ctl epitopes in epstein-barr virus isolates from highly all-positive populations by selective mutation of anchor residues. J Exp Med 1994; 179: 1297-1305

[380] Kim S], Choi JY, Hyun SH et al. Risk stratification on the basis of Deauville score on PET-CT and the presence of Epstein-Barr virus DNA after completion of primary treatment for extranodal natural killer/T-cell lymphoma, nasal type: A multicentre, retrospective analysis. Lancet Haematol 2015; 2: e66-e74

[381] Tse E, Kwong YL. How i treat NK/T-cell lymphomas. Blood 2013; 121: 4997-5005

[382] Kwong YL, Kim WS, Lim ST et al. SMILE for natural killer/T-cell lymphoma: Analysis of safety and efficacy from the Asia Lymphoma Study Group. Blood 2012; 120: 2973-2980

[383] Alexiou C, Kau R], Dietzfelbinger $\mathrm{H}$ et al. Extramedullary plasmacytoma: Tumor occurrence and therapeutic concepts. Cancer 1999; 85: 2305-2314

[384] Miller FR, Lavertu P, Wanamaker JR et al. Plasmacytomas of the head and neck. Otolaryngol - Head Neck Surg 1998; 119: 614-618

[385] Patel TD, Vázquez A, Choudhary MM et al. Sinonasal extramedullary plasmacytoma: A population-based incidence and survival analysis. Int Forum Allergy Rhinol 2015; 5: 862-869

[386] Soutar R, Lucraft $\mathrm{H}$, Jackson $\mathrm{G}$ et al. Guidelines on the diagnosis and management of solitary plasmacytoma of bone and solitary extramedullary plasmacytoma. $\mathrm{Br}$ J Haematol 2004; 124: 717-726

[387] Lorsbach RB, Hsi ED, Dogan A et al. Plasma cell myeloma and related neoplasms. In: American Journal of Clinical Pathology 2011; 168-182

[388] Susnerwala SS, Shanks JH, Banerjee SS et al. Extramedullary plasmacytoma of the head and neck region: Clinicopathological correlation in 25 cases. Br J Cancer 1997; 75: 921-927

[389] Hussong JW, Perkins SL, Schnitzer B et al. Extramedullary plasmacytoma: A form of marginal zone cell lymphoma? Am J Clin Pathol 1999; 111: 111-116

[390] Boll M, Parkins E, O'Connor SJM et al. Extramedullary plasmacytoma are characterized by a „myeloma-like“ immunophenotype and genotype and occult bone marrow involvement. $\mathrm{Br}$ J Haematol 2010; 151: 525-527

[391] Galieni P, Cavo M, Pulsoni A et al. Clinical outcome of extramedullary plasmacytoma. Haematologica 2000; 85: 47-51

[392] Sasaki R, Yasuda K, Abe E et al. Multi-institutional analysis of solitary extramedullary plasmacytoma of the head and neck treated with curative radiotherapy. Int J Radiat Oncol Biol Phys 2012; 82: 626-634 
[393] Knowling MA, Harwood AR, Bergsagel DE. Comparison of extramedullary plasmacytomas with solitary and multiple plasma cell tumors of bone. J Clin Oncol 1983; 1: 255-262

[394] Hamre M, Hedberg J, Buckley J et al. Langerhans cell histiocytosis: An exploratory epidemiologic study of 177 cases. Med Pediatr Oncol 1997; 28: 92-97

[395] Laman JD, Leenen PJM, Annels NE et al. Langerhans-cell histiocytosis „insight into DC biology“. Trends Immunol 2003; 24: 190-196

[396] Orphanet: Langerhans Zell Histiozytose. Im Internet: https://www. orpha.net $/$ consor $/$ cgi-bin/OC_Exp.php?Lng $=$ DE\&Expert $=389$

[397] Kostyra K, Kostkiewicz B. Langerhans cell histiocytosis of the orbit and frontal sinus of the adult woman: A first case report in Poland. Surg Neurol Int 2019; 10: 234

[398] Mani S, Thomas R, Mathew J et al. Langerhan's cell histiocytosis of sphenoid sinus causing vision loss: A case report. J Nepal Med Assoc 2019; 57: 281-284

[399] Gündüz K, Palamar M, Parmak N et al. Eosinophilic granuloma of the orbit: Report of two cases. J AAPOS 2007; 11: 506-508

[400] Esmaili N, Harris G]. Langerhans Cell Histiocytosis of the Orbit: Spectrum of Disease and Risk of Central Nervous System Sequelae in Unifocal Cases. Ophthal Plast Reconstr Surg 2016; 32: 28-34

[401] Prayer D, Grois N, Prosch $\mathrm{H}$ et al. MR imaging presentation of intracranial disease associated with langerhans cell histiocytosis. Am J Neuroradiol 2004; 25: 880-891

[402] Allen CE, Li L, Peters TL et al. Cell-Specific Gene Expression in Langerhans Cell Histiocytosis Lesions Reveals a Distinct Profile Compared with Epidermal Langerhans Cells. J Immunol 2010; 184: 4557-4567

[403] Hyman DM, Diamond EL, Vibat CRT et al. Prospective blinded study of BRAFV600E mutation detection in cell-free DNA of patients with systemic histiocytic disorders. Cancer Discov 2015; 5: 64-71

[404] Berres ML, Lim KPH, Peters T et al. BRAF-V600E expression in precursor versus differentiated dendritic cells defines clinically distinct LCH risk groups. J Exp Med 2014; 211: 669-683

[405] Wladis E], Tomaszewski JE, Gausas RE. Langerhans cell histiocytosis of the orbit 10 years after involvement at other sites. Ophthal Plast Reconstr Surg 2008; 24: 142-143

[406] Herwig MC, Wojno T, Zhang Q et al. Langerhans Cell Histiocytosis of the Orbit: Five Clinicopathologic Cases and Review of the Literature. Surv Ophthalmol 2013; 58: 330-340

[407] Windfuhr JP. Primitive neuroectodermal tumor of the head and neck: Incidence, diagnosis, and management. Ann Otol Rhinol Laryngol 2004; 113: 533-543

[408] Hafezi S, Seethala RR, Stelow EB et al. Ewing's Family of Tumors of the Sinonasal Tract and Maxillary Bone. Head Neck Pathol 2011; 5: 8-16

[409] Specht K, Sung YS, Zhang L et al. Distinct transcriptional signature and immunoprofile of CIC-DUX4 fusion-positive round cell tumors compared to EWSR1-rearranged ewing sarcomas: Further evidence toward distinct pathologic entities. Genes Chromosom Cancer 2014; 53: 622-633

[410] Lin JK, Liang J. Sinonasal Ewing Sarcoma: A Case Report and Literature Review. Perm J 2018; 22

[411] Allam A, El-Husseiny G, Khafaga Y et al. Ewing's sarcoma of the head and neck: A retrospective analysis of 24 cases. Sarcoma 1999; 3: $11-15$

[412] Balamuth N], Womer RB. Ewing's sarcoma. Lancet Oncol 2010; 11 : 184-192

[413] Broich G, Pagliari A, Ottaviani F. Esthesioneuroblastoma: A general review of the cases published since the discovery of the tumour in 1924. Anticancer Res 1997; 17: 2683-2706
[414] Roussel LM, Patron V, Maubert E et al. New landmarks in endonasal surgery: from nasal bone to anterior cribriform plate including branches of anterior ethmoidal artery and nerve and terminal nerve. Int Forum Allergy Rhinol 2020; 10: 395-404

[415] Mills SE. Neuroectodermal neoplasms of the head and neck with emphasis on neuroendocrine carcinomas. Mod Pathol 2002; 15: 264-278

[416] Thompson LDR. Olfactory Neuroblastoma. Head Neck Pathol 2009; 3: $252-259$

[417] Kadish S, Goodman M, Wang CC. Olfactory neuroblastoma-A clinical analysis of 17 cases. Cancer 1976; 37: 1571-1576

[418] Morita A, Ebersold MJ, Olsen KD et al. Esthesioneuroblastoma: Prognosis and management. Neurosurgery 1993; 32: 706-715

[419] Edge SB, Compton CC. The american joint committee on cancer: The 7th edition of the AJCC cancer staging manual and the future of TNM. Ann Surg Oncol 2010; 17: 1471-1474

[420] Norton A. Tumors of the Upper Respiratory Tract and Ear. In: Hyams V, Batsakis J, Michaels L, Hrsg.. Journal of Clinical Pathology 1989; 335-335

[421] Mao L, Xia YP, Zhou YN et al. Activation of sonic hedgehog signaling pathway in olfactory neuroblastoma. Oncology 2009; 77: 231-243

[422] Ketcham AS, Wilkins RH, Van Buren JM et al. A combined intracranial facial approach to the paranasal sinuses. Am J Surg 1963; 106: 698-703

[423] Hanna E, DeMonte F, Ibrahim S et al. Endoscopic resection of sinonasal cancers with and without craniotomy: Oncologic results. Arch Otolaryngol - Head Neck Surg 2009; 135: 1219-1224

[424] Su SY, Bell D, Ferrarotto R et al. Outcomes for olfactory neuroblastoma treated with induction chemotherapy. Head Neck 2017; 39: 1671-1679

[425] Dulguerov P, Allal AS, Calcaterra TC. Esthesioneuroblastoma: A meta-analysis and review. Lancet Oncol 2001; 2: 683-690

[426] Ow T], Hanna EY, Roberts DB et al. Optimization of long-term outcomes for patients with esthesioneuroblastoma. Head Neck 2014; 36: $524-530$

[427] Almutuawa DM, Strohl MP, Gruss C et al. Outcomes of sinonasal mucosal melanomas with endoscopic and open resection: a retrospective cohort study. J Neurooncol. 2020;

[428] Thompson LDR, Wieneke JA, Miettinen M. Sinonasal tract and nasopharyngeal melanomas: A clinicopathologic study of 115 cases with a proposed staging system. Am J Surg Pathol 2003; 27: 594-611

[429] Moreno MA, Roberts DB, Kupferman ME et al. Mucosal melanoma of the nose and paranasal sinuses, a contemporary experience from the M. D. Anderson cancer center. Cancer 2010; 116: 2215-2223

[430] Patel SG, Prasad ML, Escrig M et al. Primary mucosal malignant melanoma of the head and neck. Head Neck 2002; 24: 247-257

[431] Zebary A, Jangard M, Omholt $\mathrm{K}$ et al. KIT, NRAS and BRAF mutations in sinonasal mucosal melanoma: A study of 56 cases. Br J Cancer 2013; 109: 559-564

[432] Van Essen TH, Van Pelt S, Versluis M et al. Prognostic parameters in uveal melanoma and their association with bap1 expression. $\mathrm{Br}$ ] Ophthalmol 2014; 98: 1738-1743

[433] Dauer EH, Lewis JE, Rohlinger AL et al. Sinonasal melanoma: A clinicopathologic review of 61 cases. Otolaryngol - Head Neck Surg 2008; 138: 347-352

[434] Bachar G, Kwok SL, O'Sullivan B et al. Mucosal melanomas of the head and neck: The Princess Margaret Hospital experience. Head Neck 2008; 30: 1325-1331

[435] Lund VJ, Chisholm E], Howard DJ et al. Sinonasal malignant melanoma: An analysis of 115 cases assessing outcomes of surgery, postoperative radiotherapy and endoscopic resection. Rhinology 2012; 50: 203-210 
[436] Thierauf J, Glück AM, Plinkert P et al. Mucosal melanoma of the cranio-facial region: Surgical challenges and therapeutic options. Auris Nasus Larynx 2019; 46: 252-259

[437] Gore MR, Zanation AM. Survival in sinonasal melanoma: A metaanalysis. J Neurol Surgery, Part B Skull Base 2012; 73: 157-162

[438] Ganly I, Patel SG, Singh B et al. Craniofacial resection for malignant melanoma of the skull base: Report of an International Collaborative Study. Arch Otolaryngol - Head Neck Surg 2006; 132: 73-78

[439] Jarrom D, Paleri V, Kerawala C et al. Mucosal melanoma of the upper airways tract mucosal melanoma: A systematic review with meta-analyses of treatment. Head Neck 2017; 39: 819-825

[440] Li ], Kan H, Zhao L et al. Immune checkpoint inhibitors in advanced or metastatic mucosal melanoma: a systematic review. Ther Adv Med Oncol 2020; 12

[441] Misra P, Husain Q, Svider PF et al. Management of sinonasal teratocarcinosarcoma: A systematic review. Am J Otolaryngol - Head Neck Med Surg 2014; 35: 5-11

[442] Chao KK, Eng TY, Barnes ] et al. Sinonasal Teratocarcinosarcoma. Am J Clin Oncol Cancer Clin Trials 2004; 27: 29-32
[443] Fukuoka K, Hirokawa M, Shimizu M et al. Teratocarcinosarcoma of the nasal cavity. Report of a case showing favorable prognosis. Apmis 2000; 108: 553-557

[444] Heffner DK, Hyams VJ. Teratocarcinosarcoma (malignant teratoma?) of the nasal cavity and paranasal sinuses: A clinicopathologic study of 20 cases. Cancer 1984; 53: 2140-2154

[445] Wei S, Carroll W, Lazenby A et al. Sinonasal teratocarcinosarcoma: report of a case with review of literature and treatment outcome. Ann Diagn Pathol 2008; 12: 415-425

[446] Vranic S, Caughron SK, Djuricic S et al. Hamartomas, teratomas and teratocarcinosarcomas of the head and neck: Report of 3 new cases with clinico-pathologic correlation, cytogenetic analysis, and review of the literature. BMC Ear, Nose Throat Disord 2008; 8

[447] Lim CCT, Thiagarajan A, Sim CS et al. Craniospinal dissemination in teratocarcinosarcoma: Case report. J Neurosurg 2008; 109: 321-324

[448] Terasaka S, Medary MB, Whiting DM et al. Prolonged survival in a patient with sinonasal teratocarcinosarcoma with cranial extension. Case report. J Neurosurg 1998; 88: 753-756

[449] Dicke TE, Gates GA. Malignant Teratoma of the Paranasal Sinuses: Report of a Case. Arch Otolaryngol 1970; 91: 391-394 